PSU-IRL-SCl-457

Classification Numbers 1.5.2, 1.5.3, 1.9, 1.9.3, 1.9.4

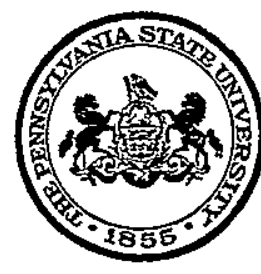

THE PENNSYLVANIA

STATE UNIVERSITY

IONOSPHERIC RESEARCH

Scientific Report 457

\title{
THE ENERGY BALANCE OF THE NIGHTTIME THERMOSPHERE
}

\author{
by \\ David Alan Glenar \\ November, 1977
}

The research reported in this document has been supported by The National Aeronautics and Space Administration under Grant No. NGL-39-009-003

\section{IONOSPHERE RESEARCH LABORATORY}

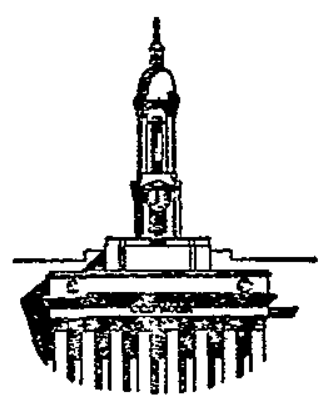

University Park, Pennsylvania 


\begin{tabular}{|c|c|}
\hline REPORT DOCUMENTATION PACL & $\begin{array}{l}\text { RI.AD INS IRUCIIONS } \\
\text { BEFORE COMPLETING FORM }\end{array}$ \\
\hline $\begin{array}{l}\text { T REPORT NUMBER } \\
457\end{array}$ & 3 RECIPIENT'S CATALOG NUMBER \\
\hline \multirow{2}{*}{$\begin{array}{l}4 \text { TITLE (and Sublulle) } \\
\text { The Energy Balance of the NIghttime } \\
\text { Thermosphere }\end{array}$} & $\begin{array}{l}5 \text { TYPE OF REPORT A PERIOD COVERED } \\
\text { Scientific Report }\end{array}$ \\
\hline & $\begin{array}{l}6 \text { PERFORMING ORG. REPORT NUMBER } \\
\text { PSU-IRL-SCI- } 457\end{array}$ \\
\hline David Alan Glenar & $\begin{array}{l}\text { C CONTRACT OR GRANT NUMBER(s) } \\
\text { NASA NGL-39-009-003 }\end{array}$ \\
\hline $\begin{array}{l}\text { PERFORMING ORGANIZATION NAME AND ADDRESS } \\
\text { National AeronautICS and Space Administration } \\
\text { Washington, D. C. } 20546\end{array}$ & $\begin{array}{l}\text { 10. PROGRAM ELEMENT, PROJECT, TASK } \\
\text { AREA \& WORK UNIT NUMBERS }\end{array}$ \\
\hline \multirow[t]{2}{*}{11 CONTROLLING OFFICE NAME AND ADDRESS } & $\begin{array}{l}12 \text { REPORT DATE } \\
\text { NoVEmber, } 1977\end{array}$ \\
\hline & $\begin{array}{l}13 \text { NUMBER OF PAGES } \\
135\end{array}$ \\
\hline \multirow[t]{2}{*}{14 MONITORING AGENCY NAME Q ADORESS(Il dIlforont from Controlling Offlco) } & $\begin{array}{l}15 \text { SECURITY CLASS (of thla roport) } \\
\text { NONE }\end{array}$ \\
\hline & $\begin{array}{l}\text { 15. OECLASSIFICATION/DOWNGRADING } \\
\text { SCHEDULE }\end{array}$ \\
\hline $\begin{array}{l}16 \text { DISTRIBUTION STATEMENT (ol this Roport) } \\
\text { Supporting Agencies }\end{array}$ & 16 DISTRIBUTION STATEMENT (ol thio Roport) \\
\hline \multicolumn{2}{|c|}{17 DISTRIBUTION STATEMENT (ot the abetract ontered In Block 20, il dilforont from Roport) } \\
\hline \multicolumn{2}{|l|}{18 SUPPLEMENTARY NOTES } \\
\hline \multicolumn{2}{|c|}{$\begin{array}{l}19 \text { KEY wOROS (Contlinuo on rovorso aldo If nocoesary and ldontlfy by block numbot) } \\
\text { E-Region } \\
\text { F-Region } \\
\text { Structure of the Upper Atmosphere } \\
\text { Heterosphere } \\
\text { Interaction Between the Neutral Atmosphere and the Ionosphere }\end{array}$} \\
\hline \multicolumn{2}{|c|}{$\begin{array}{l}\text { There has been considerable speculation as to the energy balance of the } \\
\text { thermosphere and in particular about the fraction of the total energy input } \\
\text { supplied by ultra-violet radiation. The problem is considerably simplifled by } \\
\text { considerlng the energy balance of the nlghttime hemlsphere alone. Sunrlse and } \\
\text { sunset vapor trall measurements provide data on the wind systems at the } \\
\text { terminator boundary, and temperature measurements provide information on the } \\
\text { vertical energy conduction. North-south winds from high latitude vapor trall } \\
\text { measurements provide a measure of the energy input from auroral processes. }\end{array}$} \\
\hline
\end{tabular}

\footnotetext{
DD, FORM 1473 EOITION OF I NOV 65 IS OBSOLETE 
The discrepancy between the Inputs from the day hemisphere and the observed loss rates is discussed in terms of Ion-neutral processes and gravity wave inputs.

NONE

SECURTTY CLASSIFICATION OF THIS PAGE(Hion Data Entered) 
PSU-IRL-SCI-457

Classification Numbers $1.5 .2,1.5 .3,1.9,1.9 .3,1.9 .4$

Scientific Report 457

The Energy Balance of the Nighttime Thermosphere

by

David Alan Glenar

November, 1977

The research reported in this document has been supported by The National Aeronautics and Space Administration under Grant No. NGL-39-009-003.

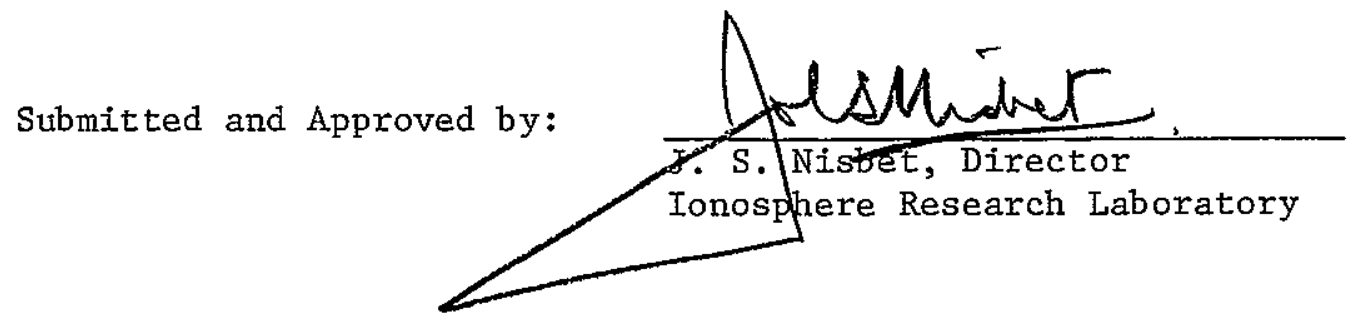

Ionosphere Research Laboratory

The PennsyIvania State University

University Park, Pennsylvanıa 16802 


\begin{abstract}
There has been considerable speculation as to the energy balance of the thermosphere and in particular about the fraction of the total energy input supplied by ultra-violet radiation. The problem is considerably simplified by considering the energy balance of the nighttime hemisphere alone. Sunrise and sunset vapor trail measurements provide data on the wind systems at the terminator boundary, and temperature measurements provide information on the vertical energy conduction. North-south winds from high latitude vapor trail measurements provide a measure of the energy input from auroral processes. The discrepancy between the inputs from the day hemisphere and the observed loss rates is discussed in terms of ion-neutral processes and gravity wave inputs.
\end{abstract}


ABSTRACT

LIST OF TABLES

LIST OF FIGURES

A CKNOW LEDGEMENTS

CHAPTER I INTRODUCTION . . . . . . . . I

1.1 General Statement of the Problem . . . . I

1.2 Previous Related Studies . . . . . . . 2

1.2.1 Estimates of Solar EUV Radiation . . 2

1.2.2 Mid Latitude Wind Observations . . . 7

1.2.3 Joule Heating and the High Latitude

Neutral Winds. . . . . ... . . 12

1.2.4 Dynamical Heating at Thermospheric 20 Heights • . . • . . . . .

1.3 Specific Statement of the Problem . . . . 26

CHAPTER II METHOD OF ANALYSIS . • . • 27

2.1 Analytic Eorm of the Contributions to the

Energy Balance • . . . . . . . 27

2.2 The Coordinate System Employed • . . . 32

CHAPTER III CONTRIBUTIONS TO THE ENERGY

BALANCE FROM THE THERMO-

SPHERIC WINDS . • • • • . 。 39

3.I Energy Transport Via the Low and Mid

Latitude Wind System . . . . . . . 39

3.1.1 Sources of Wind Data: Vapor Trail Measurements . . . . . . . 40

3.1.2 Analysis of Temperature and Density Data from Arecibo and St. Santin 
3.2 The Polar Thermospheric Wind System . . . 63

3.2.1 Method. . . . . . . . . . . 64

3.2.2 Boundary Conditions . • • • . . . 66

3.2.3 Results of the High Latitude Analysis . 71 CHAPTER IV ENERGY LOSS PROCESSES • • • 82

4.1 Downward Conduction at the Lower Boundary . 82

4.2 Infrared Radiative Losses . . . . . . . 89

4.2.1 Emission at $63 \mu$ from Thermospheric Atomic Oxygen . . . . . . 89

4.2.2 Emission at $15 \mu$ from Thermospheric Carbon Dioxide . . . . . . 96

4.2.3 Total Radiative Loss . . . . . . 97 CHAPTER V RESULTS OF THE ANALYSIS * • • 99

5.1 Conclusions . . . . . . . . . . 99

5.1.1 Conduction and Radiation Losses . . . 99

5.1.2 High Latitude Thermospheric Winds . . 100

5.1.3 Low Latitude Thermospheric Winds . . 101

5.2 Summary of Contributions to the Energy Input and Loss Processes . . . . . . . . . 102

5.3 Recommendations for Further Experimental

Work. • • • • • • • • • • • . . 105

REFERENCES • • • • • . • • . • • • • • . 107

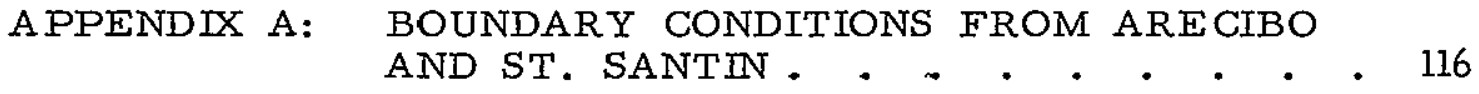




\section{LIST OF TABLES}

Table

Page

la Mid Latitude Vapor Trail Measurements Near Fall and Spring Equinox

1b Mid Latitude Vapor Trail Measurements Near Summer Solstice . . . . . . . . . 42

Ic Mid Latitude Vapor Trail Measurements Near Winter Solstice. . . . . . . . . . 43

2 Summary of Arecibo Results . . • • . . . . 57

3 Summary of St. Santin Results . . . . . . . 61

4 High Latitude Vapor Trail Measurements . . . . 67

5 Summary of Energy Inputs and Losses . . . . . 103

A.1 Arecibo Boundary Conditions . • . . . . . 117

A.2 St. Santin Boundary Conditions . . . . . . . 126 


\section{LIST OF FIGURES}

Eigure

Page

1 Neutral wind vectors and the auroral zone in geomagnetic coordinates. (Reference: Meriwether et al., 1973). . . . . . . . . . . .

2 Geometry employed in performing the energy balance of the nighttime thermosphere at equinox. .

3 Contributions (symbolic) to the energy balance from the energy input and loss processes. . . . .

4 Height variation of the average eastward neutral wind at twilight, from mid latitude vapor trail measurements. The numbers in parentheses are the number of flights used in obtaining the

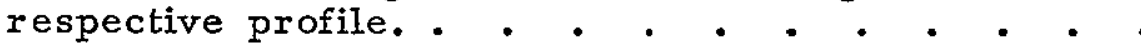

5 Terminator normal component of energy flux into nighttime region above $120 \mathrm{~km}$. . . . . . .

6a Variation with local time of boundary parameters during spring and fall equinox for $\mathrm{Kp} 0.0-1.2$. Data is representative of $70^{\circ} \mathrm{N}$ and $70^{\circ} \mathrm{S}$ geomagnetic latitudes.

6b Variation with local time of boundary parameters during spring and fall equinox for $\mathrm{Kp} 1.3-4.0$. Data is representative of $70^{\circ} \mathrm{N}$ and $70^{\circ} \mathrm{S}$ geomagnetic latitudes.

6c Variation with local time of boundary parameters during spring and fall equinox for $K p$ 4.1-9.0. Data is representative of $70^{\circ} \mathrm{N}$ and $70^{\circ} \mathrm{S}$ geomagnetic latitudes.

7 Total mass flow above $120 \mathrm{~km}$ derived from 23 high latitude vapor trail measurements. The center of each arrow corresponds to the location of each measurement.

8 Energy flow above $120 \mathrm{~km}$ derived from 23 high latitude vapor trail measurements. The center of each arrow corresponds to the location of each measurement. 
9 North components $\left(\beta_{M}(\theta, t)\right)$ of total mass flux at $70^{\circ} \mathrm{N}$ geomagnetic latitude $\left(\theta=20^{\circ}\right)$, height integrated above $120 \mathrm{~km}$. $\log _{10}$ values of the derived $120 \mathrm{~km}$ atomic oxygen density $(\mathrm{Kp} 0.0-$ 1.2) have been shown for comparative purposes. .

10 North components $\left(\epsilon_{M}(\theta, t)\right)$ of total energy flux at $70^{\circ} \mathrm{N}$ geomagnetic latitude $\left(\theta=20^{\circ}\right)$, height integrated above $120 \mathrm{~km}$. $\log _{10}$ values of the derived $120 \mathrm{~km}$ atomic oxygen density ( $\mathrm{Kp} 0.0-$ 1.2) have been shown for comparative purposes.

11 Diurnal variation of downward heat conduction at $120 \mathrm{~km}$. . . . . . . . . • • . . 87

12. Atomic oxygen ground state transitions. (Reference: Kockarts and Peetermans, 1970) • . . 91

13 Reduction factor resulting from radiative transfer applied to $63 \mu$ emission. (Reference: Banks and Kockarts, 1973) . . . • . . . . . . 


\section{A CKNOW LEDGEMENTS}

The author wishes to express his appreciation to Drs. John S. Nisbet and Ernst Bleuler for their advice and guidance during the course of this work, and for serving on his thesis committee. He also wishes to extend his gratitude to Dr. Ernst Bleuler and Mr. Robert Divany for developing many of the computer programs used in this study.

The author is indebted to Dr. Gaston Kockarts of the Institut D'Aeronomie Spatiale de Belgique for helpful suggestions regarding the computation of infrared losses, and to Dr. John F. Bedinger of the GCA Corporation for providing much of the wind data used for flux calculations. Thanks also go to Martha, Jennifer and Mark Glenar for their continued support and tolerance. This work was supported by the National Aeronautics and Space Administration under Grant No. NGI-39-009-003. 


\section{INTRODUCTION}

\subsection{General Statement of the Problem}

The thermosphere has received a considerable amount of attention since the advent of satellites and it is therefore surprising that at this time there is still considerable uncertainty about the relative importance of the various energy inputs and transport mechanisms in controlling the energy balance.

Several studies of the overall energy balance of the thermosphere have been performed by Swartz et al. (1972), Chandra (1973) and Roble and Dickenson (1973). It may be said that these investigations have not yet provided any concrete results. While there are good measurements of densities at satellite altitudes, there are not nearly as many measurements of the temperatures and very few are available in the critical lower thermosphere where much of the energy is stored and dissipated. Very few rocket vapor trail wind observations are available at times other than sunrise and sunset and incoherent scatter sounding provides little information on the critical zonal winds. While extensive series of measurements have been made of the EUV fluxes, there are problems with the absolute calibration of the intensities in some of the older measurements obtained at higher solar activity levels. The heating efficiency in the thermosphere has major uncertainties as well. The Joule heating at high latitudes and the processes by which the energy of Joule heating is transported to lower latitudes are not well understood. 
In addition, the energy transported upwards by tidal motions and gravity waves into the thermosphere from below is largely undetermined.

When the entire thermosphere is considered, the uncertainty in these sources and sinks are of the same order of magnitude as the EUV heating which is generally believed to be the major heat input and it is difficult to determine whether another major source is required. It therefore seemed of interest to examine the energy balance of the nighttime thermosphere by itself. The EUV heating is a very minor input while the loss rates are almost the same as those present during the day and so this approach provides a good opportunity to study the effects of transport from the day hemisphere. In addition, the vapor trail wind measurements made at sunrise and sunset provide data on the winds at the terminator and additional vapor trail measurements at high latitudes provide data on the meridional winds at this boundary.

It is the general aim of the present study to attempt to determine the rate of energy loss from the night hemisphere and compare this with the energy inputs from the day hemisphere to determine if another major energy source is required.

\subsection{Previous Related Studies}

\subsubsection{Estimates of Solar EUV Radiation}

The importance of accurate estimates of the solar extreme ultraviolet (EUV) flux has been recognized for a number of years. Decimeter flux measurements (i.e. the $F_{10.7}$ index) serve as good indicators of overall solar activity, but direct observations of the EUV flux responsible for photodissociation and ionization processes 
in the thermosphere are required for the bulk of all aeronomical calculations in this region. The term EUV has been used to designate the portion of the spectrum from roughly $1750 \AA$ to $170 \AA$, while XUV, often taken to be equivalent to EUV, includes in addition the $\mathrm{X}$-ray spectrum below $170 \AA$ with no well defined short wavelength limit.

Early low resolution measurements of solar EUV radiation were performed by Detwiler et al. (1961) using photographicphotometric equipment aboard an Aerobee-high rocket. The results were obtained in the altitude range from 148 to $220 \mathrm{~km}$ and covered the wavelength range from $850 \AA$ to $2600 \AA$. A number of factors confributed to uncertainty in the results, including a lack of good calibration standards and an uncertainty as to the amount of atmospheric absorption along the optical path.

A synopsis of observations of the thermosphere during 1963, including estimates of photoionization cross sections, rate coefficients and neutral density distributions was presented by Hinteregger and Hall (1965). This paper has been most often referred to for its compilation of EUV observations by spectrophotometric methods in the wavelength range from $1750 \AA$ to $1 \AA$. Data obtained between July and August of 1963 agreed quite well and the uncertainty in these measurements was estimated to be less than 30 percent. A much greater uncertainty existed in the $350 \AA-56 \AA$ results however, and the fluxes here are thought to be uncertain by as much as a factor of 3 to 5 . The uncertainty in Hinteregger's results were again largely due to a lack of reliable absolute calibration standards in the ultraviolet. 
A major concern of the EUV measurements has been improved estimates of the flux in the Schumann-Runge continuum, in the wavelength range from about $1250 \AA$ to greater than $2000 \AA$. These fluxes are responsible for the rapid dissociation of $\mathrm{O}_{2}$ in the lower thermosphere and as such, their knowledge has important implications for the global distribution of atomic oxygen in this height range as well as the EUV energy input.

Intensity measurements of the solar continuum from $1400 \AA$ to $1875 \AA$ using a rocket borne photoelectric spectrometer were made in September of 1968 by Parkinson and Reeves (1969) in an effort to improve on spectral resolution and the intensity calibration employed in obtaining previous data. The data collected were limited to the center of the solar disk. Their results suggested a blackbody temperature of approximately 4600 ' $\mathrm{K}$ and the intensity measurements at the short wavelength end ( $1400 \AA)$ agreed closely with the results of Goldberg et al. (1968). The derived intensities were lower by a factor of three, however, than the then current estimate of Whiting and Purcell (1969).

The next comprehensive tabulation of solar EUV data was published by Hinteregger (1970) and included the region of the spectrum from about $1800 \AA$ to $30 \AA$. The fluxes arrived at here represented medium solar activity $\left(F_{10.7}=130-170 \times 10^{-22} \mathrm{~W} \mathrm{~m}^{-2}\right.$ $\mathrm{Hz}^{-1}$ ) and were consuderably smaller than those presented in his earlier work (Hinteregger and Hall, 1965) and nearly a factor of three less than the results of Detwiler (1961) and Parkinson and Reeves (1969). This new information, then, suggested a much lower intensity of solar flux in the Schumann-Runge continuum 
with the consequence that previous estimates of $\mathrm{O}_{2}$ dissociation rates and EUV heating should be reduced substantially.

Measurements in the $1300 \AA-280 \AA$ interval were obtained using a scanning spectrophotometer aboard the NASA OSO-III satellite while fluxes in the range $280 \AA-30 \AA$ were obtained from an AFCRI rocket using an improved scanning monochromator.

Hinteregger warned against comparing these values with earlier estimates for the purpose of deducing solar cycle variations, the reason being the poor quality of these earlier estimates and the lack of secure absolute calibration in the earlier flights. He suggested, rather, that these new estimates supersede the older ones and that any knowledge of the variation over a solar cycle remains to be determined.

Roble and Dickinson (1973) calculated global mean temperature profiles using as heat sources Hinteregger's (1970) EUV fluxes for wavelengths less than $1300 \AA$ and the results of Widing et al. (1970) for wavelengths greater than $1300 \AA$. Using a heating efficiency of 33 percent, they balanced these EUV sources against calculated values of conduction and 63 micron cooling by atomic oxygen. The temperature profiles arrived at were considerably lower than those given by the Jacchia, 1971 empirical model. The results suggested that the Hinteregger, 1970 fluxes were low and it was found that uniformly doubling or tripling these fluxes brings both the calculated and neutral electron temperature profiles into good agreement with observations.

Further evidence pointing to a combined uncertainty in thermospherıc densities and the Hinteregger, 1970 fluxes was 
provided by Swartz and Nisbet (1973). This study involved a balance between electron recombination rates determined using Arecibo electron density profiles and production rates based on Hinteregger's 1970 fluxes, both characteristic of medium solar activity. Photoionization and photo-absorption cross sections were taken from Schoen (1969) and Huffman (1969). The results showed that the calculated recombination rate exceeds the photoionization rate and indicated that an increase by a factor of two or three in the EUV flux is required to remove the discrepancy. A serious error in the reaction rates was thought unlikely since this would involve all of the rates of interest. The conclusion reached was that additional energy input to the F-region is required, either by EUV or some new source of energy not yet considered.

In constructing a photochemical model of the daytime F-region G. Scialom (1974) used neutral profiles from incoherent scatter and rocket borne mass spectrometer results obtained during 1973. As an energy source he employed Hinteregger's 1970 EUV fluxes using a scaling factor as a free parameter. Once again, best agreement between experimental ionic concentration profiles and model results was obtained when the fluxes were increased by a factor of three. From a comparison of chemical production and loss rates, Prasad and Furman (1974) reached a somewhat different conclusion and questioned the need for increasing observed EUV fluxes. Their deduced loss rate profiles were considerably smaller than those of the above mentioned authors and in fairly good agreement with production rates based on Hinteregger's 1970 fluxes. An alternative treatment by Prasad and Furman which used 
electron temperatures consistent with observed ion profiles suggested also that Hinteregger's 1970 fluxes were low by no more than 20 percent. To solve the problem, they suggested, as did Hinteregger, repeated, reliable measurements of the EUV flux under a variety of conditions and/or an alternative way of examining the problem.

\subsubsection{Mid Latitude Wind Observations}

Studies of the thermospheric neutral wind system at low and mid latitudes have proceeded along two fronts; the development of models of the neutral wind based on measurements of thermospheric pressure and temperature distributions, and experimental techniques for the direct measurement of wind velocities.

Using simplifying assumptions appropriate for the thermosphere, model calculations of thermospheric winds can be performed using the equation of motion for the neutral gas (Rishbeth, 1972) given by

$$
\frac{d \vec{U}}{d t}+2 \vec{\Omega} \times \vec{U}=\vec{F}-v_{n i}(\vec{U}-\vec{V})+\frac{\mu}{\rho} \nabla^{2} \vec{U}+\vec{g}
$$

where $\vec{U}$ is the velocity of the neutral wind

$2 \vec{\Omega} \times \vec{U}$ is the Coriolis force ( $\vec{\Omega}$ being the earth's angular velocity)

$\vec{F}$ is the driving force per unit mass due to pressure gradients

$-v_{n i}(\vec{U}-\vec{V})$ is the so-called ion drag term $\left(v_{n i}\right.$ is the ionneutral collision frequency and $\vec{V}$ is the ion velocity, 
controlled both by electric and magnetic fields and by coupling with the neutral gas)

$(\mu / \rho) \nabla^{2} \vec{U}$ is the viscous drag term $(\mu / \rho$ being the kinematic viscosity)

$\vec{g}$ is the acceleration of gravity

Evaluating the ion drag term in the above expression requires an estimate of the ion-neutral collision frequency $v_{n i}$. This quantity has been studied by Dalgarno (1964) and Stubbe (1968) and has been found to be density dependent and somewhat temperature dependent.

Empirical models of thermospheric pressure distributions have been determined (Jacchia, 1965,1971) based on the results of satellite drag measurements. These models display the density and pressure distributions as a function of latitude and local solar time and show a characteristic enhancement of the pressure, known as the "diurnal bulge", near 1400 hours local time. These results allow the determination of the force due to pressure gradients given by $\vec{F}$ in the expression above. The problem with this approach lies with the pressure gradients in the neutral models. It has been shown by Blamont et al. (1973) and Thuillier et al. (1976), that the maximum temperature is not in the equatorial region but at high latitudes in the summer hemisphere. This difference has a profound effect on the meridional pressure gradient as shown by Nisbet et al. (1977).

It has been customary to divide the experimental methods of determining upper atmosphere motions into two broad classes (Kent, 1970). The first involves the measurement of ion motions, 
from which the neutral motions are derived. The second involves the direct determination of the motion of the neutral gas.

Ion motions at thermospheric heights are commonly derived using the incoherent scatter technique. Here, reflections occur from a beam of $V H F$ or $U H F$ radio waves as a result of Thompson scattering by electrons and give information on electron concentrations at heights up to greater than $1000 \mathrm{~km}$. The difference in frequency between the peak of the thermally broadened return-signal and the incident signal gives an indication of the velocity of the bulk motion of the ions.

Using incoherent scatter measurements of electron and ion temperatures, and electron density and vertical plasma drift obtained at Millstone $\mathrm{Hill}\left(42.6^{\circ} \mathrm{N}, 71.5^{\circ} \mathrm{W}\right)$, Roble et al. (1974) have calculated neutral winds for two geomagnetically quiet days in March and September of 1970. The derived zonal winds near 300 $\mathrm{km}$ show a general west to east flow during the afternoon, peaking near sunset. A similar peak was found to occur in the east to west wind near sunrise. The results obtained were based on an electric field model derived from quiet condition electric field measure- ments at Millstone Hill (Salah, 1972). As such, the derived winds were considered representative of only geomagnetically quiet conditions.

Of the available techniques for direct measurement of neutral thermospheric winds, the rocket vapor trail technique has been the most widely employed (Kent, 1970; Haerendal et al., 1969).

The release of several kilograms of sodium at altitudes up to $200 \mathrm{~km}$ has proven an effective means of measuring neutral wind 
motions near the morning and evening terminators. The sodium charge is expelled from the rocket and produces a long visible yellow trail as a result of resonant scattering of sunlight at $5890 \AA$ and $5896 \AA$, the wavelengths of the sodium doublet. As a result of diffusion, trail lifetimes vary from several tens of minutes at 100 $\mathrm{km}$ to roughly 30 seconds at $160 \mathrm{~km}$. An improvement upon the sodium vapor technique involves the use of chemiluminescent trails which react with atomic oxygen to form Iuminous trails visible throughout the night. Frequently used chemicals are trimethylaluminum (called TMA) and nitric oxide (Rosenberg and Edwards, 1964; Rosenberg, 1966).

Manring et al. (1964) performed an analysis of 22 vapor trail measurements performed at Wallops Island, Virginia $\left(37.8^{\circ} \mathrm{N}\right.$, $\left.75.5^{\circ} \mathrm{W}\right)$, utilizing the sodium vapor technique in the height range from 85 to $135 \mathrm{~km}$. Data was analyzed in terms of 24, 12 and 8 hour components and although large variations of the wind profile were observed from flight to flight, a general pattern of wind flow was revealed.

Rosenberg and Edwards (1964) used chemiluminescent trails in the altitude range from 90 to $150 \mathrm{~km}$ to measure winds throughout the night of December 3, 1962 and May 17-18, 1963 at Elgin Air Force Base, Florida $\left(30^{\circ} \mathrm{N}, 87^{\circ} \mathrm{W}\right)$. The results showed a consistent clockwise rotation of the wind with height as viewed from above. The direction of the wind displayed a sinusoidal pattern with height, the wavelength increasing from $10 \mathrm{~km}$ at 100 $\mathrm{km}$ altitude.

From an analysis of 25 sodium cloud experiments in the 70 
to $190 \mathrm{~km}$ height range and near the morning and evening terminators, Kochanski (1964) attempted to resolve the observed motions into contributions from (i) the prevailing seasonal drift, (ii) tidal components and (iii) internal gravity waves. He showed that the winds in general exhibit large variability in both magnitude and direction up to about $130 \mathrm{~km}$ and a common feature is a rotation of the wind direction with height, in agreement with that observed by Rosenberg and Edwards (1964). All profiles showed velocity oscillations with wavelengths of about $6 \mathrm{~km}$ below $120 \mathrm{~km}$ altitude and increasing to greater than $80 \mathrm{~km}$ at $180 \mathrm{~km}$ altitude, indicating the presence of gravity waves: The analysis suggested that between 120 and $140 \mathrm{~km}$, during both summer and winter, most of the winds near both terminators are in the same direction, indicating that either the 12 hour tidal harmonic is dominant, or that tidal components are smaller in magnitude than the general drift.

In similar fashion, Woodrum and Justus (1968) used wind data from 38 chemical releases at Elgin $\operatorname{AFB}\left(30.4^{\circ} \mathrm{N}, 86.7^{\circ} \mathrm{W}\right)$, obtained during the period from October, 1962 to November, 1965. Their results indicated a predominant vertical wavelength of $23 \mathrm{~km}$ between 90 and $120 \mathrm{~km}$ in agreement with tidal theory (Hines, 1968), and a mean downward phase progression from dusk to dawn. Once again, the results showed a clockwise rotation of both prevailing and diurnal wind components.

Observations of changes in the orbital inclination of satellites allows a coarse determination of the neutral zonal wind velocity in a reference frame fixed with respect to the sun. Using this principle, King-Hele $(1964,1966)$ has monitored the orbits of a 
number of satellites and observed changes different from what would be observed if the atmosphere rotated strictly at the same rate as the earth. Among the results obtained by King-Hele was an indication that the atmosphere superrotates in the altitude range from 200 to $300 \mathrm{~km}$ with an angular velocity of about 1.4 times that of the earth. The possible effects of gravitational forces, both terrestrial and luni-solar were investigated and found to be negligible for the purposes of the study.

Some success has been achieved in deriving wind motions from atomic oxygen airglow emissions at both $577.7 \mathrm{~nm}$ and 630.0 nm (Kent, 1970; Nagy et al., 1971). Successful measurements of strong (>300 $\mathrm{m} \mathrm{sec}^{-1}$ ) meridional winds were obtained at the Michigan Airglow Observatory $\left(42^{\circ} \mathrm{N}, 83^{\circ} \mathrm{W}\right)$ during the night of March 14-15, 1969. In addition, a comparison between airglow winds and those deduced from incoherent scatter measurements at Millstone Hill during October of 1969 indicated good agreement. Important questions remain, however, about the interpretation of these observations in deducing neutral gas motions.

\subsubsection{Joule Heating and the High Latitude Neutral Winds}

Joule heating, or resistive heating of the neutral atmosphere through collisions between neutrals and ionospheric currents, constitutes a large energy source at thermospheric heights, particularly at high latitudes. Discussions of the basic parameters involved in the theory of electrodynamic heating by the ionospheric plasma, including the effects of viscous dissipation, are given by Cole (1971) and Egelend (1975). The driving force for the ions originates in the ionospheric convection electric field, of magneto- 
spheric origin. The energy of the field is transferred to the neutral atmosphere via collisions between the ions and neutrals. This process results in enhanced neutral temperatures and pressure gradients which transfer energy from the region in the form of neutral winds.

In order to establish improved global thermospheric models, it is essential to understand the effect of high latitude heat sources, particularly Joule heating, on the global wind and temperature structure of the thermosphere. To this end, a number of authors have examined the temporal and spatial variation of the high latitude electric and geomagnetic fields and the motions of both ions and neutrals at ionospheric heights.

Neutral wind and velocity measurements in the range from 90 to $230 \mathrm{~km}$ have been made over Esrange, Kiruna (Rees, 1971) using rocket borne chemical releases. The results showed that high neutral wind velocities in this region result mainly from ion drag acceleration. A comparison of disturbed and quiet condition results also showed a correlation of the zonal neutral wind component above $120 \mathrm{~km}$ and the south-north magnetic perturbation vector. This relationship arises since ionospheric currents and neutral winds are both functions of the electric field and the electron density. Under disturbed conditions, high neutral wind speeds have been found near $130-140 \mathrm{~km}$ and Rees suggested that the southerly propagation of these winds gives rise to anomalously high winds at lower latitudes following geomagnetic disturbances. The relationship between such disturbances and the neutral temperature was discussed by Chanin et al. (1972) using 
temperature measurements from two series of rocket launchings duxing 1969 and 1970. The experiments were performed at Heiss Island $\left(80.4^{\circ} \mathrm{N}\right.$ geographic latitude; $74^{\circ} \mathrm{N}$ geomagnetic latitude) and temperatures were obtained in the range from 120 to $160 \mathrm{~km}$ by measuring atmospheric absorption of sunlight through sodium clouds. Combined with the results of earlier experiments at this location (Polaskov et al., 1969) the complete data set represented the results of approximately 20 launchings, and suggested a relationship between the neutral temperature and the time rate of change of the horizontal magnetic field component several hours prior to each measurement. In addition, the data suggested that a slight local cooling preceeds the heating from the magnetic disturbance in each case. The authors conjectured that most of the observed heatings are small scale phenomena resulting from the local precipitation of soft $(<1 \mathrm{keV})$ electrons. The rapid disappearance of the sodium clouds during magnetically active periods was thought to imply $a^{-}$connection between this localized heating and strong winds.

Using a simplified analysis, Fedder and Banks (1972) demonstrated the importance of ion drag at high latitudes in establishing the thermospheric wind system. The model employed a spatially uniform time-dependent electric field in the dawn to dusk direction, chosen to be representative of the onset of a magnetic disturbance, and a uniform magnetic field directed vertically downward. The results of this study showed that through ion drag, electric fields largely control the flow of neutrals and generate a twin-cell pattern over the polar regions. This pattern describes a 
gen eral $\mathrm{n}$ ight to day flow in the auroral zone and large day to night flows over the cap itself where solar tidal winds are the dominant driving force. These processes have important implications for a global heat balance, since the system is a source of both kinetic energy of motion and thermal energy as a result of the gas being heated from various polar processes.

In an attempt to establish statistically appropriate boundaries for the polar cap and the auroral zone, Heppner (1972) has analyzed the results of OGO-6 electric field measurements at high latitudes from a large number of orbits. In this study the polar cap was taken to be the region of dawn-dusk electric fields, and the auroral zone the adjacent lower latitude region of poleward and equatorward electric fields in the evening and morning sectors respectively. While the measurements showed a large variability at the daytime boundary location, it was found that the overall high latitude electric field pattern is fairly consistent and does not fluctuate on a large scale during the incidence of substorms. A transition in the electric field from the evening to the morning pattern was found to occur in the premidnight sector-near 2200 hours geomagnetic local time.

Meriwether et al. (1973) observed the motion of both ions and neutrals at high magnetic latitudes $\left(>65^{\circ}\right.$ ) from electrically neutral luminous cloud and barium ion cloud pairs. These releases were made at various locations in the polar cap, the auroral belt and the transition region and the neutral cloud motions were determined using the photographic triangulation technique. The resultant height averaged wind vectors were plotted in geomagnetic latitude and 
geomagnetic local time. The location of the auroral zone and the polar cap boundaries, as defined by Heppner (1972) was found to vary depending on convection conditions at the time of flight. As such, the choice of latitude and local time coordinates for certain of the wind vectors was somewhat a matter of discretion. Figure 1 shows the relative positions of the neutral wind vectors and the auroral zone as determined statistically by Heppner (1972). Meriwether et al. observed a significant spatial rotation of the wind in the transition region between the auroral zone and the polar cap and in addition, a transition from westward to eastward convection near local midnight. With the exception of the early morning hours, it was found that the observed wind velocities could be modeled fairly well in terms of ion drag forces.

A quantitative analysis of the variation of the Joule heating rate at various latitudes was performed by Ching and Chiu (1973) using measurements of ionospheric electric fields on a global basis (Haerendel, 1970; $\overline{\mathrm{M}} \overline{\mathrm{oz}} \mathrm{er}, 1971$; Caufman and Gurnell, 1971). This study showed the variation of Joule heating rates over a solar cycle and included both the altitude and latitude dependence as well. The calculated Joule heating rate at high latitudes was shown to be similar in magnitude and height distribution to the global solar EUV heating rate. Joule heating was thus thought to be a major contributor to the maintenance of the nighttime thermosphere.

Using the incoherent scatter radar at Chatanika, Alaska (geomagnetic and geographic latitudes, $65.1^{\circ} \mathrm{N}$, invariant latıtude $\left.\Lambda=65.5^{\circ} \mathrm{N}\right)$, Brekke and Doupnik (1973) have derived neutral winds for the E-region from measurements of ion drift motions for 


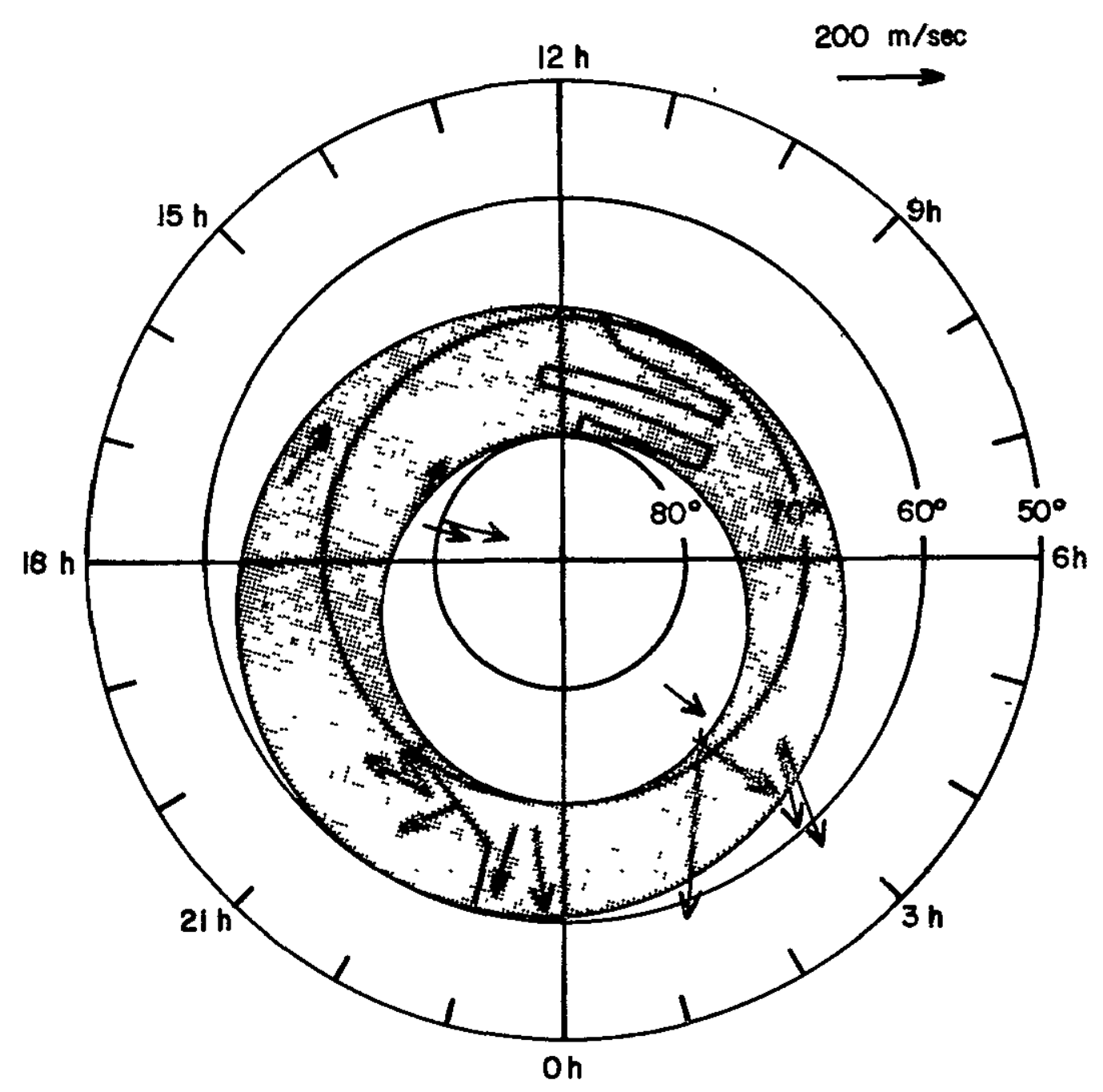

Figure 1 Neutral wind vectors and the auroral zone in geomagnetic coordinates. (Reference: Meriwether et al., 1973) 
both magnetically quiet and moderately disturbed days $(\operatorname{Kp} \leqslant 3)$. The results represented the height range from 110 to $170 \mathrm{~km}$ and were modeled assuming a day to night motion from the solar tide, as well as the ion drag force in the polar cap and auroral zone. The neutral atmosphere employed in the model was taken from Banks and Kockarts (1973). In summary, their observations indicated;

(i) a strong poleward flow of the neutral winds near local noon and an equatorward motion in the morning ( 0700 Alaskan Standard Time) and evening (2000 Alaskan Standard Time) hours.

(ii) a clear correlation between electric field directions (deduced from ion motions near $170 \mathrm{~km}$ where ionneutral coupling is minimal) and neutral wind directions.

(iii) the importance of knowing the observers location relative to the auroral oval in making sense of observed wind vectors.

Nagy et al. (1974) performed simultaneous neutral wind measurements from Fabry-Perot interferometer studies of the $6300 \AA$ atomic oxygen line at Ester Dome, Alaska and ionization drift measurements from the Chatanika radar station. Their results represented motions near $200 \mathrm{~km}$ with a spatial resolution of ion and neutral motions of about 150 and $400 \mathrm{~km}$ respectively in the horizontal direction. In geomagnetic latitude and local time coordinates, the observations fell within the general region of convective motion from the nighttime to the daytime region, as determined statistically by Heppner (1972). The results conformed 
to the general pattern observed in this region by Meriwether et al. (1973) and show a generally westward motion of ionization and the zonal component of the neutral wind in the pre-magnetic midnight sector. In the post midnight sector, the neutral gas did not, in general, follow the reversal of direction to the east as exhibited by the ion motion, implying either some additional unexplained force on the neutrals or a decrease in the ion drag force, presumably the effect of recombination. In order to explain occasional departures from the above general pattern, the authors suggested a combination of effects, including diurnal pressure gradients, energy input from auroral activity, Joule heating and energy deposition from fast particles.

Using a uniform neutral density distribution and assuming height independent electron and ion densities, Maeda (1976) has solved the equations of motion for both ions and neutrals in the polar cap and auroral zone in the height range from 100 to $200 \mathrm{~km}$. The electric field configuration used in the analysis was similar in magnitude and latitudinal variation to that observed by OGO- 6 (Gurnett, 1972). The model results were represented by polar plots of ion and neutral gas motion at altitudes of 110 and $200 \mathrm{~km}$. Better agreement between the model and observations was found in the motion of the ions than that of the neutrals. The calculated neutral wind pattern, however, was found to depend critically on the degree of coupling between ions and neutrals and hence, on the assumptions made concerning the ion densities. In addition, certain of the observations used for comparative purposes were obtained on fairly disturbed days, whereas the density 
distributions assumed in the model corresponded to a relatively quiet state of the polar ionosphere.

\subsubsection{Dynamical Heating at Thermospher1c Heights}

In addition to solar energy input, a major source of heating

at thermospheric heights has long been thought to be due to dynamical heating from atmospheric tidal motions of various scales.

One of the early discussions pertaining to these tidal motions was given by Hines (1960). Hines asserted that a variety of irregular motions observed in the upper atmosphere can be explained in terms of upward propagatıng gravity waves generated low in the atmosphere and deriving their energy from either tidal oscillations and their harmonics or the low altitude wind system. Hines discusses gravity waves in terms of propagating adiabatic waves and cites direct evidence for the existence of these waves as shown by the results of early scattering experiments and height variations of the displacement of meteor trails.

It was easy to account for these effects in terms of a wave theory since the wave interpretation accounted for observed large horizontal velocity components compared with vertical ones and, in addition, the large horizontal to vertical wavelength ratio of these disturbances.

According to the theory developed by Hines (1960), the general pattern of these disturbances is revealed by a cyclic variation of wind direction with increasing height. Phase propagation is in a downward direction and energy propagation generally upward, the energy of a given mode being removed by damping 
effects as height increases. This effect is greater for modes with shorter periods and thus the longer period modes dump their energy at preferentially higher altitudes.

Hines (1965) reviewed some aspects of his earlier theory in the light of observational data obtained after 1960. From an analysis of mid latitude wind profiles obtained from rocket vapor trails, Kochanski (1964) found a relationship between the density p, the height $z$ and the wave induced horizontal wind speed given by

$$
\rho \mathrm{U}_{\mathrm{x}}^{2}=\text { Const. } \cdot \exp \left(-9.26 \mathrm{z} / \mathrm{z}_{\mathrm{o}}\right) \quad \mathrm{z}_{\mathrm{o}}=140 \mathrm{~km}
$$

This exponential decline in the product $\rho U_{x}^{2}$ tended to confirm the losses discussed by Hines (1960) and in addition, dominant modes observed both by Kochanski (1964) and by Zimmerman (1964). This decline also gave excellent agreement with the theoretical cutoff of smaller wavelength modes by viscous damping.

Hines stated that gravity waves may profoundly affect the structure of the entire thermosphere and may in fact be the source of the rapid increase in temperature with height in the region from 100 to $110 \mathrm{~km}$. As a source of heating at F-region heights, particularly at times of high geomagnetic activity, Hines proposed that the energy of gravity waves at high geomagnetic latitudes propagates horizontally over large distances to the low and mid latitude thermosphere, and is the source of heating observed by satellite measurements (Jacchia, 1964). In discussing the energy input to the E-region from the semi-diurnal tidal flux, Hines (1965) suggested that the semi-diurnal tide may be created in-situ and 
that it may, in fact, be the diurnal tide and the prevailing winds that are responsible for electrodynamic heating at higher altitudes. This has been discussed more recently by Salah and Evans (1973).

Direct confirmation of the presence of wavelike density variations in the thermosphere was provided by Newton et al. (1969) using density gauges aboard the Explorer 32 satellite. Data was obtained in the altitude range from 286 to $510 \mathrm{~km}$ with a spatial resolution along the orbital path of about $16 \mathrm{~km}$. Their results indicated a general north-south phase propagation with maximum horizontal wavelengths of several hundred $\mathrm{km}$, in agreement with earlier analyses by Thome (1964) and Georges (1968). These observations were best explained in terms of gravity waves propagating predominantly horizontally in a north to south direction with horizontal wavelengths between $130 \mathrm{~km}$ and $520 \mathrm{~km}$.

Observations of the F-region from incoherent scatter at St. Santin - Nançay during magnetically disturbed conditions have been performed by Testud (1970). These results revealed an enhancement of oscillations in the wind and temperature structure following magnetic events, with a time delay of about 1 hour. These disturbances have been interpreted in terms of gravity waves, and simultaneous observations by the European network of ionospheric observatories showed that the disturbances propagate southward (Testud and Vasseur, 1969). They are thus thought to be of auroral origin, in agreement with the theory of Hines (1965) and Newton et a1. (1969). A theoretical analysis by Testud once again supported the view that large scale travelling ionospheric disturbances (TID) are generated at high latitudes and transport energy to mid and 
low latitudes.

Klostermeyer (1973) performed a theoretical study yielding an estimate of the height distribution of reversible heat input from gravity waves and the resulting temperature increase of the neutral gas. The calculations were performed using parameters typical of both quiet and disturbed conditions. In the quiet condition set, the author employed the 1966 U.S. Standard Atmosphere Supplements assuming an exospheric temperature of $900 \mathrm{~K}$. The ion number density distribution was represented by an $\alpha$-Chapman layer with a maximum density of $5 \times 10^{11} \mathrm{~m}^{-3}$ at $300 \mathrm{~km}$. The height distribution of heat input from a single wave mode was found to be similar to that of solar EUV heating, as presented in a theoretical study by Volland (1969) and resulted in an increase of about $40 \mathrm{~K}$ in the exospheric temperature over a period of about 2 hours.

The calculations for increased geomagnetic activity employed a perturbed density distribution and an expression relating the exospheric temperature to the $\mathrm{Kp}$ index (Jacchia et al., 1967). The results showed good agreement with observed temperatures for $\mathrm{Kp}$ levels $\geqslant 5$, and best results occured when a time delay between disturbance and effect of about 6 hours was assumed, implying speeds of horizontal propagation of the waves comparable to the local sound speed.

A study of the effects of viscous and thermal dissipation on horizontally ducted acoustic-gravity waves was given by Francis (1973a). An important difference between the analysis by Francis and earlier ones was the use of a more realistic sound speed profile in the thermosphere. The author interpreted traveling 
ionospheric disturbances (TID) as upper atmosphere gravity modes detected by virtue of their effect on the F-region electron density. Included as a subset of this broader classification are those waves generated in the auroral zone during magnetic substorms. The results confirmed that large scale TID with speeds greater than $300 \mathrm{~m} \mathrm{sec}^{-1}$ are ducted horizontally for large distances with varying degrees of attenuation, depending on the vertical component of the energy flux. In addition, the author discussed the temperature dependence of the horizontal phase velocity in the upper thermosphere. The velocity was found to vary by roughly a factor of 2 between the extremes of temperature encountered and was larger for a given mode during daylight than at night.

In a later paper, Francis (1973b) suggested that medium scale TID are manifestations of freely propagating gravity waves rather than ducted modes, used to explain large scale TID, and that the direction of propagation is constrained to follow the curvature of the earth as a result of refraction by the earth's gravitational field.

In addition to gravity waves with periods above the Brunt Vaisälä cutoff and below the viscous dissipation limit, there exist atmospheric oscillations related to the solar tide. These periodic oscillations are also revealed in temperature and density profiles as well as in the winds, and involve a fundamental period of one solar day and the various harmonics. In tidal theory these oscillations are represented by an expansion in spherical harmonics over the indices $1, \mathrm{~m}$ and $\mathrm{n}$. It is customary to designate a given term by $S_{1 n}^{m}$ where the indices 1 and $m$ classify the term as to 
wave family and the $\mathrm{n}$ index further subdivides it into wave type. The index 1 specifies the period of the wave, given by $1^{-1}$ of a mean solar day, and $I$ and $n$ together $(1, n)$ are normally used to specify the tidal mode under consideration.

Using incoherent scatter data obtained at Millstone Hill $\left(42.6^{\circ} \mathrm{N}\right)$ and St. Santin, France $\left(44.6^{\circ} \mathrm{N}\right)$, Salah and Wand (1974) have studied the average behavior and variability of tidal oscillations in the lower mid latitude thermosphere. Good agreement was obtained between the results from the two stations. Analysis of the data revealed that the dominant tidal component at mid latitudes in the lower thermosphere is the semi-diurnal $(2,4)$ mode.

The semi-diurnal oscillations can be resolved into two semidiurnal tidal modes, the $(2,2)$ and the $(2,4)$ modes. The results of Salah and Wand indicated an attenuation of the tidal $(2,4)$ mode in contrast with theory (Butler and Small, 1963; Richmond, 1971; Lindzen and Hong, 1974), yet the contribution of the $(2,2)$ mode at heights between 100 and $125 \mathrm{~km}$ is significantly less than predicted, allowing the $(2,4)$ mode to dominate in this region. Additional disagreement between theory and observations was found in the height of maximum amplitude of the two modes and in the damping rates above these heights. 


\subsection{Specific Statement of the Problem}

It is the intent of this study to;

1) provide estimates of the energy transported into or out of the nighttime thermosphere via conduction, radiation and the low and mid latitude thermospheric wind system.

2) estimate the global energy input from the polar cap to the mid latıtude nighttime thermosphere via the high latitude wind system.

3) ascertain the need for additional thermospheric energy sources based on a comparison of the energy input and loss terms. 


\section{METHOD OF ANALYSIS}

Z.1 Analytic Form of the Contributions to the Energy Balance

For a composite of several neutral constituents $i$, the thermal balance of the system under steady state conditions requires the solution of the energy equation. The form used here is that given by Banks and Kockarts (1973, equation 14.12).

$$
\begin{gathered}
\frac{\partial}{\partial t} \frac{N n k T}{2}+\vec{\nabla} \cdot\left(\frac{N n k T}{2} \vec{v}_{o}\right)+\vec{\nabla} \cdot \vec{E}+p \vec{\nabla} \cdot \vec{v}_{o} \\
-\sum_{i} n_{i} \vec{F}_{i} \cdot \vec{V}_{i}=P-L
\end{gathered}
$$

where the heat flow vector $\vec{E}$ is

$$
\mathrm{E}=-\lambda \vec{\nabla} \mathrm{T} \bar{f} \sum_{1}\left(1+\frac{N}{2}\right) \mathrm{n}_{\mathrm{i}} \mathrm{k} \mathrm{T} \overrightarrow{\mathrm{V}}_{\mathrm{i}}
$$

In addition, the continuity equation for the total density is given by

$$
\sum_{i}\left[\frac{\partial n_{1} m_{1}}{\partial t}+\vec{\nabla} \cdot n_{i} m_{i} \vec{v}_{0}\right]=0
$$

In the above expressions

$$
\begin{aligned}
& \vec{v}_{0} \text { is the mass average or bulk velocity } \\
& n_{i}, m_{i} \text {, and } \vec{V}_{i} \text { are, respectively, the concentration, mass } \\
& \text { and diffusion velocity of the } i^{i} \text { th constituent }
\end{aligned}
$$


$\mathrm{n}$ is the total concentration of neutral constituents

$T$ is the temperature

$\lambda$ is the thermal conductivity

$p$ is the total hydrostatic pressure

$\mathrm{k}$ is the Boltzmann constant

$\vec{F}_{i}$ are external forces acting on the $i^{1}$ th . constituent

$N$ is the average number of degrees of freedom for the

$$
\begin{aligned}
& \text { constituents, defined by } \\
& N=\frac{\sum_{i} N_{i} n_{i}}{\sum_{i} n_{i}}=\frac{1}{n} \sum_{i} N_{i} n_{i}
\end{aligned}
$$

The work term $p \vec{\nabla} \cdot \vec{v}_{0}$ in equation (2.1) can be rewritten as

$$
\mathrm{p} \vec{\nabla} \cdot \vec{v}_{\mathrm{o}}=\vec{\nabla} \cdot\left(\mathrm{p} \overrightarrow{\mathrm{v}}_{\mathrm{o}}\right)-\overrightarrow{\mathrm{v}}_{\mathrm{o}} \cdot \vec{\nabla}_{\mathrm{p}}
$$

Assuming hydrostatic equilibrium, equation (2.5) becomes

$$
\mathrm{p} \vec{\nabla} \cdot \overrightarrow{\mathrm{v}}_{\mathrm{o}}=\vec{\nabla} \cdot\left(\mathrm{nkT} \overrightarrow{\mathrm{v}}_{\mathrm{o}}\right)-\overrightarrow{\mathrm{v}}_{\mathrm{o}} \cdot(\mathrm{n} \overrightarrow{\mathrm{m}} \overrightarrow{\mathrm{g}})
$$

Writing

$$
\vec{g}=-\vec{\nabla} \varphi
$$

where $\varphi$ is the gravitational potential, equation (2.6) becomes

$$
\mathrm{p} \vec{\nabla} \cdot \overrightarrow{\mathrm{v}}_{\mathrm{o}}=\vec{\nabla} \cdot\left(\mathrm{nkT} \overrightarrow{\mathrm{v}}_{\mathrm{o}}\right)+\overrightarrow{\mathrm{v}}_{\mathrm{o}} \cdot(\mathrm{nm} \vec{\nabla} \varphi)
$$


and expanding gives

$$
\mathrm{p} \vec{\nabla} \cdot \overrightarrow{\mathrm{v}}_{\mathrm{o}}=\vec{\nabla} \cdot\left(\mathrm{n} \mathrm{kT} \overrightarrow{\mathrm{v}}_{\mathrm{o}}\right)+\vec{\nabla} \cdot\left(\mathrm{n} \overrightarrow{\mathrm{m}}_{\mathrm{v}_{0}} \varphi\right)-\varphi \vec{\nabla} \cdot\left(\mathrm{n} \overrightarrow{\mathrm{m}}_{\mathrm{v}_{\mathrm{o}}}\right)
$$

From equation (2.3) and for steady state conditions,

$$
\vec{\nabla} \cdot\left(n \vec{m} \vec{v}_{o}\right)=0
$$

Thus, equation (2.6) can be rewritten as

$$
\mathrm{p} \vec{\nabla} \cdot \overrightarrow{\mathrm{v}}_{0}=\vec{\nabla} \cdot\left(\mathrm{nkT} \overrightarrow{\mathrm{v}}_{\mathrm{o}}\right)+\vec{\nabla} \cdot\left(\mathrm{n} \overrightarrow{\mathrm{m}}_{\mathrm{v}} \varphi\right)
$$

In performing the heat balance calculations, the zero of potential energy has been taken to lie on the lower system boundary at $120 \mathrm{~km}$, as shown in Figure 2. For a flat earth approximation, the gravitational potential energy term $\varphi$ in equations (2.8) through (2.11) is given by $g\left(h-h_{0}\right)$. This approximation is within 6 percent of the true value at $\mathrm{h}=300 \mathrm{~km}$ and within 2 percent at $\mathrm{h}=150 \mathrm{~km}$. Making this substitution and integrating equation (2.1) over the entire system volume, one gets

$$
\begin{gathered}
\int_{S}\left\{\left[\left(\frac{N}{2}+1\right) n k T+n \bar{m} g\left(h-h_{0}\right)\right] \vec{v}_{o}-\lambda \vec{\nabla}_{T}\right. \\
\left.+\sum_{i}\left(\frac{N}{2}+1\right) n_{i} k T \vec{V}_{i}\right\} \cdot \overrightarrow{d S} \\
\quad-\sum_{i} \int_{v i l} \int_{i} n_{i} \vec{F}_{i} \cdot \vec{V}_{i} d V+Q_{R}=W
\end{gathered}
$$


where $Q_{R}$ is the total radiative energy loss rate

$\vec{m}$ is the mean molecular mass

$W$ is the difference between the total observed losses and the energy sources shown

The term $\sum_{i} n_{i} \vec{F}_{i} \cdot \vec{V}_{i}$ represents the work done on the type $i$ particles by the vector sum $\vec{F}_{i}$ of the external forces. The only external forces that contribute to this term are frictional forces arising from the relative motion between the neutral gas and ionic species present in the gas. This interaction is commonly labeled ion drag.

It is among the purposes of this study to establish the need for additional energy source or loss terms based on estimates of the conduction, radiation and the thermospheric wind system under steady state conditions. These additional terms can be accounted for in terms of either ion-drag or the quantity $W$ on the right hand side of equation (2.12). The thermal balance, then, requires an estimate of each of the following established energy input and loss terms, expressed as fluxes across the system boundaries.

Energy input terms:

(i) thermal kinetic energy of the major constituents

$$
-\oiiint_{S}\left[\left(\frac{N}{2}+1\right) n k T \vec{v}_{0}+\sum_{i}\left(\frac{N}{2}+1\right) n_{i} k T \vec{v}_{i}\right] \cdot \overrightarrow{d S}
$$


(1i) gravitational potential energy with respect to the lower boundary at $120 \mathrm{~km}$

$$
-\oint_{S} n \bar{m} g\left(h-h_{0}\right) \vec{v}_{0} \cdot \overrightarrow{d S}
$$

Energy loss terms:

(iii) downward conduction $\left(Q_{C}\right)$ at $120 \mathrm{~km}$ due to the vertical temperature gradient $\partial \mathrm{T} / \partial \mathrm{z}$ at that height

$$
\begin{aligned}
& Q_{C}=-\iint_{S} \lambda \vec{\nabla} \mathrm{T} \cdot \overrightarrow{\mathrm{dS}} \sim-\lambda \iint_{S} \frac{\partial \mathrm{T}}{\partial z} \hat{\mathrm{z}} \cdot \overrightarrow{\mathrm{dS}} \\
& \text { (iv) infrared radiative cooling } Q_{R}
\end{aligned}
$$

The energy input terms arise mainly from the transport of neutral gas into the nighttime region via the horizontal thermospheric wind system. The problem of the energy flow, then, requires a simultaneous mass balance, and this entails the solution of the mass continuity equation (2.3). For a steady state process, the integration of equation (2.3) over the volume of the system yields

$$
\sum_{i} \oiint_{S} n_{i} m_{i} \vec{v}_{0} \cdot \overrightarrow{d S}=0
$$

Thus, a mass flux into or out of the system from the thermospheric winds gives rise to a compensating flux at the $120 \mathrm{~km}$ 
boundary. This boundary flow, in turn, results in an accompanying energy flux across the lower boundary which must also be considered in order to arrive at a net energy gain to the system.

The transport of energy into the thermosphere via gravity wave propagation and in addition particle precipitation and Joule heating processes at high latitudes has been well established (Hines, 1965, 1969; Roper, 1966; Justus, 1967). These processes constitute independent energy sources in addition to those considered above. Recent estimates (Klostermeyer, 1973) show that thermospheric heating from these sources is comparable in size with the above mentioned processes. The difference between the total energy input and loss rates given by items (i) through (iv), then, should provide an independent estimate of the thermospheric heating from the less well understood processes in the nighttime region.

\subsection{The Coordinate System Employed}

The choice of suitable boundaries for the nighttime thermosphere is influenced by a number of factors. Estimates of the fluxes across the boundaries require a distribution of experimental data over at least part of the surface, and hence the choice must correspond to the locations of the largest body of available measurements.

The geometry involved in performing the-energy balance of the nighttime thermosphere for equinoctial conditions is shown in simplified form in Figure 2. The system is defined as the antisolar region bounded below by a spherical surface $120 \mathrm{~km}$ from the surface of the earth, and in front by the morning and evening terminators. At equinox, the polar axis and the terminator lie in a 


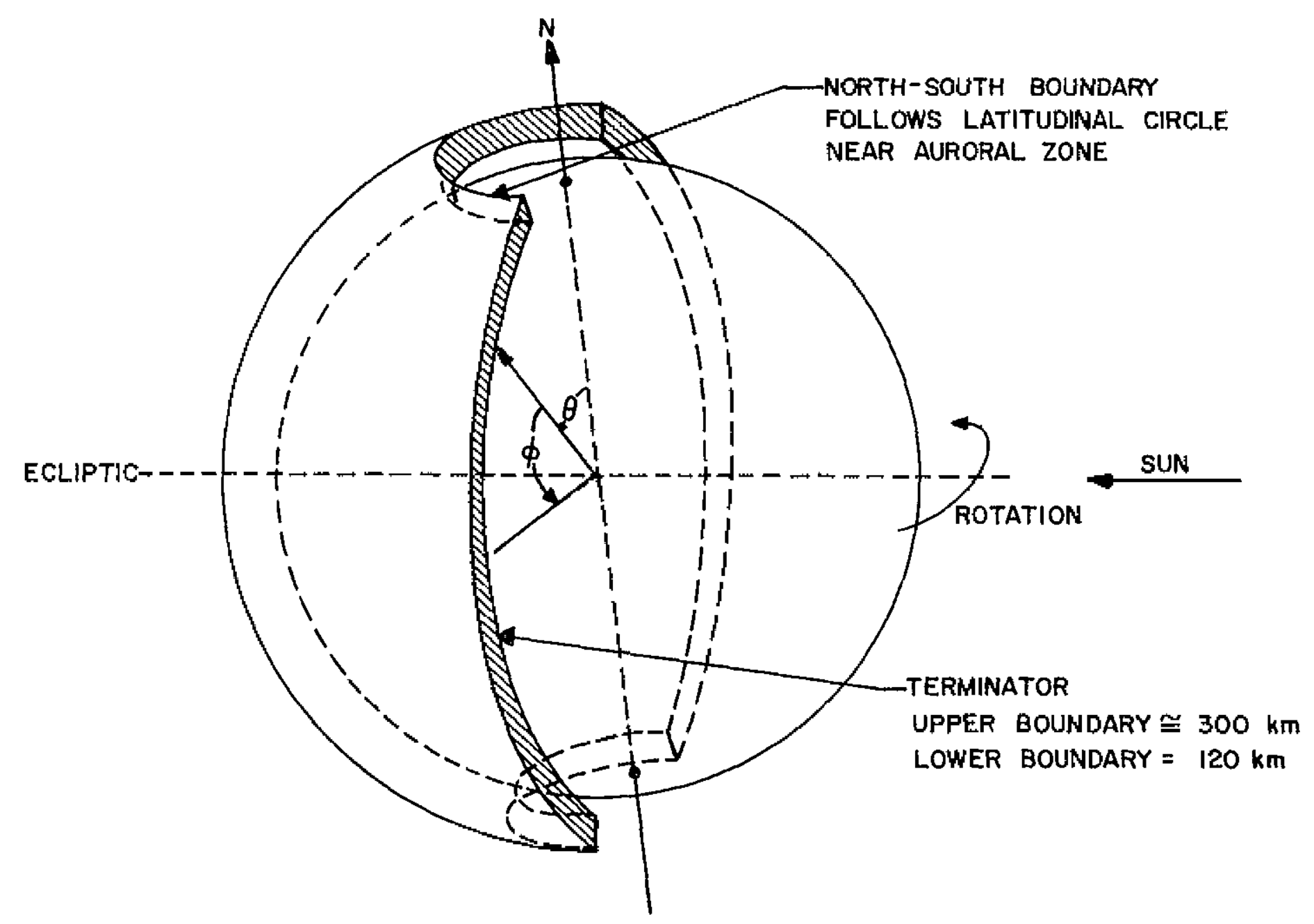

Figure 2 Geometry employed in performing the energy balance of the nighttime thermosphere at equinox. 
common plane and the corotating component of the total horizontal wind is normal to the terminator at each point. At other than equinoctial conditions, the polar axis is inclined at an angle to the plane containing the terminators, this angle being a maximum of 23.5 degrees at summer and winter solstice. The upper boundary is typically taken as the height $z$ where the quantity $\int_{\mathbf{Z}}^{\infty} n k T d z '$ has diminished to a small fraction $(<.01)$ of the value at $120 \mathrm{~km}$. This insures that the contributions to the energy balance from heights above this level are negligible in comparison. In practically all cases this requirement has been met at an altitude of $300 \mathrm{~km}$. As shown in Figure 2, the nighttime thermosphere considered here is taken to be fixed with respect to a coordinate system having the earth-sun line as one axis. The motion of the neutral gas across the terminator boundaries as viewed in this fixed frame is the vector sum

$$
\vec{v}_{\text {fixed }}=\vec{v}_{\text {moving }}+\vec{\omega} \times \vec{r}
$$

where $\vec{v}_{\text {moving }}$ is the velocity of the neutral wind observed in the rotating frame. These relative velocities are measured or deduced using rocket vapor trail and incoherent scatter techniques.

$\vec{\omega}$ is the angular velocity of the earth's rotation $\vec{v}_{\text {fixed }}$ is the velocity of the neutral gas in the fixed frame of reference. This is the velocity used in the computation of the horizontal energy and mass fluxes 
and is related to $\vec{v}_{0}$ and $\vec{V}_{i}$ discussed earlier by

$\vec{v}_{f_{1 x e d}}=\vec{v}_{0}+\vec{v}_{i}$

for the $i^{1}$ th constituent.

$\vec{r}$ is the radius vector from the center of the earth to the location of the observed air parcel.

The polar regions have been excluded from the nighttime system defined here since the energy considerations are completely different as discussed by Nisbet and Glenar (1977). While the high latitude boundaries are defined by the cutaway portions at the top and bottom of Figure 2, the polar winds are ordered in geomagnetic local time and latitude. It has been assumed for the present analysis that the average energy transported by the winds across the 70 degree geographic latitude into the nighttime thermosphere is equal to the energy transported by the winds across the 70 degree geomagnetic latitude over the corresponding range of geomagnetic local times. These south directed energy and mass fluxes constitute the energy input to the system from auroral processes and are treated in detail in Section 3.2.

An additional complication arises at other than equinoctial conditions when a larger or smaller fraction of the polar cap area is contained within the region of interest. In such a case, the geometry shown in Figure 2 no longer applies. As discussed in a later section of this study, the small number of wind measurements made at high geomagnetic latitudes are not sufficient to show seasonal changes in the high latitude wind pattern. For 
this reason, and since the terminator is always within a few degrees of the polar cap, the high latitude energy source is in each case taken to be the energy outflow from the cap between 18 and 6 hours geomagnetic local times.

Figure 3 shows pictorially the contributions to the energy balance described in Section 2.1. The treatment of the energy input from thermospheric winds has been divided into contributions from the low and mid latitude wind system and contributions from the polar regions. For this reason, the manner of presentation of contributing terms differs slightly from that listed in Section 2.1. Each quantity in the figure related to the horizontal wind contains both the thermal and gravitational potential energy contributions to the total flux. The contributing terms in Figure 3 may be defined as follows;

$$
\begin{aligned}
Q_{P}= & \text { net energy gain to the nighttime system from the } \\
& \text { polar thermospheric wind system } \\
\Phi_{P}= & \text { total mass flow entering the system through the } \\
& \text { polar boundary, induced by the polar winds } \\
Q_{L}= & \text { net energy gain to the system from the mid and low } \\
& \text { latitude thermospheric winds } \\
\Phi_{L}= & \text { total mass flow entering the system, induced by the } \\
& \text { mid and low latitude winds }
\end{aligned}
$$

Some additional mention should be made regarding the definition of net energy gain as it is used here. As shown in Figure 3, the net energy gain represents only the portion of the 


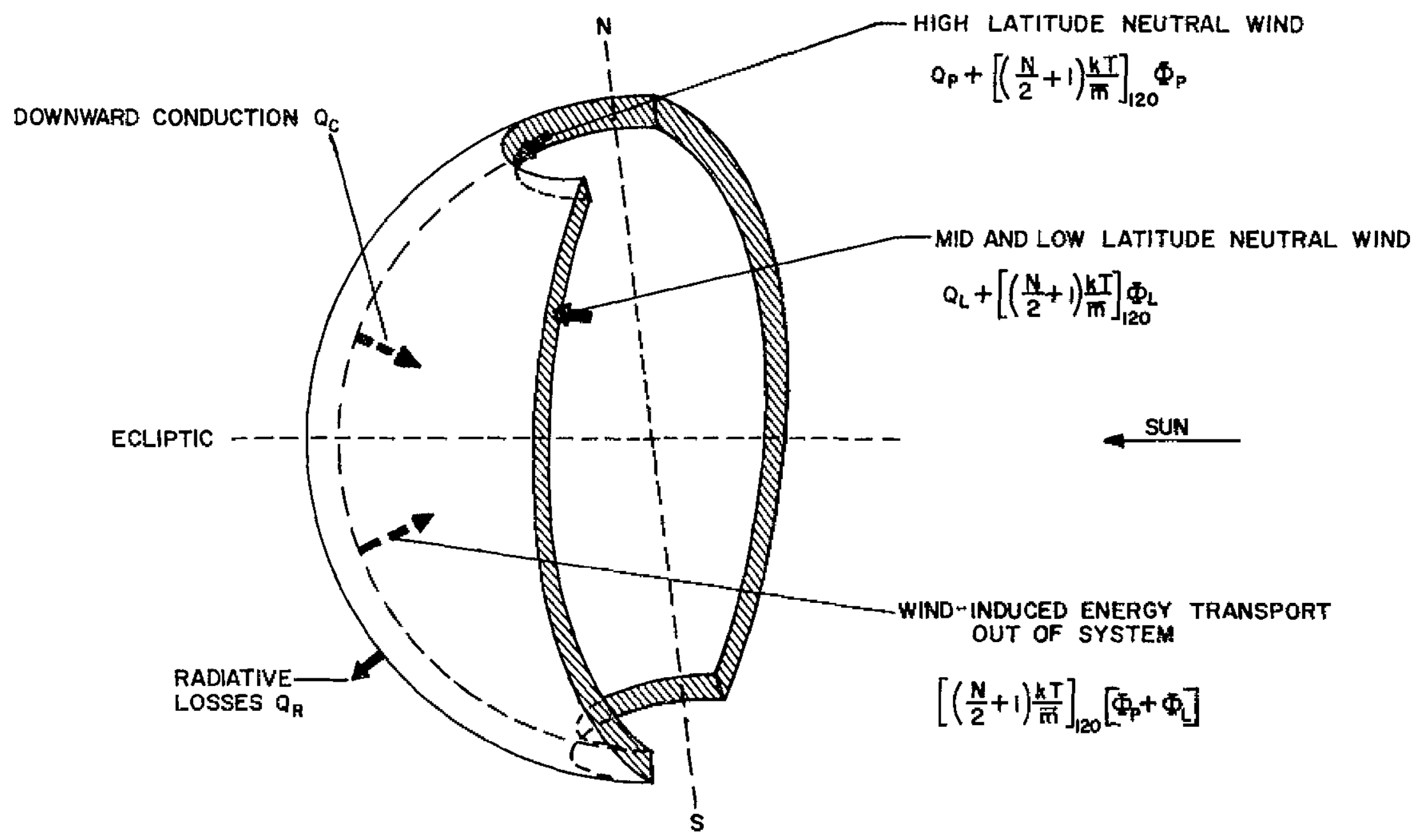

Figure 3 Contributions (symbolic) to the energy balance from the energy input and loss processes. 
energy conveyed by the horizontal winds across the system boundaries which may be considered as energy input in performing the heat balance. By the mass continuity equation (2.16), the mass inflow through the terminator or polar boundary is assumed to leave the system at the $120 \mathrm{~km}$ boundary with some suitable estimate for the $120 \mathrm{~km}$ temperature. The energy leaving in this manner must be subtracted to arrive at a net energy gain. Each of the terms above is discussed in detail in a later section of this study. 
CONTRIBUTIONS TO THE ENERGY BALANCE FROM THE THERMOSPHERIC WINDS

\subsection{Energy Transport Via the Low and Mid Latitude Wind System}

As shown in Figure 2, the low and mid latitude thermospheric winds convey energy into or out of the nighttime system at the terminator boundaries and it is the component of the horizontal wind normal to the morning and evening terminators that contributes to this exchange. The portion of the energy surface integral over the morning and evening terminators $Q_{I}$, expressed in polar coordinates, is given by equation (3.1). The diffusion velocities $\vec{V}_{i}$ have been found to be small compared to the total horizontal wind velocity $\left(v_{0}^{2}+v_{i}^{2}\right)^{1 / 2}$ and the contribution from $v_{i}$ in equations (2.12) and (2.13) has thus been omitted here.

$$
\begin{aligned}
Q_{L}=S_{M E} & \int_{R_{0}}^{R_{0}} \int_{-120}^{300} \int_{-70^{\circ}}^{70^{\circ}}\left[\left(\frac{N}{2}+1\right) n k T v_{\perp}+n \bar{m} g\left(r-R_{0}-120\right) v_{\perp} d \varphi r d r\right. \\
& -\left[\left(\frac{N}{2}+1\right) \frac{k T}{\bar{m}}\right] \Phi_{L}
\end{aligned}
$$

where $v_{\perp}$ is the component of the total horizontal wind velocity $\vec{v}_{0}$ normal to the terminator (positive into the system) $R_{0}$ is the radius of the earth $(6370 \mathrm{~km})$

$\mathrm{S}_{\mathrm{ME}}$ indicates the sum over both terminators

The second term on the right hand side of equation (3.1) arises from a consideration of the mass continuity equation (2.16) and 
represents the thermal energy lost at the lower boundary. Again, $\Phi_{L}$ is the mass flux delivered to the system by the horizontal winds.

$$
\Phi_{L}=s_{M E} \sum_{i}^{R} \int_{R_{0}}^{R} \int_{-120}^{+300}\left(n_{i} m_{i} v_{\perp}\right) d \varphi r d r
$$

It is clear from equations (3.1) and (3.2) that an estimate of the potential and thermal kinetic energy flow across the terminator boundaries requires a knowledge of the height and latitudinal dependence of the neutral temperature, the major constituent number densities and the thermospheric wind velocities.

\subsubsection{Sources of Wind Data: Vapor Trail Measurements}

Rocket vapor trail measurements provide information on the magnitude and direction of the horizontal winds at heights up to nearly $200 \mathrm{~km}$. The results of these flights are particularly valuable for the purposes of this study since the technique involves

a direct measurement of the wind velocity and since a large number of the rocket flights are made at or near the terminator location so that trails illuminated by the sun can be observed against a dark background.

In this analysis, data has been examined from a number of morning and evening pairs of sodium and lithium vapor trail measurements made at mid latitudes between the years 1961 and 1972. A summary of these flights and associated observations is given in Table 1. In grouping the results according to season, data obtained within thirty days of either equinox was considered representative of that equinox, while the remaining firings were 
Table 1a. Mid Latitude Vapor Trail Measurements Near Fall and Spring Equinox

\begin{tabular}{|c|c|c|c|c|c|c|c|}
\hline $\begin{array}{c}\text { Date } \\
\text { Mo/Day/Yr }\end{array}$ & Day & $\begin{array}{l}\text { Time } \\
\text { of Day }\end{array}$ & Launch Site & $\mathrm{K}_{\mathrm{p}}^{\dagger}$ & $\mathrm{F}_{10.7}$ & $\begin{array}{l}\text { Altitude Range } \\
(\mathrm{km})\end{array}$ & Ref. \\
\hline $\begin{array}{l}9 / 7 / 61 \\
9 / 8 / 61\end{array}$ & $\begin{array}{l}250 \\
251\end{array}$ & $\begin{array}{l}\text { PM } \\
\text { AM }\end{array}$ & $\begin{array}{l}\text { Sardinia, Italy } \\
\quad 39.6^{\circ} \mathrm{N}, 9.5^{\circ} \mathrm{E}\end{array}$ & $\begin{array}{l}0.6 \\
0.8\end{array}$ & $\begin{array}{l}115 \\
117\end{array}$ & $\begin{array}{l}90-200 \\
90-140\end{array}$ & A \\
\hline $\begin{array}{l}9 / 16 / 61 \\
9 / 17 / 61\end{array}$ & $\begin{array}{l}259 \\
260\end{array}$ & $\begin{array}{l}\text { PM } \\
\text { AM }\end{array}$ & $\begin{array}{l}\text { Wa1lops Island, Va. } \\
\quad 37.8^{\circ} \mathrm{N}, 75.5^{\circ} \mathrm{W}\end{array}$ & $\begin{array}{l}2.0 \\
3.4\end{array}$ & $\begin{array}{l}133 \\
124\end{array}$ & $\begin{array}{l}100-150 \\
100-170\end{array}$ & A \\
\hline $\begin{array}{l}10 / 7 / 64 \\
10 / 8 / 64\end{array}$ & $\begin{array}{l}280 \\
281\end{array}$ & $\begin{array}{l}\text { PM } \\
\text { AM }\end{array}$ & WaIlops Island, Va. & $\begin{array}{l}1.6 \\
2.8\end{array}$ & $\begin{array}{l}74 \\
77\end{array}$ & $\begin{array}{l}90-150 \\
85-160\end{array}$ & A \\
\hline $\begin{array}{l}10 / 16 / 69 \\
10 / 17 / 69\end{array}$ & $\begin{array}{l}289 \\
290\end{array}$ & $\begin{array}{l}\text { AM } \\
\text { PM }\end{array}$ & Woomera, Australia & $\begin{array}{l}0.8 \\
1.5\end{array}$ & $\begin{array}{l}116 \\
123\end{array}$ & $\begin{array}{l}95-200 \\
95-240\end{array}$ & B \\
\hline $\begin{array}{l}4 / 19 / 61 \\
4 / 20 / 61\end{array}$ & $\begin{array}{l}109 \\
110\end{array}$ & $\begin{array}{l}\text { PM } \\
\text { AM }\end{array}$ & $\begin{array}{r}\text { Sardinia, Italy } \\
39.6^{\circ} \mathrm{N}, 9.5^{\circ} \mathrm{E}\end{array}$ & $\begin{array}{l}1.4 \\
2.5\end{array}$ & $\begin{array}{l}105 \\
.03\end{array}$ & $\begin{array}{r}85-185 \\
110-190\end{array}$ & A \\
\hline $\begin{array}{l}4 / 19 / 61 \\
4 / 20 / 61 \\
4 / 21 / 61\end{array}$ & $\begin{array}{l}109 \\
110 \\
111\end{array}$ & $\begin{array}{l}\text { AM } \\
\text { PM } \\
\text { AM }\end{array}$ & Wallops Island, $\mathrm{Va}$. & $\begin{array}{l}2.0 \\
1.0 \\
0.2\end{array}$ & $\begin{array}{l}105 \\
103 \\
104\end{array}$ & $\begin{array}{l}90-160 \\
80-160 \\
85-160\end{array}$ & A \\
\hline $\begin{array}{l}3 / 1 / 62 \\
3 / 2 / 62\end{array}$ & $\begin{array}{l}60 \\
61\end{array}$ & $\begin{array}{l}\text { PM } \\
\text { AM }\end{array}$ & Wallops Island, Va. & $\begin{array}{l}2.1 \\
1.9\end{array}$ & $\begin{array}{l}121 \\
112\end{array}$ & $\begin{array}{l}70-125 \\
65-125\end{array}$ & A \\
\hline $\begin{array}{l}4 / 12 / 72 \\
4 / 13 / 72 \\
4 / 14 / 72 \\
4 / 14 / 72\end{array}$ & $\begin{array}{l}102 \\
103 \\
104 \\
104\end{array}$ & $\begin{array}{l}\text { PM } \\
\text { AM } \\
\text { PM } \\
\text { PM }\end{array}$ & $\begin{array}{l}\text { Elgin AFB, Fla. } \\
\quad 30.4^{\circ} \mathrm{N}, 86.7^{\circ} \mathrm{W}\end{array}$ & $\begin{array}{l}1.4 \\
2.9 \\
2.5 \\
2.5\end{array}$ & $\begin{array}{l}128 \\
128 \\
124 \\
124\end{array}$ & $\begin{array}{r}104-168 \\
123-174 \\
82-132 \\
183-194\end{array}$ & C \\
\hline
\end{tabular}

References: A. Bedinger (1966), B. Lloyd et a1. (1972), C. Roper and Edwards (1974), D. Justus and Edwards (1965), E. Rees et a1. (1972), F. Montgomery et a1. (1968).

$\dagger$ Average of three values preceding measurement. 
Table 1b. Mid Latitude Vapor Trail Measurements Near Summer Solstice

\begin{tabular}{|c|c|c|c|c|c|c|c|}
\hline $\begin{array}{c}\text { Date } \\
\text { Mo/Day/Yr }\end{array}$ & Day & $\begin{array}{l}\text { Time } \\
\text { of Day }\end{array}$ & Launch Site & $\mathrm{K}_{\mathrm{p}}^{\dagger}$ & $\mathrm{F}_{10.7}$ & $\begin{array}{c}\begin{array}{c}\text { Altitude Range } \\
(\mathrm{km})\end{array} \\
\end{array}$ & Ref. \\
\hline $\begin{array}{l}6 / 5 / 62 \\
6 / 5 / 62\end{array}$ & $\begin{array}{l}156 \\
156\end{array}$ & $\begin{array}{l}\mathrm{AM} \\
\mathrm{PM}\end{array}$ & $\underset{31^{\circ} \mathrm{N}, 3{ }^{\mathrm{O}} \mathrm{W}}{\text { Hammaguir }}$ & $\begin{array}{l}2.8 \\
1.6\end{array}$ & $\begin{array}{l}85 \\
85\end{array}$ & $\begin{array}{l}100-150 \\
105-140\end{array}$ & A \\
\hline $\begin{array}{l}6 / 5 / 62 \\
6 / 5 / 62\end{array}$ & $\begin{array}{l}156 \\
156\end{array}$ & $\begin{array}{l}\mathrm{AM} \\
\mathrm{PM}\end{array}$ & $\begin{array}{l}\text { Reggan, Algeria } \\
26.70^{\mathrm{N}}, 0^{\circ}\end{array}$ & $\begin{array}{l}2.8 \\
1.6\end{array}$ & $\begin{array}{l}85 \\
85\end{array}$ & $\begin{array}{l}95-140 \\
95-120\end{array}$ & A \\
\hline $\begin{array}{l}5 / 20 / 63 \\
5 / 21 / 63 \\
5 / 21 / 63\end{array}$ & $\begin{array}{l}140 \\
141 \\
141\end{array}$ & $\begin{array}{l}\mathrm{PM} \\
\mathrm{AM} \\
\mathrm{PM}\end{array}$ & $\begin{array}{l}\text { Sardinia, Italy } \\
\quad 39.6^{\circ} \mathrm{N}, 9.5^{\circ} \mathrm{E}\end{array}$ & $\begin{array}{l}0.5 \\
0.5 \\
1.6\end{array}$ & $\begin{array}{l}91 \\
88 \\
88\end{array}$ & $\begin{array}{l}95-195 \\
95-160 \\
85-180\end{array}$ & A \\
\hline $\begin{array}{l}5 / 17 / 63 \\
5 / 18 / 63\end{array}$ & $\begin{array}{l}137 \\
138\end{array}$ & $\begin{array}{l}\text { PM } \\
\text { AM }\end{array}$ & $\begin{array}{l}\text { Elgin } \mathrm{AFB}, \mathrm{Fla} \\
\quad 30.4^{\circ} \mathrm{N}, 86.7^{\circ} \mathrm{W}\end{array}$ & $\begin{array}{l}0.6 \\
0.4\end{array}$ & $\begin{array}{r}100 \\
98\end{array}$ & $\begin{array}{r}95-170 \\
100-160\end{array}$ & A \\
\hline $\begin{array}{l}5 / 17 / 63 \\
5 / 18 / 63 \\
5 / 21 / 63\end{array}$ & $\begin{array}{l}137 \\
138 \\
141\end{array}$ & $\begin{array}{l}\text { PM } \\
\text { AM } \\
\text { PM }\end{array}$ & Elgin AFB, Fla. & $\begin{array}{l}0.6 \\
0.4\end{array}$ & $\begin{array}{r}100 \\
\times \quad 98\end{array}$ & $\begin{array}{l}71-170 \\
99-105 \\
69-140\end{array}$ & $\mathrm{D}$ \\
\hline $\begin{array}{l}5 / 31 / 68 \\
5 / 31 / 68\end{array}$ & $\begin{array}{l}151 \\
151\end{array}$ & $\begin{array}{l}\mathrm{AM} \\
\mathrm{PM}\end{array}$ & $\begin{array}{l}\text { Woomera, Australia } \\
\quad 31^{\circ} \mathrm{S}, 137^{\circ} \mathrm{E}\end{array}$ & & $\begin{array}{l}145 \\
145\end{array}$ & $\begin{array}{l}95-240 \\
95-240\end{array}$ & $\mathrm{E}$ \\
\hline
\end{tabular}

References: A. Bedinger (1966), B. Lloyd et a1. (1972), C. Roper and Edwards (1974), D. Justus and Edwards (1965), E. Rees et al. (1972), F. Montgomery et al. (1968).

+ Average of three values preceding measurement. 
Table 1c. Mid Latitude Vapor Trail Measurements Near Winter Solstice

\begin{tabular}{|c|c|c|c|c|c|c|c|}
\hline $\begin{array}{c}\text { Date } \\
\text { Mo/Day/Yr }\end{array}$ & Day & $\begin{array}{l}\text { Time } \\
\text { of Day }\end{array}$ & Launch Site & $\mathrm{k}_{\mathrm{p}}^{+}$ & $\mathrm{F}_{10.7}$ & $\begin{array}{r}\text { Altitude Range } \\
(\mathrm{km})\end{array}$ & Ref. \\
\hline $\begin{array}{l}11 / 27 / 62 \\
11 / 30 / 62\end{array}$ & $\begin{array}{l}331 \\
334\end{array}$ & $\begin{array}{l}\mathrm{PM} \\
\mathrm{AM}\end{array}$ & $\begin{array}{l}\text { Chamical, Argentina } \\
30.5^{\circ} \mathrm{S}, 66^{\circ} \mathrm{W}\end{array}$ & $\begin{array}{l}1.7 \\
3.5\end{array}$ & $\begin{array}{l}75 \\
77\end{array}$ & $\begin{array}{l}105-170 \\
100-170\end{array}$ & A \\
\hline $\begin{array}{l}11 / 30 / 64 \\
12 / 1 / 64\end{array}$ & $\begin{array}{l}334 \\
335\end{array}$ & $\begin{array}{l}\text { PM } \\
\text { AM }\end{array}$ & $\begin{array}{l}\text { Sonmiani, Pakistan } \\
226^{\circ} \mathrm{N}, 67^{\circ} \mathrm{E}\end{array}$ & $\begin{array}{l}3.4 \\
1.9\end{array}$ & $\begin{array}{l}74 \\
76\end{array}$ & $\begin{array}{l}120-155 \\
100-205\end{array}$ & A \\
\hline $\begin{array}{l}11 / 11 / 64 \\
11 / 12 / 64\end{array}$ & $\begin{array}{l}315 \\
316\end{array}$ & $\begin{array}{l}\text { PM } \\
\text { AM }\end{array}$ & $\begin{aligned} \text { Ship _at } & 34.4^{\circ} \mathrm{N}, 74.7^{\circ} \mathrm{W} \\
& 34.4^{\circ} \mathrm{N}, 76.3^{\circ} \mathrm{W}\end{aligned}$ & $\begin{array}{l}0.8 \\
2,4\end{array}$ & $\begin{array}{l}72 \\
72\end{array}$ & $\begin{array}{l}80-155 \\
90-155\end{array}$ & A \\
\hline $\begin{array}{l}11 / 17 / 65 \\
11 / 18 / 65 \\
11 / 18 / 65 \\
11 / 18 / 65\end{array}$ & $\begin{array}{l}321 \\
322 \\
322 \\
322\end{array}$ & $\begin{array}{l}\text { PM } \\
\text { AM } \\
\text { AM } \\
\text { AM }\end{array}$ & $\begin{array}{l}\text { E1gin } A F B, F 1 \mathrm{a} \\
30.4^{\circ} \mathrm{N}, 86.7_{\mathrm{W}}\end{array}$ & $\begin{array}{l}0.5 \\
1.5 \\
1.5 \\
1.5\end{array}$ & $\begin{array}{l}74 \\
75 \\
75 \\
75\end{array}$ & $\begin{array}{l}97-155 \\
94-152 \\
89-171 \\
78-138\end{array}$ & $\mathrm{~F}$ \\
\hline $\begin{array}{l}1 / 16 / 67 \\
1 / 16 / 67 \\
1 / 16 / 67 \\
1 / 16 / 67\end{array}$ & $\begin{array}{l}16 \\
16 \\
16 \\
16\end{array}$ & $\begin{array}{l}\text { AM } \\
\text { AM } \\
\text { PM } \\
\text { PM }\end{array}$ & $\begin{aligned} \text { Elgin AFB, Fla } & (\text { Upleg) } \\
& \text { (Downleg) } \\
& \text { (Upleg) } \\
& \text { (Downleg) }\end{aligned}$ & $\begin{array}{l}2.7 \\
2.7 \\
1.7 \\
1.7\end{array}$ & $\begin{array}{l}124 \\
124 \\
124 \\
124\end{array}$ & $\begin{array}{r}86-158 \\
100-156 \\
88-162 \\
92-102\end{array}$ & $\mathrm{~F}$ \\
\hline
\end{tabular}

References: A. Bedinger (1966), B. Lloyd et aI. (1972), C. Roper and Edwards (1974), D. Justus and Edwards (1965), E. Rees et al. (1972), F, Montgomery et al. (1968).

$\dagger$ Average of three values preceding measurement. 
considered representative of either summer or winter solstice. With the exception of the two pairs of Australian rocket firings shown in Tables $1 \mathrm{~b}$ and 1c, all of the morning-evening rocket flights were performed in northern latitudes. For computation purposes the average wind profiles in Figure 4 are thus considered to represent only the northern hemisphere.

For each date involved, the wind flow into the system is evaluated by first considering the angle between the east-west direction and the terminator and then evaluating the component of the wind normal to the terminator. By averaging the results obtained at each terminator in increments of $5 \mathrm{~km}$, irregularities in the wind system from propagating waves of various scales has been largely removed and a consistent trend in the variation of wind propagation with height is revealed (Figure 4).

The effects of changing magnetic activity have been taken into account by monitoring the magnitude and daily range of the $\mathrm{Kp}$ index for the date of each firing. The observed $\mathrm{Kp}$ values are all characteristic of low or medium levels of magnetic activity and in no case is there a wide daily range in $K p$ indicating a sudden increase in magnetic activity between the morning and evening firings. Thus, the contribution from this variable to the daily wind variations is thought to be small.

Another of the uncertainties involved in these calculations is the effect of variations in solar activity as indicated by the $F_{10.7}$ index, on the energy transported into the nighttime region and hence on the observed zonal fluxes at the terminators. A density 


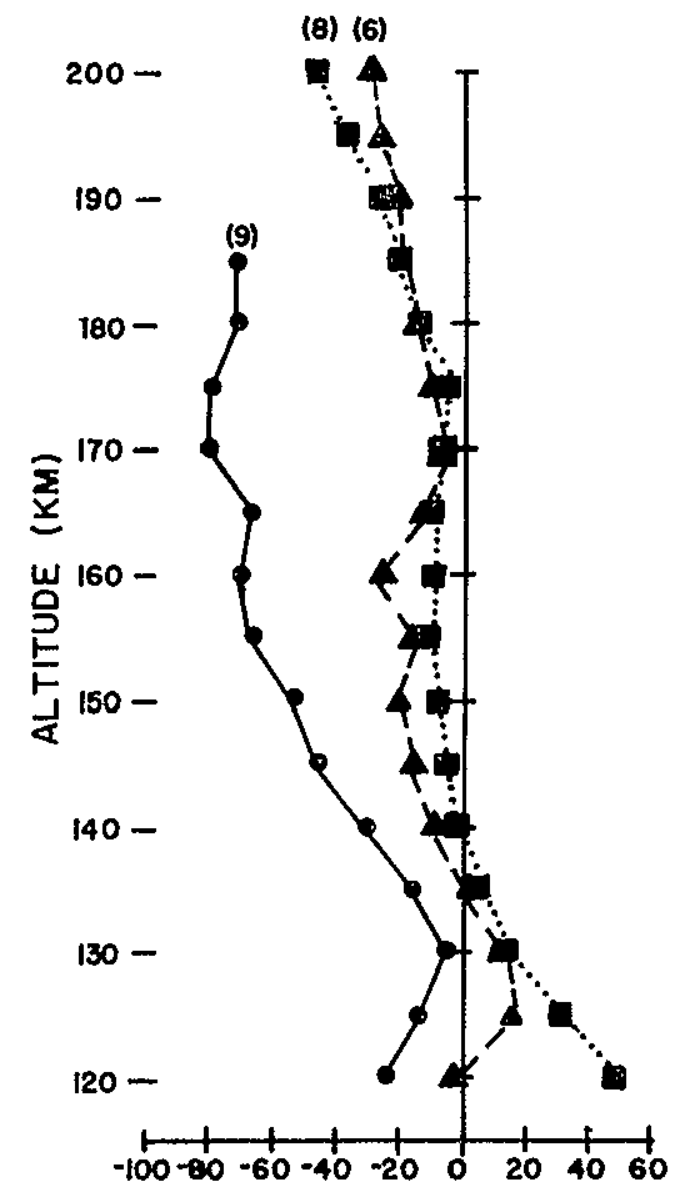

a) MORNING PROFILE ( $\left.V_{\text {AM }}\right)$ $\left(m \sec ^{-1}\right)$

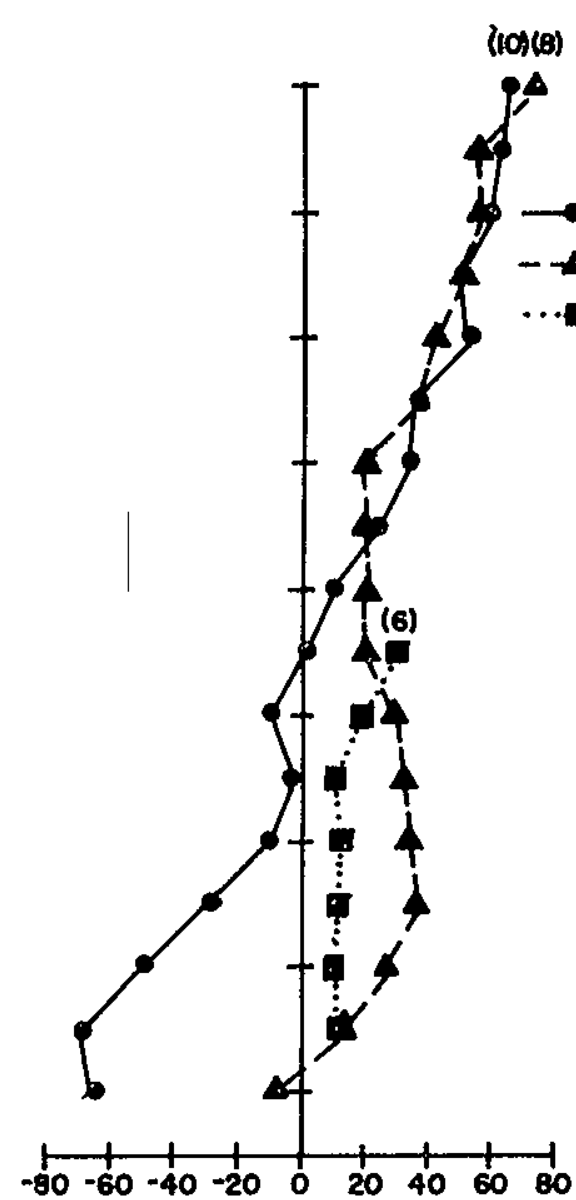

b) EVENING PROFILE ( $v_{\text {PMI }}$ )

$\left(m \sec ^{-1}\right)$

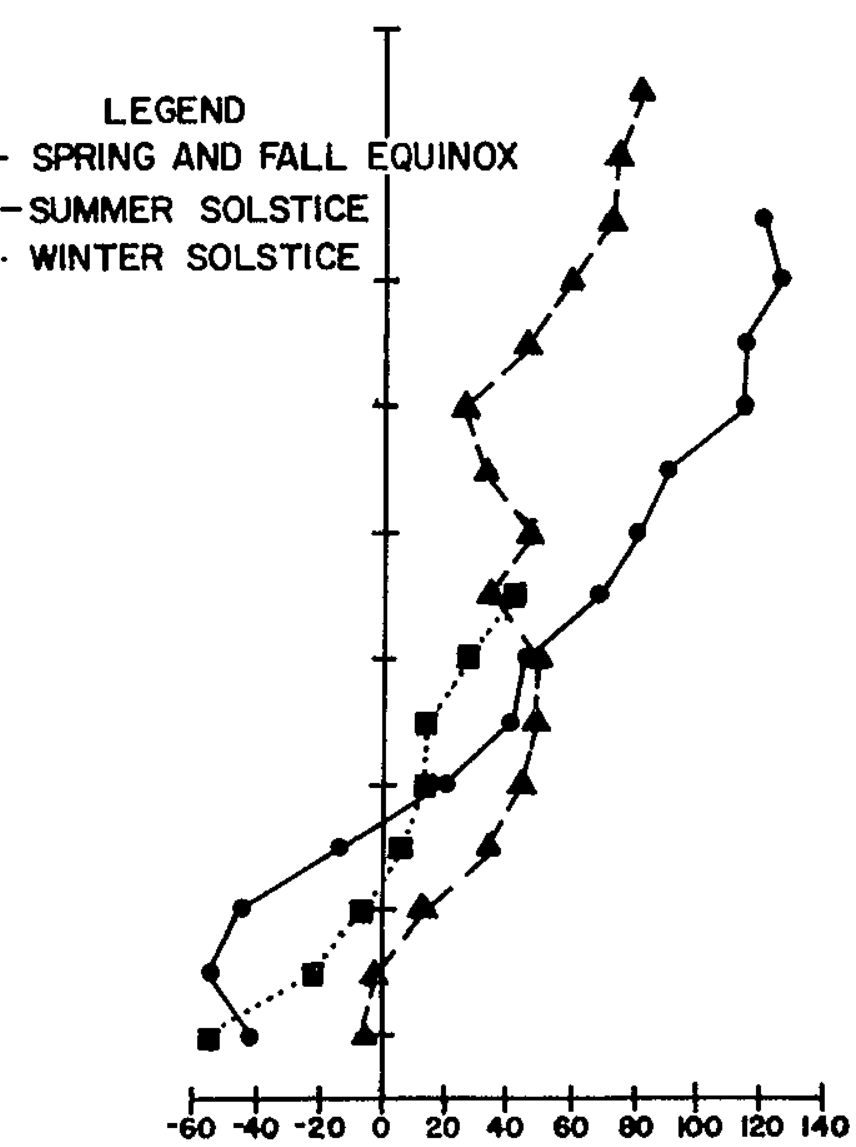

c) DIFFERENCE PROFILE (

$\left(m \sec ^{-1}\right)$

Figure 4 Height variation of the average eastward neutral wind at twilight, from mid-1atitude vapor trail measurements. The numbers in parentheses are the number of flights used in obtaining the respective profile. 
weighted average velocity $\bar{v}_{\perp}$ above $120 \mathrm{~km}$ was defined by

$$
\begin{aligned}
& \bar{v}_{\perp}=\frac{1}{\overline{\mathrm{H}}_{120}} \int_{120}^{\infty} \frac{\rho_{z}}{\rho_{120}} v_{\perp}(z) d z \\
& \bar{v}_{\perp}=\frac{1}{\overline{\mathrm{H}}_{120}} \int_{120}^{\infty} \frac{\mathrm{T}_{120}}{\mathrm{~T}_{\mathrm{z}}} \exp \left[-\int_{120}^{z} \frac{\mathrm{dz}^{\prime}}{\overline{\mathrm{H}}_{\mathrm{z}^{\prime}}}\right] \mathrm{v}_{\perp}(\mathrm{z}) \mathrm{dz}
\end{aligned}
$$

where $\rho_{z}, \bar{H}_{z}$ and $T_{z}$ are the density, mean scale height and temperature at height $z$. Here, $\bar{v}_{\perp}$ is defined such that a positive value of $\bar{v}_{\perp}$ indicates wind flow from the dayside to the nightside hemisphere. This quantity should provide an indication of the direction of height integrated mass and energy flow above $120 \mathrm{~km}$.

To check the effect of solar activity on the values of $\vec{v}_{\perp}$, a correlation study was made between the values of $\bar{v}_{\perp}$ for each flight and the $F_{10.7}$ value at the time of each flight. Representative temperature distributions were taken from the COSPAR International Reference Atmosphere (CIRA, 1972). No significant correlation between the values of $\bar{v}_{\perp}$ and the $F_{10.7}$ index was observed, and since the range in observed values of $\mathrm{F}_{10.7}$ was not excessive (72-145), no restrictions were placed on values of the solar index in selecting applicable data.

The profiles obtained by averaging wind data for the same season are shown in Figure 4. Figure $4 \mathrm{c}$ has been included to illustrate the height variation of mass and energy transport from the dayside to the nighttime region. At heights above $140 \mathrm{~km}$, these profiles invariably show, as expected, an anti-solar flow, presumably the result of dayside solar heating. With the exception 
of the summer solstice results, the direction of the net wind curiously reverses in the region near $135 \mathrm{~km}$, and the density weighted average velocity $\bar{v}_{\perp}$ is found to be -22 and $-20 \mathrm{~m} \mathrm{sec}^{-1}$ for equinox and winter solstice periods. For comparative purposes, a similar analysis was performed on characteristic summer and winter wind profiles deduced by Kochanski (1964), and extending to $140 \mathrm{~km}$. These were based on $25 \mathrm{mid}$ latitude morning and evening twilight rocket vapor trail measurements.

A negative value for $\bar{v}_{\perp}$ was obtained using Kochanski's summer data, but will not be discussed since the data is not completely independent of that used in this study. All of the morning and evening flights grouped into Kochanski's winter classification are different from those used here, however, and application of equation ( $3.3 \mathrm{~b}$ ) to these results shows a value for $\vec{v}_{\perp}$ of $-15 \mathrm{~m} \mathrm{sec}^{-1}$, in reasonable agreement with the winter solstice value stated above.

At heights above $140 \mathrm{~km}$, Figure 4 shows a westward flowing wind at the morning terminator and an eastward flowing wind at the evening terminator with an accompanying day to night energy flow, in agreement with tidal theory. A significant change in wind direction is evident at lower altitudes, however, particularly in the equinoctial results. The effect of this is to produce a complete turn-around in the direction of the height integrated mass and energy flow at the terminator as the lower integration limit is moved from 135 down to $120 \mathrm{~km}$. 


\subsubsection{Analysis of Temperature and Density Data from Arecibo and St. Santin}

In order to calculate the energy transport across the morning and evening terminators, it is necessary to make use of the wind results from the previous section. In addition, estimates of the densities and temperatures at both terminators and at the altitudes of interest are required. An additional source of data, then, are incoherent scatter measurements of densities and temperatures at the terminators as provided by the Arecibo $\left(18.3^{\circ} \mathrm{N}\right)$ and the St. Santin $\left(44.6^{\circ} \mathrm{N}\right)$ incoherent scatter facilities.

The Arecibo facility provides measurements of the total collision frequency at selected heights in the altitude range from 90 to $110 \mathrm{~km}$ which have been scaled to provide the total collision frequency and hence the total density at $120 \mathrm{~km}$. In order to estimate the atomic oxygen number density at $120 \mathrm{~km}$, it was assumed that the CIRA, 1972 model represents the atomic oxygen density correctly at $320 \mathrm{~km}$ and that diffusive equilibrium allows the calculation of the $120 \mathrm{~km}$ density with the aid of the temperature profile discussed below. The molecular number density was divided between $\mathrm{O}_{2}$ and $\mathrm{N}_{2}$ in the ratio $1: 7$, again following CIRA. The temperature profile at the altitudes of importance is deduced using observed ion temperatures at heights between 118 and $260 \mathrm{~km}$ where it is assumed that the neutral temperatures do not depart significantly from that of the ions. An additional neutral temperature at $320 \mathrm{~km}$ is obtained according to the procedure of Swartz and Nisbet (1971) from the CIRA, 1972 densities and the observed ion and electron temperatures. Bates (1959) represents the 
height distribution of the neutral temperature by

$$
T_{z}=T_{\infty}-\left(T_{\infty}-T_{0}\right) \exp (-s \phi)
$$

where $T_{z}$ is the neutral temperature at height $z$

$T_{\infty}$ is the exospheric temperature

$T_{0}$ is the neutral temperature at some reference altitude $z_{0}$, here taken to be $120 \mathrm{~km}$

$s$ is the shape parameter

$\phi$ is the geopotential altitude

$$
\phi=\frac{\left(z-z_{0}\right)\left(R+z_{0}\right)}{R+z} \sim z-z_{0} \text { for } z \ll R
$$

Equation (3.4) has been solved using the least squares technique to obtain the best fit values of the temperature parameters $T_{120}$, $T_{\infty}$ and $s$. The uncertainty in $T_{\infty}$ is not of any consequence here, since only temperatures well below $200 \mathrm{~km}$ are important in the computation of energy fluxes height integrated above $120 \mathrm{~km}$.

Table A.I summarizes the temperatures and densities derived in the above manner using data from 18 days observations at Arecibo between August 12, 1974 and November 17, 1976. The data used in this analysis represent low or medium levels of magnetic activity ( $\mathrm{Kp} \leqslant 4.0$ ). The dates were selected from a body of 41 days observations and represent those days where runs were made within 1.5 hours of both terminators and where the error in the observed collision frequencies was less than 50 percent of the stated value. By examining results of the first few observations in the morning and the last few in the evening of each day, one can 
infer the temperatures and densities at the location of the terminators. Since each of the observation days listed has been classified according to season, together with the appropriate wind profile (Figure 4), the values should provide the information necessary to determine the low latitude contribution to the energy surface integral, expressed by equation (3.1).

Figure 5 shows the calculated energy flux per unit terminator length at the time of each observation and the extrapolated flux across the terminators for each of the observation days considered. The term "net flux" is used to represent these values since a correction has been applied in each case for the lower boundary flux, as discussed at the beginning of this section. The base temperature used in applying this correction is the average of the $120 \mathrm{~km}$ temperatures at the morning and evening terminators for the appropriate observing day. The terminator fluxes have been determined using a linear least squares fit to the data. The error bars represent the uncertainty in each determination which arises from both the error in the derived collision frequencies and the intrinsic variability with local time of the densities in this altitude range. Table 2 lists in summary form the terminator fluxes obtained for each of the 18 observing days. The quantities $\Delta W$ and $\Delta R$ in the table represent the contributions to the daily net fiux from the measured winds and the corotating winds respectively. As can be seen in Figure 5 and Table 2, both the magnitude and sign of the net energy flux vary between measurements. When grouped according to season, the average net fluxes were found to be $0.28,-0.62,-0.93$ and $-2.20 \times 10^{4} \mathrm{~W} \mathrm{~m}^{-1}$ for summer solstice, 

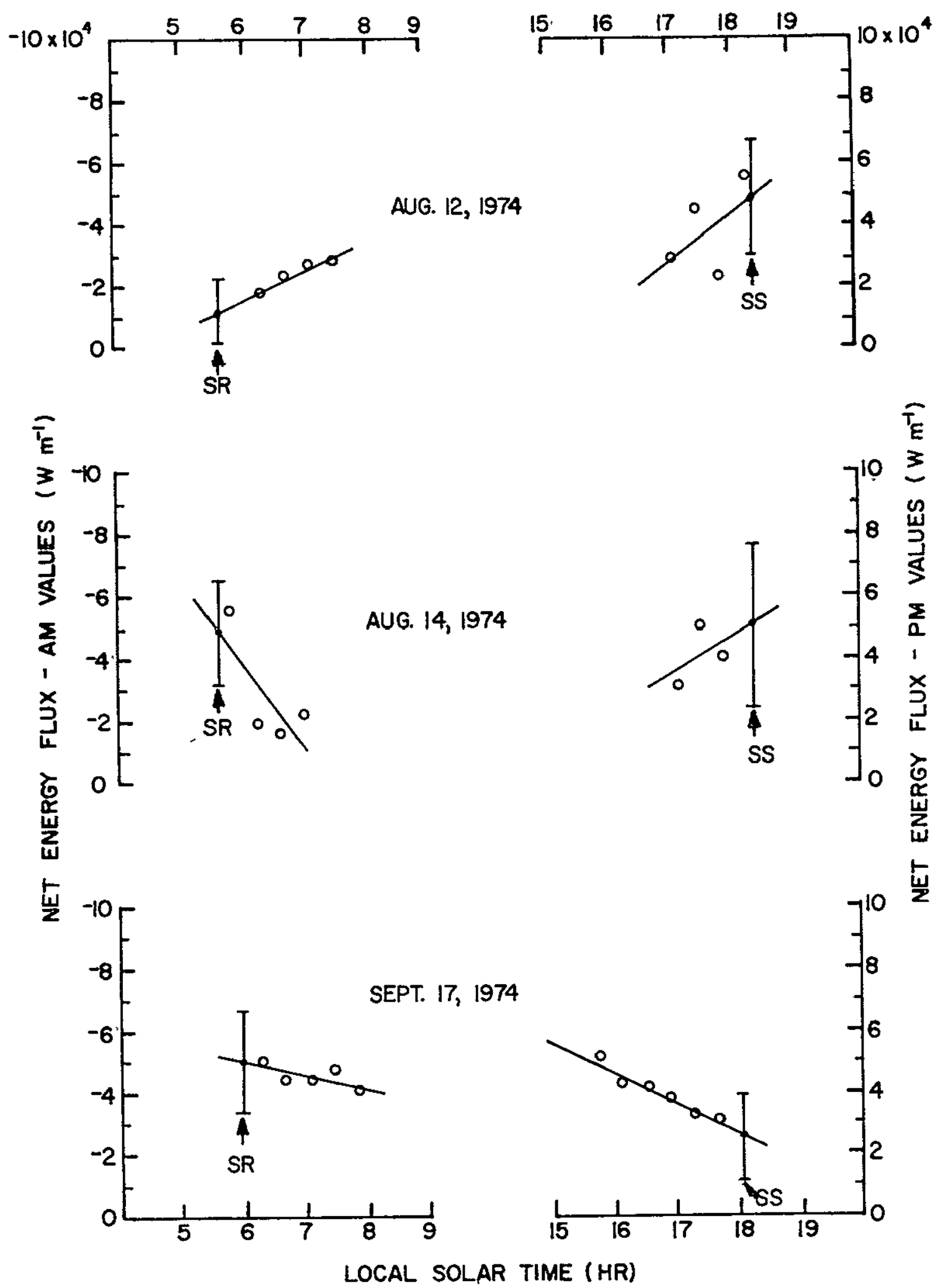
$\begin{array}{ll}\text { Figure } 5 & \begin{array}{l}\text { Terminator normal component of energy flux into nighttime } \\ \text { region above } 120 \mathrm{~km} \text {. }\end{array}\end{array}$ 

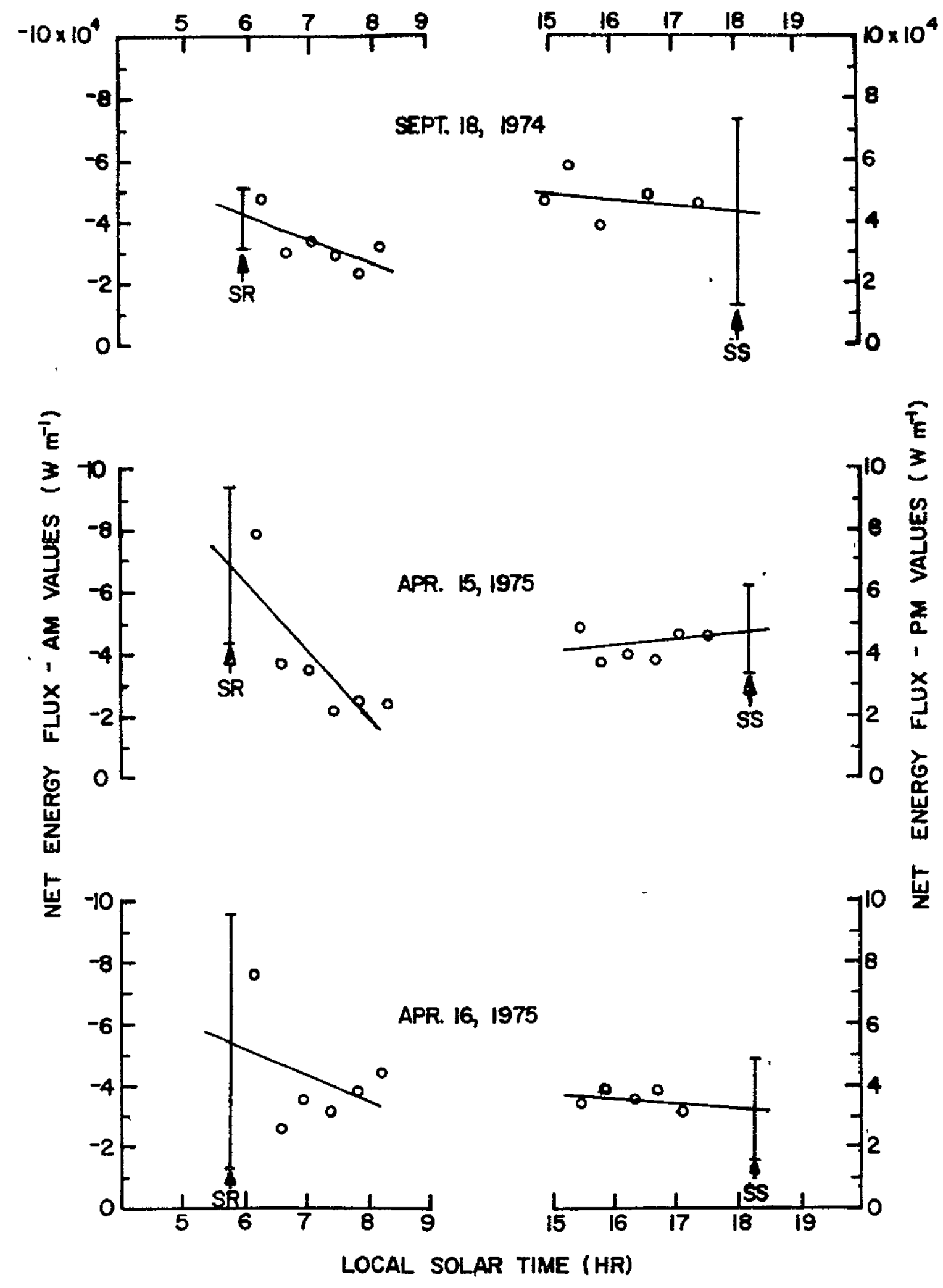

Figure 5 (Continued) 

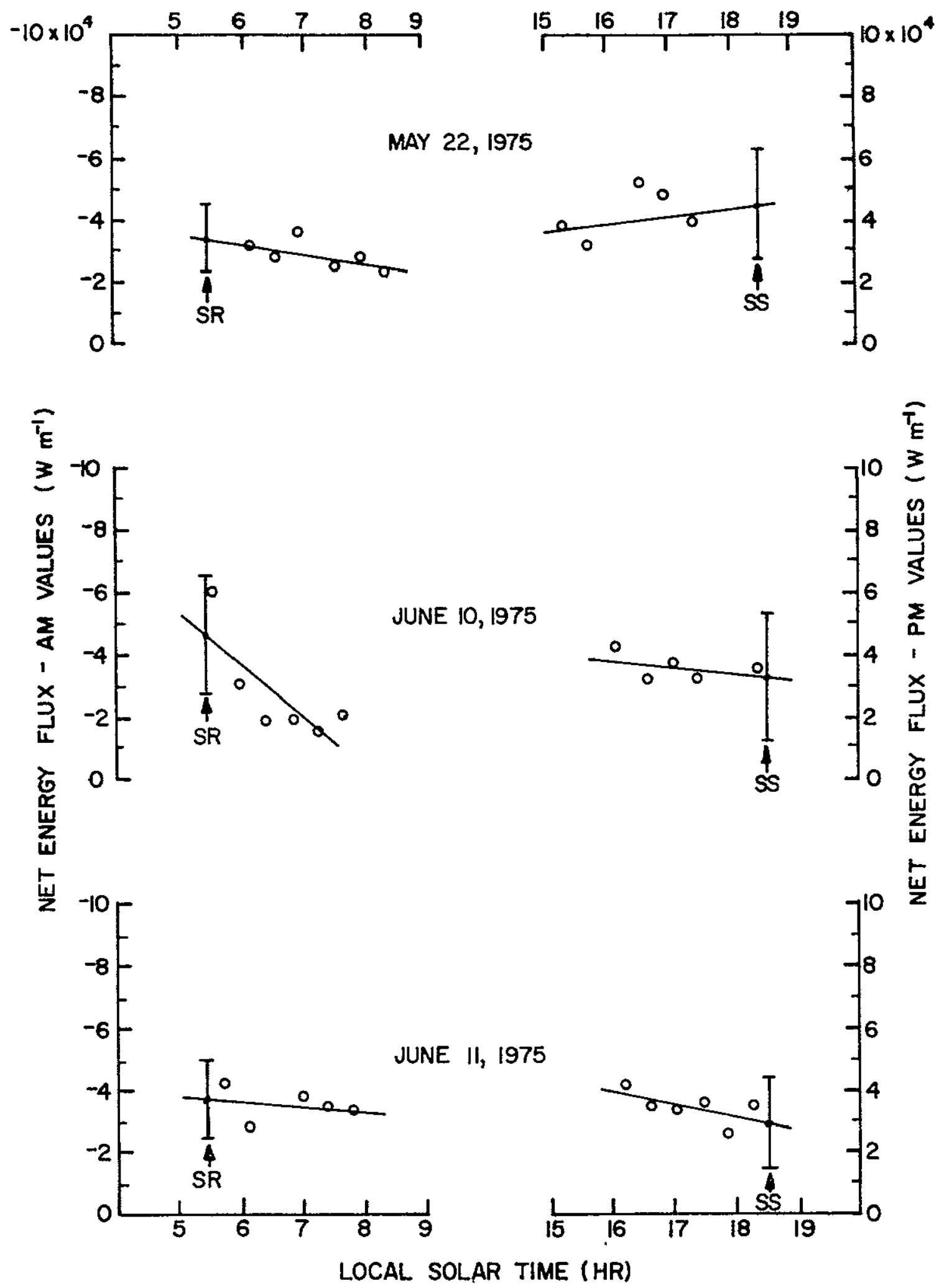

Figure 5 (Continued) 


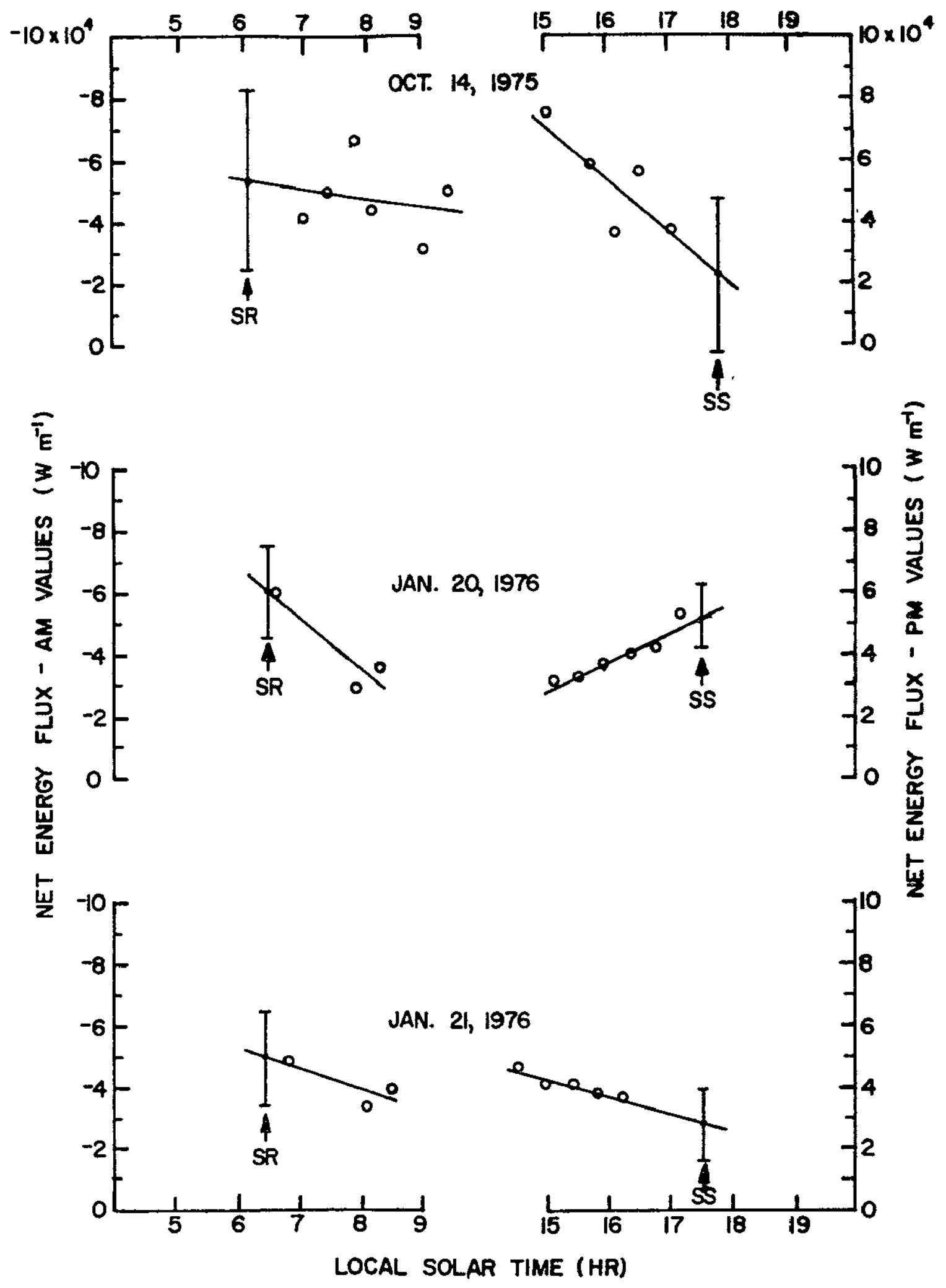

Figure 5 (Continued) 

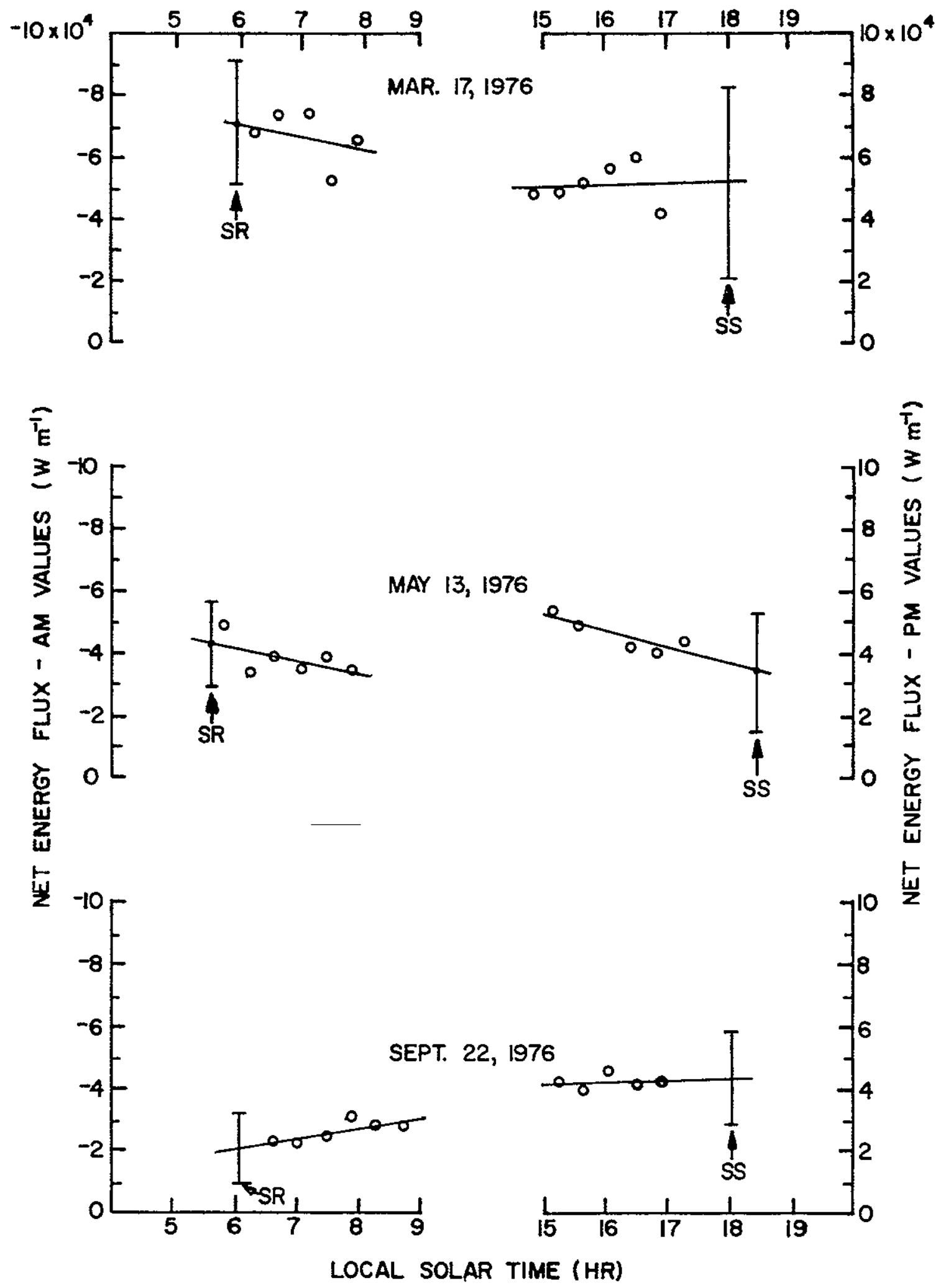

Figure 5 (Continued) 

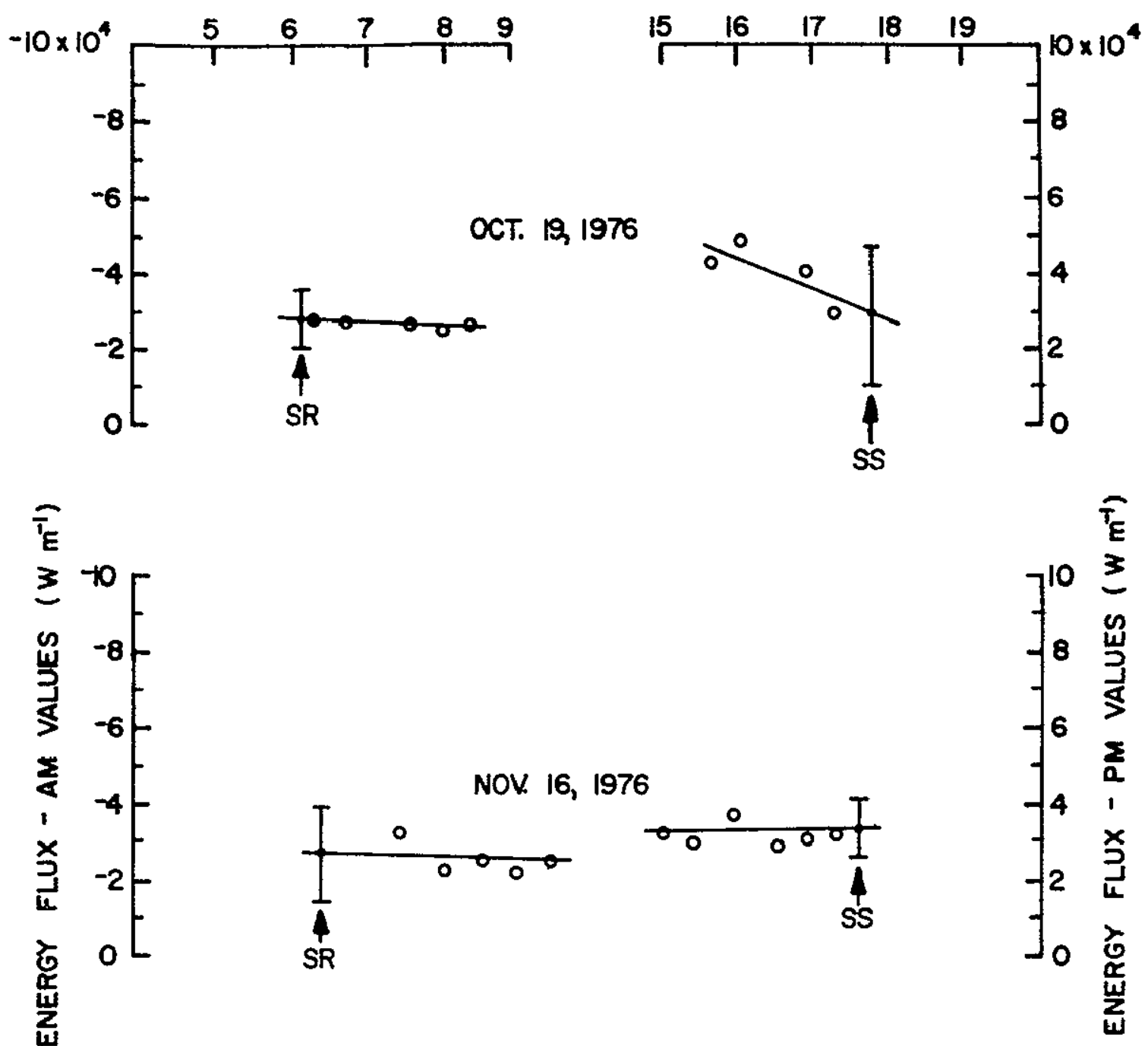

$\frac{1}{2}$

$-10$

-

NOV. 17,1976



Figure 5 (Continued) 
Table 2. Summary of Arecibo Results

\begin{tabular}{|c|c|c|c|c|c|c|}
\hline Date & L.S.T. & Season & $\begin{array}{l}\text { Net Flux Into } \\
\text { Nighttime } \\
\text { Thermosphere } \\
\left(\mathrm{W} \mathrm{m}^{-1}\right)\end{array}$ & $\begin{array}{l}\text { Daily Net Flux } \\
\Delta W+\Delta R\left(W \mathrm{~m}^{-1}\right)\end{array}$ & $\begin{array}{c}\text { Error } \\
\left(\mathrm{W} \mathrm{m}^{-1}\right)\end{array}$ & $\left|\frac{\Delta \mathrm{W}}{\Delta \mathrm{R}}\right|$ \\
\hline Aug. 12, 1974 & $\begin{array}{r}5.66 \\
18.34\end{array}$ & Summer & $\begin{array}{r}-1.1 \times 10^{4} \\
4.8 \times 10^{4}\end{array}$ & $3.7 \times 10^{4}$ & $5.8 \times 10^{4}$ & 0.22 \\
\hline Aug. 14, 1974 & $\begin{array}{r}5.67 \\
18.33\end{array}$ & Summer & $\begin{array}{r}-4.9 \times 10^{4} \\
5.1 \times 10^{4}\end{array}$ & $0.2 \times 10^{4}$ & $2.3 \times 10^{4}$ & 0.12 \\
\hline Sept. 17, 1974 & $\begin{array}{r}5.95 \\
18.05\end{array}$ & Fall & $\begin{array}{r}-5.0 \times 10^{4} \\
2.6 \times 10^{4}\end{array}$ & $-2.4 \times 10^{4}$ & $1.6 \times 10^{4}$ & 0.19 \\
\hline Sept. 18, 1974 & $\begin{array}{r}5.96 \\
18.04\end{array}$ & Fa11 & $\begin{array}{r}-4.3 \times 10^{4} \\
4.4 \times 10^{4}\end{array}$ & $0.1 \times 10^{4}$ & $2.2 \times 10^{4}$ & 0.92 \\
\hline April 15, 1975 & $\begin{array}{r}5.78 \\
18.22\end{array}$ & Spring & $\begin{array}{r}-6.9 \times 10^{4} \\
4.4 \times 10^{4}\end{array}$ & $-2.5 \times 10^{4}$ & $2.0 \times 10^{4}$ & 0.60 \\
\hline Apri1 16, 1975 & $\begin{array}{r}5.77 \\
18.23\end{array}$ & Spring & $\begin{array}{r}-5.4 \times 10^{4} \\
3.2 \times 10^{4}\end{array}$ & $-2.2 \times 10^{4}$ & $3.2 \times 10^{4}$ & 0.29 \\
\hline May 22, 1975 & $\begin{array}{r}5.53 \\
18.47\end{array}$ & Summer & $\begin{array}{r}-3.4 \times 10^{4} \\
4.5 \times 10^{4}\end{array}$ & $1.1 \times 10^{4}$ & $1.4 \times 10^{4}$ & 1.84 \\
\hline June 10, 1975 & $\begin{array}{r}5.46 \\
18.54\end{array}$ & Summer & $\begin{array}{r}-4.6 \times 10^{4} \\
3.2 \times 10^{4}\end{array}$ & $-1.4 \times 10^{4}$ & $2.0 \times 10^{4}$ & 0.23 \\
\hline June 11,1975 & $\begin{array}{r}5.46 \\
18.54\end{array}$ & Summer & $\begin{array}{r}-3.8 \times 10^{4} \\
2.9 \times 10^{4}\end{array}$ & $-0.9 \times 10^{4}$ & $1.5 \times 10^{4}$ & 0.50 \\
\hline Oct. 14,1975 & $\begin{array}{r}6.18 \\
17.82\end{array}$ & $\mathrm{Fa} 11$ & $\begin{array}{r}-5.4 \times 10^{4} \\
2.3 \times 10^{4}\end{array}$ & $-3.1 \times 10^{4}$ & $2.8 \times 10^{4}$ & 0.11 \\
\hline
\end{tabular}


Table 2. (Continued)

\begin{tabular}{|c|c|c|c|c|c|c|}
\hline Date & L.S.T. & Season & $\begin{array}{l}\text { Net Flux Into } \\
\text { Nighttime } \\
\text { Thermosphere } \\
\left(\mathrm{W} \mathrm{m}^{-1}\right)\end{array}$ & $\begin{array}{l}\text { Daily Net Flux } \\
\Delta \mathrm{W}+\Delta \mathrm{R}\left(\mathrm{W} \mathrm{m}^{-1}\right)\end{array}$ & $\begin{array}{c}\text { Error } \\
\left(\mathrm{W} \mathrm{m}^{-1}\right)\end{array}$ & $\left|\frac{\Delta W}{\Delta R}\right|$ \\
\hline Jan. 20, 1976 & $\begin{array}{r}6.47 \\
17.53\end{array}$ & Winter & $\begin{array}{r}-6.1 \times 10^{4} \\
5.3 \times 10^{4}\end{array}$ & $-0.8 \times 10^{4}$ & $1.3 \times 10^{4}$ & 0.23 \\
\hline Jan. 21, 1976 & $\begin{array}{r}6.46 \\
17.54\end{array}$ & Winter & $\begin{array}{r}-5.0 \times 10^{4} \\
2.9 \times 10^{4}\end{array}$ & $-2.1 \times 10^{4}$ & $1.4 \times 10^{4}$ & 0.13 \\
\hline Mar. 17, 1976 & $\begin{array}{r}6.02 \\
17.98\end{array}$ & Spring & $\begin{array}{r}-7.1 \times 10^{4} \\
5.2 \times 10^{4}\end{array}$ & $-1.9 \times 10^{4}$ & $2.6 \times 10^{4}$ & 0.29 \\
\hline May 13, 1976 & $\begin{array}{r}5.57 \\
18.43\end{array}$ & Summer & $\begin{array}{r}-4.4 \times 10^{4} \\
3.4 \times 10^{4}\end{array}$ & $-1.0 \times 10^{4}$ & $1.7 \times 10^{4}$ & 0.20 \\
\hline Sept. 22, 1976 & $\begin{array}{r}6.00 \\
18.00\end{array}$ & Fall & $\begin{array}{r}-2.2 \times 10^{4} \\
4.4 \times 10^{4}\end{array}$ & $2.2 \times 10^{4}$ & $1.3 \times 10^{4}$ & 0.19 \\
\hline Oct. 19,1976 & $\begin{array}{r}6.23 \\
17.77\end{array}$ & Fall & $\begin{array}{r}-2.8 \times 10^{4} \\
2.9 \times 10^{4}\end{array}$ & $0.1 \times 10^{4}$ & $1.4 \times 10^{4}$ & 6.00 \\
\hline Nov. 16,1976 & $\begin{array}{r}6.44 \\
17.56\end{array}$ & Winter & $\begin{array}{r}-3.2 \times 10^{4} \\
3.1 \times 10^{4}\end{array}$ & $-0.1 \times 10^{4}$ & $0.9 \times 10^{4}$ & 0.57 \\
\hline Nov. 17,1976 & $\begin{array}{r}6.44 \\
17.56\end{array}$ & Winter & $\begin{array}{r}-2.9 \times 10^{4} \\
2.2 \times 10^{4}\end{array}$ & $-0.7 \times 10^{4}$ & $1.2 \times 10^{4}$ & 0.16 \\
\hline
\end{tabular}


fall equinox, winter solstice and spring equinox respectively. These values suggest that the net day to night flux varies in a cyclic fashion over the course of a year and that at the latitude of Arecibo, energy tends to leave the nighttime regıon, particularly in the winter hemisphere. Because of the large uncertainties involved, however, the error in each of the above values is of the same order, or larger than, the value itself and any order which appears in the above seasonal fluxes must be viewed with caution. Using the standard deviation of the indrvidual determinations for each season and the average values quoted above, the day to night energy flux at the latitude of Arecibo has been found to lie between $-1.6 \times 10^{4}$ and $2.2 \times 10^{4} \mathrm{~W} \mathrm{~m}^{-1}$ for summer solstice, $-2.8 \times 10^{4}$ and $1.5 \times 10^{4} \mathrm{Wm}^{-1}$ for fall equinox, $-1.8 \times 10^{4}$ and $-0.1 \times 10^{4}$ for winter solstice and $-2.5 \times 10^{4}$ and $-1.9 \times 10^{4} \mathrm{~W} \mathrm{~m}^{-1}$ for spring equinox.

In order to examine the latitudinal dependence of the terminator energy fluxes, the wind results of Section 3.1 .1 have also been used in connection with incoherent scatter results at mid latitudes. Data on the height distribution of electron and ion temperatures and the electron density at altitudes above $95 \mathrm{~km}$, and the total collision frequency between 95 and $120 \mathrm{~km}$ are available from the St. Santin incoherent scatter facilıty $\left(44.6^{\circ} \mathrm{N}\right)$.

In the case of the St. Santin facility, each measurement does not furnish an entire height profile, but only data at a single. height with a repetition period of about 1.2 hours for the E-region. Further, on a given observing day, E-region measurements are made from about sunrise to close to sunset, followed by F-region measurements made during the next 26 to 30 hours. To obtain data 
at the terminator, the collision frequencies and temperatures for each height were plotted as a function of time and extrapolated visually to the time of sunrise and sunset. The total density at 120 $\mathrm{km}$ was calculated from these values and used, together with the $120 \mathrm{~km}$ temperature for the terminator flux calculations. Although the temperature profiles at the terminators were constructed from the F-region data from the following day, in no case was there a significant difference between the temperature parameters estim mated for two successive mornings or evenings.

Using this scheme, the St. Santin results were analyzed to obtain the temperature and density distribution at the morning and evening terminators during nine days in.1969, and 1970.. These selected days are characterized by low and medium levels of magnetic activity and minimum variation in $\mathrm{Kp}$ values between the morning and evening hours. Table A. 2 shows the boundary conditions obtained from the St. Santin analysis and Table 3 Ints the results obtained using the measured and corotating winds discussed previously and the listed boundary conditions. In contrast to the Arecibo findings, these results consistently indicate a net flux into the nighttime region. After grouping the results according to season, the energy flux into the nighttime thermosphere at St. Santin has been found to lie between $1.0 \times 10^{4}$ and $3.6 \times 10^{4} \mathrm{Wm}^{-1}$ for summer solstice, $1.0 \times 10^{4}$ and $3.8 \times 10^{4} \mathrm{~W} \mathrm{~m}^{-1}$ for fall equinox and $1.0 \times 10^{4}$ and $3.1 \times 10^{4} \mathrm{~W} \mathrm{~m}^{-1}$ for winter solstice.

It should be mentioned that in no case were measurements made at St. Santin before local sunrise or after local sunset. As a result, the derived temperatures and densities at the terminators 
Table 3. Summary of St. Santin Results

\begin{tabular}{|c|c|c|c|c|c|}
\hline Date & L.S.T. & Season & $\begin{array}{l}\text { Net Flux Into } \\
\text { Nighttime } \\
\text { Thermosphere } \\
\left(\mathrm{W} \mathrm{m}^{-1}\right)\end{array}$ & $\begin{array}{l}\text { Daily Net Flux } \\
\Delta \mathrm{W}+\Delta \mathrm{R}\left(\mathrm{W} \mathrm{m}^{-1}\right)\end{array}$ & $\left|\frac{\Delta \mathrm{W}}{\Delta \mathrm{R}}\right|$ \\
\hline Aug. 26, 1969 & $\begin{array}{r}5.30 \\
18.70\end{array}$ & $\begin{array}{l}\text { Fa11 \& } \\
\text { Summer }\end{array}$ & $\begin{array}{r}-2.7 \times 10^{4} \\
6.5 \times 10^{4}\end{array}$ & $3.8 \times 10^{4}$ & 0.16 \\
\hline Oct. 7, 1969 & $\begin{array}{r}6.36 \\
17.64\end{array}$ & Fall & $\begin{array}{r}-4.7 \times 10^{4} \\
5.8 \times 10^{4}\end{array}$ & $1.1 \times 10^{4}$ & 3.00 \\
\hline Nov. 25,1969 & $\begin{array}{r}7.46 \\
16.54\end{array}$ & Winter & $\begin{array}{r}-4.4 \times 10^{4} \\
5.3 \times 10^{4}\end{array}$ & $0.9 \times 10^{4}$ & 1.40 \\
\hline Dec, 23, 1969 & $\begin{array}{r}7.69 \\
16.31\end{array}$ & Winter & $\begin{array}{r}-3.7 \times 10^{4} \\
6.6 \times 10^{4}\end{array}$ & $2.9 \times 10^{4}$ & 0.28 \\
\hline Feb. 5, 1970 & $\begin{array}{r}7.09 \\
16.91\end{array}$ & Winter & $\begin{array}{r}-2.1 \times 10_{4}^{4} \\
4.4 \times 10^{4}\end{array}$ & $2.3 \times 10^{4}$ & 0.23 \\
\hline Mar. 17,1970 & $\begin{array}{r}6.09 \\
17.91\end{array}$ & Spring & $\begin{array}{l}-4.5 \times 10^{4} \\
11.7 \times 10^{4}\end{array}$ & $7.2 \times 10^{4}$ & 0.13 \\
\hline April 28, 1970 & $\begin{array}{r}5.04 \\
18.96\end{array}$ & Summer & $\begin{array}{r}-4.7 \times 10^{4} \\
6.0 \times 10^{4}\end{array}$ & $1.3 \times 10^{4}$ & 1.60 \\
\hline June 9, 1970 & $\begin{array}{r}4.36 \\
19.64\end{array}$ & Summer & $\begin{array}{r}-4.8 \times 10^{4} \\
6.7 \times 10^{4}\end{array}$ & $1.9 \times 10^{4}$ & 1.00 \\
\hline Sept. 1, 1970 & $\begin{array}{r}5.45 \\
18.55\end{array}$ & Fal1 & $\begin{array}{r}-4.2 \times 10^{4} \\
6.5 \times 10^{4}\end{array}$ & $2.3 \times 10^{4}$ & 0.53 \\
\hline
\end{tabular}


were in each case obtained by extrapolation. This undesirable feature, combined with the coarse height and local time resolution of the St. Santin facility, combine to make the St. Santin results somewhat uncertain, as are those obtained from the Arecibo measurements.

Since the boundary values are important in controlling both the magnitude and direction of the terminator fluxes, it is worthwhile to examine whether the reversal in direction of the net flux that occurs between the Arecibo and St. Santin results can be anticipated by comparison of the boundary densities and temperature parameters in Tables A.I and $A_{.} 2_{0}$. An examination of the tables reveals a positive correlation between the $120 \mathrm{~km}$ densities, when corrected for variations in the temperature parameters, and the corresponding computed terminator fluxes. Also, while the computed exospheric temperatures in Table A.1 are consistently higher near sunset than close to sunrise, the reverse is true for the $120 \mathrm{~km}$ temperature and it is these latter values, along with the boundary densities, that largely determine the magnitude of the height integrated energy fluxes. These same trends in both the exospheric and $120 \mathrm{~km}$ temperatures at Arecibo have been observed by Swartz and Nisbet (1971) using data from one summer day (June 26) and two winter days (Jan. 13, 14) in 1968. A gradual decline in the $120 \mathrm{~km}$ temperature from the morning to the evening hours is readily apparent from the summer data and is suggested by the winter results also, although not as conclusively. Fontanari (1973) has performed a harmonic analysis of data from St. Santin obtained during equinox and solstice periods for 
the years 1969 and 1970. His results show the height variation of the mean temperature for each season along with the amplitude and phase of the diurnal temperature variations and reveal enhanced temperatures at the evening terminator during summer solstice and at both equinoxes. These findings tend to confirm the $120 \mathrm{~km}$ temperatures summarized in Table A. 2 and together with the results of Swartz and Nisbet (1971), point up the latitudinal dependence of the lower boundary temperature at the terminators.

In arriving at global flux estimates under equinoctial cond1tions, the geometry of the problem allows the use of symmetry in the latitudinal dependence of the energy flux between the northern and southern hemispheres. Using the equinox flux values appropriate for the latitudes of Arecibo and St. Santin, this assumption provides four points which represent the variation of the energy flux with latitude. A similar scheme is employed using the solstice results by using the values appropriate for the latitudes of St. Santin and Arecibo in the northern hemisphere and applying these results to the conjugate hemisphere six months later.

Using this approach and the maximum and minimum values quoted previously, the energy flow $Q_{L}$ into the nighttime thermosphere via the low and mid latitude thermospheric winds was found to lie between $-3.9 \times 10^{10} \mathrm{~W}$ and $11.2 \times 10^{10} \mathrm{~W}$ at equinox and between $-1.5 \times 10^{10} \mathrm{~W}$ and $9.4 \times 10^{10} \mathrm{~W}$ at solstice.

\subsection{The Polar Thermospheric Wind System}

The complexity of the polar thermospheric wind system has been deduced from observations and has been considered in detail 
by a number of authors (Fedder and Banks, 1972; Meriwether et al., 1973; Nagy et al., 1974; Brekke and Doupnik, 1973; Maeda, 1976). The actual wind system is thought to be a superposition of the solar tidal winds and the winds due to the motion of the ions which are, in turn, influenced by a general dawn to dusk electric field. The resultant pattern of the horizontal wind field changes with height, since it depends on the degree of coupling between the ion and neutral motions. This interaction between the ions and neutrals allows a transfer of the electric field energy (of magnetospheric origin) to the neutral atmosphere with a resulting temperature enhancement and an overall outflow of gas from the polar region at heights above $120 \mathrm{~km}$ (Brekke et al., 1973; Nisbet and Glenar, 1977).

\subsubsection{Method}

The polar region is treated here as an independent energy source which supplies a flow of the neutral gas at elevated temperatures to the low and mid latitude nighttime thermosphere via the south component of the horizontal polar wind system. The global energy flux transported by the neutral wind from the high latitude regions into the mid latitude thermosphere can be obtained using equations (2.13) and (2.14) where in this case the integral is over the surface separating the polar caps and the nighttime thermosphere, as shown in Figure 2.

Letting $\mathrm{dt}$ be an increment in local time, and assuming symmetry in the wind system between the north and south polar regions, we may write the energy. input to the nighttime sector as 


$$
Q_{P}=(2)(\pi / 12) \int_{18}^{6} \epsilon_{M}(\theta, t) R_{0} \sin \theta d t-\left[\left(\frac{N}{2}+1\right) \frac{k T}{-\frac{k}{m}}\right]_{120} \Phi_{P}
$$

where $\epsilon_{M}(\theta, t)=\sum_{i} \int_{120}^{\infty}\left[\left(\frac{N_{i}}{2}+1\right) n_{i} k T+n_{i} m_{i} g(h-120)\right] v_{M} d h$

In the above relations $v_{M}$ is the mexidional component of the horizontal neutral wind directed into the nighttime region. In addition, the variation of $R$ with height $h$ is neglected and $R_{0}$ is taken to be the radius at the lower boundary $(6490 \mathrm{~km})$. The first term in equation (3.9) represents the outflow from the polar. regions between 18 and 6 hours local time. The second term represents the energy leaving the system at the lower $(120 \mathrm{~km})$ boundary. Here, $\Phi_{\mathrm{P}}$ is the magnitude of the mass flow leaving the nighttime system and by the mass continuity equation (2.16), the defining equation for this quantity can be expressed as

$$
\frac{1}{2} \Phi_{P}=\frac{\pi}{12} \int_{18}^{6} \beta_{-M}(\theta, t) R_{0} \sin \theta d t
$$

where $\beta_{M}(\theta, t)=\sum_{i} \int_{120}^{\infty}\left(n_{i} m_{i} v_{M}\right) d h$

The expressions $\epsilon_{M}(\theta, t)$ and $\beta_{M}(\theta, t)$ represent the meridional component of the energy and mass flow entering the system at geomagnetic colatitude $\pm \theta$, and local time t. Similar expressions may be obtained for the zonal components using the corresponding 
zonal component of the horizontal wind.

An estimate of these quaritities, then, requires both the direction and magnitude of the neutral wind velocity vector as a function of height above $120 \mathrm{~km}$ and this has been established using the results of 26 high latitude vapor trail measurements. For the purposes of this paper, the pattern of outflow is examined using geomagnetic latitude and geomagnetic time as the coordinate variables. Table 4 shows the geomagnetic latitudes of each of the flights, ranging from about $59^{\circ} \mathrm{N}$ to $74^{\circ} \mathrm{N}$ with a mean latitude of about $67^{\circ} \mathrm{N}$. Since all of the information is contained in this latitude region, the boundary defining the emitting region has been taken to lie at $70^{\circ} \mathrm{N}$ latitude $\left(\theta=20^{\circ}\right)$.

\subsubsection{Boundary Conditions}

The results of each flight provide information on the height distribution of the horizontal neutral wind at a fixed local time and fixed geomagnetic north latitude near $70^{\circ}$. Using suitably chosen boundary conditions, then, it is possible to estimate the meridional

components of the energy flow $\epsilon_{M}(\theta, t)$ and mass flow $\beta_{M}(\theta, t)$ for each of the flights using equations (3.7) and (3.9).

Rees (1971) has analysed fluorescent emissions from aluminum oxide (A1O) and barium oxide ( $\mathrm{BaO}$ ) during a number of twilight rocket launches at high latitudes. The results indicate that a correlation exists between the morning and evening twilight temperatures at 140 and $165 \mathrm{~km}$, and the $C 9$ daily magnetic character. This relation is linear in the magnetic index and is expressed quantitatively by Rees as 
Table 4. High Latitude Vapor Trail Measurements

\begin{tabular}{|c|c|c|c|c|c|c|c|c|c|c|c|}
\hline \multirow[b]{2}{*}{ No. } & \multicolumn{2}{|c|}{ Location } & \multirow{2}{*}{$\begin{array}{c}\text { Time } \\
\text { UT }\end{array}$} & \multicolumn{2}{|c|}{ Date } & \multicolumn{2}{|c|}{ Geomagnetic } & \multirow{2}{*}{$\mathrm{K}_{\mathrm{p}}^{\top}$} & \multirow{2}{*}{$\mathrm{F}_{10.7}$} & \multirow{2}{*}{$\begin{array}{l}\text { Altitude } \\
\text { Range }(\mathrm{km})\end{array}$} & \multirow[b]{2}{*}{ Ref. } \\
\hline & N.Lat. & E.Long. & & Day & Year & GLT. & G. Lat. & & & & \\
\hline 1 & 65.1 & 212.5 & $16.7 \mathrm{hr}$ & 288 & 72 & 4.6 & 71.2 & 3.0 & 95 & $110-160$ & $\mathrm{~A}$ \\
\hline 2 & 65.1 & 212.5 & $15.2 \mathrm{hr}$ & 288 & 72 & 3.1 & 71.2 & 3.0 & 95 & $100-180$ & $\mathrm{~A}$ \\
\hline 3 & 65.1 & 212.5 & $22.1 \mathrm{hr}$ & 23 & 76 & 9.6 & 71.2 & 3.4 & 72 & $105-125$ & B \\
\hline 4 & 65.1 & 212.5 & $9.6 \mathrm{hr}$ & 86 & 73 & 21.6 & 71.2 & 0.2 & 74 & $95-160$ & $\mathrm{C}$ \\
\hline 5 & 65.1 & 212.5 & $7.7 \mathrm{hr}$ & 50 & 74 & 20.0 & 71.2 & .5 & 85 & $95-132$ & $\mathrm{C}$ \\
\hline 6 & 58.8 & 265.7 & $3.5 \mathrm{hr}$ & 142 & 63 & 21.8 & 73.4 & .7 & 91 & $80-175$ & $\mathrm{D}$ \\
\hline 7 & 58.8 & 265.7 & $4.1 \mathrm{hr}$ & 143 & 63 & 22.4 & 73.4 & 1.2 & 89 & $80-160$ & $\mathrm{D}$ \\
\hline 8 & 58.8 & 265.7 & $8.3 \mathrm{hr}$ & 143 & 63 & 2.2 & 73.4 & .6 & 89 & $85-160$ & $\mathrm{D}$ \\
\hline 9 & 58.8 & 265.7 & $6.0 \mathrm{hr}$ & 306 & 64 & 0.4 & 73.4 & 1.2 & 75 & $95-130$ & D \\
\hline 10 & 58.8 & 265.7 & $0.0 \mathrm{hr}$ & 58 & 65 & 18.0 & 73.4 & 1.8 & 74 & $90-160$ & $\mathrm{D}$ \\
\hline 11 & 67.8 & 20.4 & $7.7 \mathrm{hr}$ & 32 & 68 & 10.9 & 58.5 & 1.6 & 262 & $90-160$ & $\mathrm{E}$ \\
\hline 12 & 67.8 & 20.4 & $7.6 \mathrm{hr}$ & 35 & 68 & 10.8 & 58.5 & 3.8 & 227 & $90-165$ & $\mathrm{E}$ \\
\hline 13 & 67.8 & 20.4 & $18.5 \mathrm{hr}$ & 289 & 68 & 21.3 & 58.5 & 1.3 & 138 & $90-155$ & $\mathrm{E}$ \\
\hline 14 & 67.8 & 20.4 & $6.7 \mathrm{hr}$ & 306 & 68 & 9.8 & 58.5 & 4.3 & 156 & $90-170$ & $\mathrm{E}$ \\
\hline 15 & 80.6 & 58.0 & $13.6 \mathrm{hr}$ & 57 & 70 & 18.3 & 65.9 & 2.6 & 182 & $100-160$ & $\mathbf{F}$ \\
\hline 16 & 80.6 & 58.0 & $16.9 \mathrm{hr}$ & 76 & 71 & 21.7 & 65.9 & 2.2 & 117 & $100-160$ & $\mathrm{~F}$ \\
\hline 17 & 80.6 & 58.0 & $17.2 \mathrm{hr}$ & 77 & 71 & 22.0 & 65.9 & 1.1 & 115 & $100-160$ & $\mathbf{F}$ \\
\hline 18 & 80.6 & 58.0 & $10.2 \mathrm{hr}$ & 307 & $=71$ & 15.2 & 65.9 & .8 & 117 & $100-160$ & $F$ \\
\hline 19 & 80.6 & 58.0 & $9.3 \mathrm{hr}$ & 311 & 71 & 14.4 & 65.9 & 2.2 & 107 & $100-160$ & $F$ \\
\hline 20 & 80.6 & $58.0^{\circ}$ & $12.9 \mathrm{hr}$ & 52 & 72 & 17.7 & 65.9 & 2.4 & 194 & $100-160$ & $F$ \\
\hline 21 & 80.6 & 58.0 & $16.9 \mathrm{hr}$ & 76 & 72 & 21.7 & 65.9 & 2.7 & 135 & $100-160$ & $\mathrm{~F}$ \\
\hline 22 & 80.6 & 58.0 & $21.8 \mathrm{hr}$ & 79 & 72 & 2.4 & 65.9 & 1.2 & 136 & $100-155$ & $\mathbf{F}$ \\
\hline 23 & 80.6 & 58.0 & $12.3 \mathrm{hr}$ & 46 & 74 & 17.1 & 65.9 & 1.1 & 86 & $100-140$ & $\mathbf{F}$ \\
\hline 24 & 80.6 & 58.0 & $17.5 \mathrm{hr}$ & 78 & 74 & 22.3 & 65.9 & .2 & 81 & $100-140$ & $\mathbf{F}$ \\
\hline 25 & 80.6 & 58.0 & $16.3 \mathrm{hr}$ & 72 & 71 & 21.0 & 65.9 & 4.9 & 114 & $110-160$ & $\mathrm{~F}^{*}$ \\
\hline 26 & 80.6 & 58.0 & $22.9 \mathrm{hr}$ & 72 & 71 & 3.5 & 65.9 & 5.0 & 114 & $115-160$ & $\mathrm{~F} *$ \\
\hline
\end{tabular}

References: A. Bedinger (1973), B. Nielsen (1976), C. Bedinger (1975), D. Bedinger (1966), E. Rees (1971), F. Andreeva et al. (1975).

$t \mathrm{~K}_{\mathrm{p}}$ values represent average of $12 \mathrm{hrs}$. preceding flight.

*Data obtained from six spherical clouds. 


$$
\begin{aligned}
& T(140 \mathrm{~km})=420+25 \cdot \mathrm{C} 9 \mathrm{~K} \\
& \mathrm{~T}(165 \mathrm{~km})=450+50 \cdot \mathrm{C} 9 \mathrm{~K}
\end{aligned}
$$

for morning twilight and

$$
\begin{aligned}
& T(140 \mathrm{~km})=500+25 \cdot \mathrm{C} 9 \mathrm{~K} \\
& T(165 \mathrm{~km})=550+50 \cdot \mathrm{C} 9 \mathrm{~K}
\end{aligned}
$$

for evening twilight.

In the absence of any additional experimental information, it is assumed here that the temperature change between the evening and morning sectors at these altitudes varies linearly with local time in the nighttime hemisphere. This assumption allows the temperatures at 140 and $165 \mathrm{~km}$ to be estimated at each of the launch times for the rocket firings previously discussed. For purposes of this study, then, the adopted temperatures between 18 and 6 hours become

$$
\begin{aligned}
& T_{140}=540-6.67 \bmod (t+12,24)+25 \cdot \mathrm{C9} \quad \mathrm{K} \\
& T_{165}=600-8.33 \bmod (t+12,24)+50 \cdot \mathrm{C9} \quad \mathrm{K}
\end{aligned}
$$

where $t$ is the geomagnetic local time in hours. 
$120 \mathrm{~km}$ atomic oxygen and molecular nitrogen densities and the exospheric temperatures at the times and locations of each of the rocket flights listed in Table 3 . The OGO-6 satellite quadrupole mass spectrometer has been used to measure $\mathrm{O}$ and $\mathrm{N}_{2}$ densities in the height range from 400 to $600 \mathrm{~km}$ (Hedin et al., 1974). In addition, neutral temperatures in the altitude range from 200 to 320 $\mathrm{km}$ have been obtained using $630 \mathrm{~nm}$ oxygen emission line results from the Fabry-Perot interferometer on board the OGO-6 (Blamont and Luton, 1972). The neutral temperatures at these altitudes are within $100 \mathrm{~K}$ of the exospheric temperature and a good approximation of $T_{\infty}$ is obtained by using the method of Nisbet et al. (1973).

The vertical temperature distribution above $120 \mathrm{~km}$ can then be found using this value for $T_{\infty}$ and the temperatures at 140 and $165 \mathrm{~km}$ obtained from equations (3.17) and (3.18). Using these. values, equation (3.4) can be solved to obtain

$$
s=\frac{1}{25} \ln \left[\frac{T_{\infty}-T_{140}}{T_{\infty}-T_{165}}\right]
$$

and

$$
T_{120}=T_{\infty}-\left(T_{\infty}-T_{140}\right)\left[\frac{T_{\infty}-T_{140}}{T_{\infty}-T_{165}}\right]^{4 / 5}
$$

The results of the OGO-6 density and temperature measurements have been grouped according to latitude, season, geomagnetic local time and $\mathrm{Kp}$ range. Measurements made between $65^{\circ}$ and $75^{\circ}$ latitude and near spring and fall equinox are particularly useful, since the polar boundary is fixed at $70^{\circ} \mathrm{N}$ latitude and since 
the symmetry of the problem during equinox allows the use of data from both hemispheres. The local time variation of the densities and temperatures is examined by collecting and averaging all data obtained in increments of 1 hour. The time variation can then be represented by a series of 24 values, from 0 to 24 hours geomagnetic local time.

In using these results to estimate the atomic oxygen densities at $120 \mathrm{~km}$, the diffusive equilibrium assumption is first made and the effects of departures from diffusive equilibrium are then taken into account. Nisbet and Glenar (1977) have shown that the atomic oxygen densities at $120 \mathrm{~km}$ and near $70^{\circ} \mathrm{N}$ geomagnetic latitude can be related to the diffusive equilibrium values by

$$
\left.\log _{10} n(O)\right)_{120}=\log _{10} n(O)_{120}^{*}+0.96 \bar{v}_{z}(O)_{120}
$$

where $\mathrm{n}(\mathrm{O})_{120}$ is the estimate of the $120 \mathrm{~km}$ atomic oxygen density taking into account the effects of diffusion $\mathrm{n}(\mathrm{O})_{120}^{*}$ is the diffusive equilibrium value $\bar{v}_{z}(O)_{120}$ is the average upward vertical velocity of atomic oxygen at $120 \mathrm{~km}$, in $\mathrm{msec}^{-1}$

Using horizontal winds obtained from the vapor trail measurements listed in Table 4, Nisbet and Glenar, have derived a value for $\bar{v}_{z}(O)_{120}$ of $0.76 \mathrm{~m} \mathrm{sec}^{-1}$, appropriate for geomagnetic latitudes close to 70 degrees. Inserting this value in equation (3.18) the required correction for the atomic oxygen densities at geomagnetic latitudes near 70 degrees becomes 


$$
\mathrm{n}(\mathrm{O})_{120}=5.4 \mathrm{n}(\mathrm{O})_{120}^{*}
$$

Figure 6 shows the boundary conditions calculated in the above manner using the temperature results of Rees (1971) and the OGO- 6 temperature and density data. Since the rocket firings occur under a variety of geomagnetic activity levels, boundary ,parameters have been determined for three ranges of $\mathrm{Kp}: 0.0-1.2$, 1.3-4.0 and 4.1-9.0. In each case one sees an enhancement of both the temperatures and the atomic oxygen densities near the evening terminator and a corresponding depression near the morning terminator.

\subsubsection{Results of the High Latitude Analysis}

Analyses of the motion of rocket vapor trails released at high latitudes show the height variation of wind velocity and direction at the location of each firing. Using these results, and values of the boundary temperature and density profiles appropriate to each flight, equations $(3.6)$ and $(3.8)$ have been used to estimate the height integrated horizontal energy and mass flux above $120 \mathrm{~km}$ in each case and the resulting net energy exchange from the high latitude region to the nighttime thermosphere.'The results from three of the twenty six flights listed in Table 4 have not been used in evaluating these fluxes. Wind velocity data for flight number 3 was only obtained to an altitude of $125 \mathrm{~km}$. Also, the results of measurements 25 and 26 were obtained from observations of spherical clouds during magnetically disturbed periods with a Kp index at flight time of approximately 5. The choice was made to 


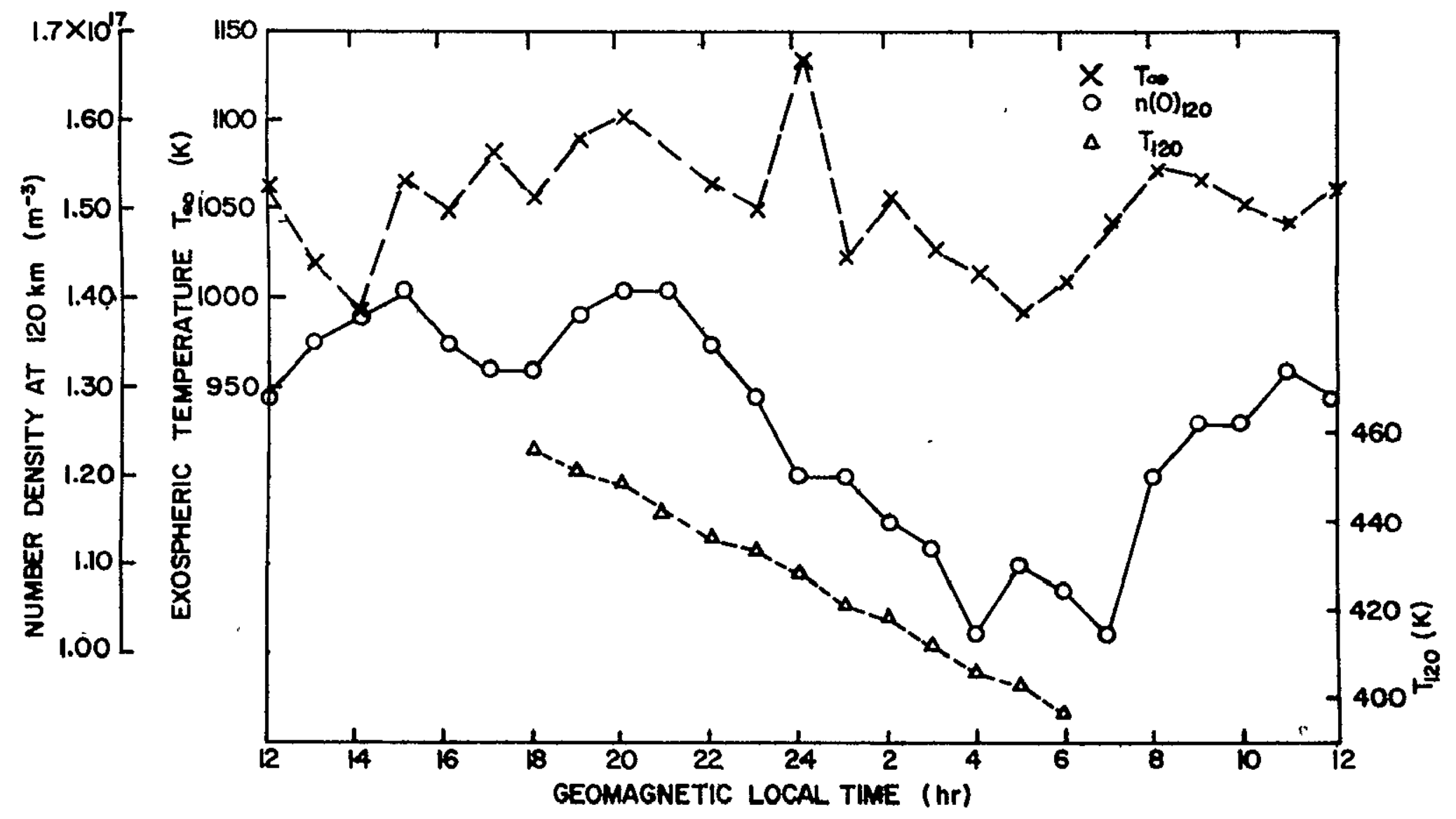

Figure 6a Varlation with local time of boundary parameters during spring and fall equinox for $\mathrm{Kp} 0.0-1.2$. Data is representative of $70^{\circ} \mathrm{N}$ and $70^{\circ} \mathrm{S}$ geomagnetic latitudes. 


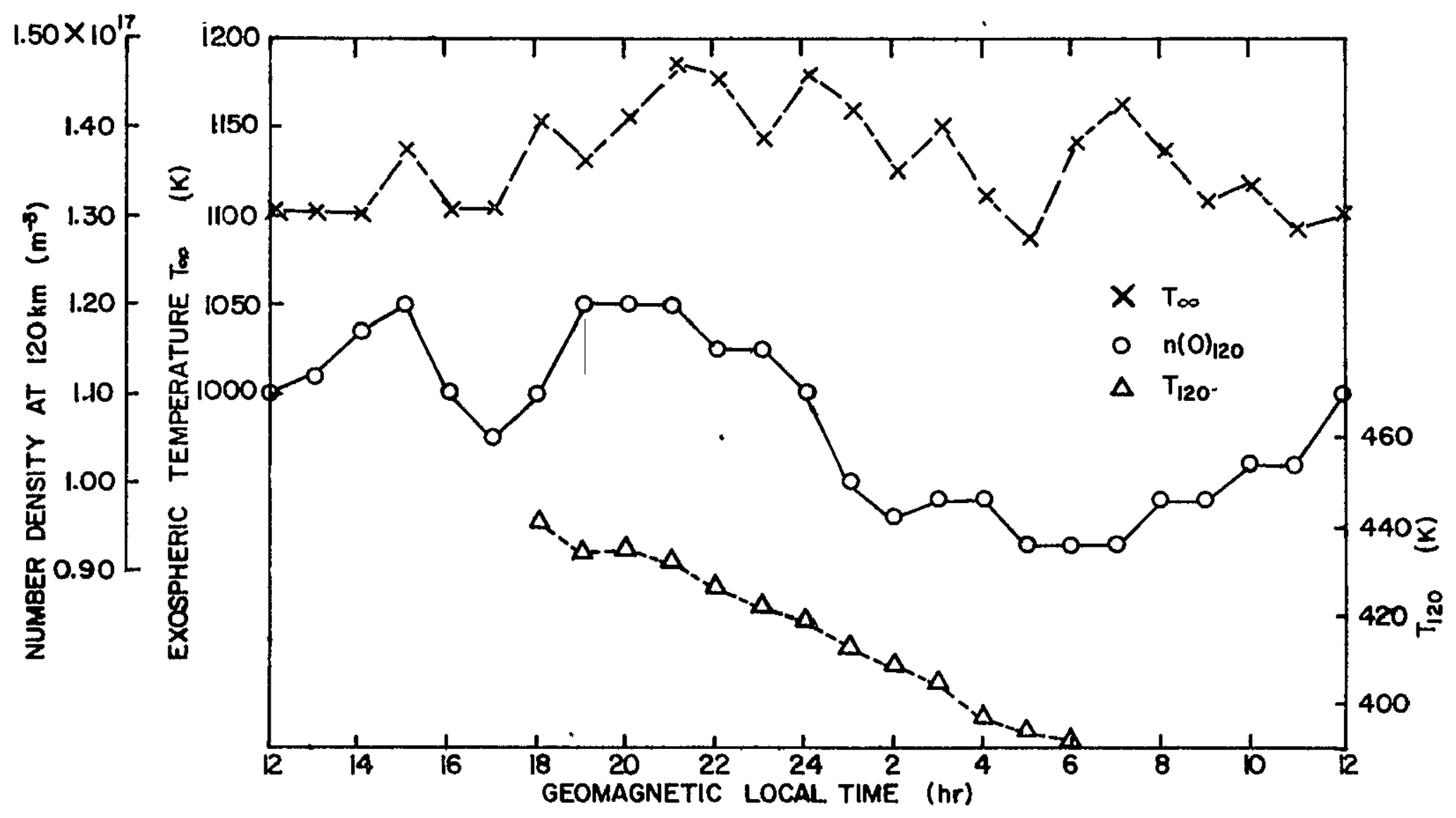




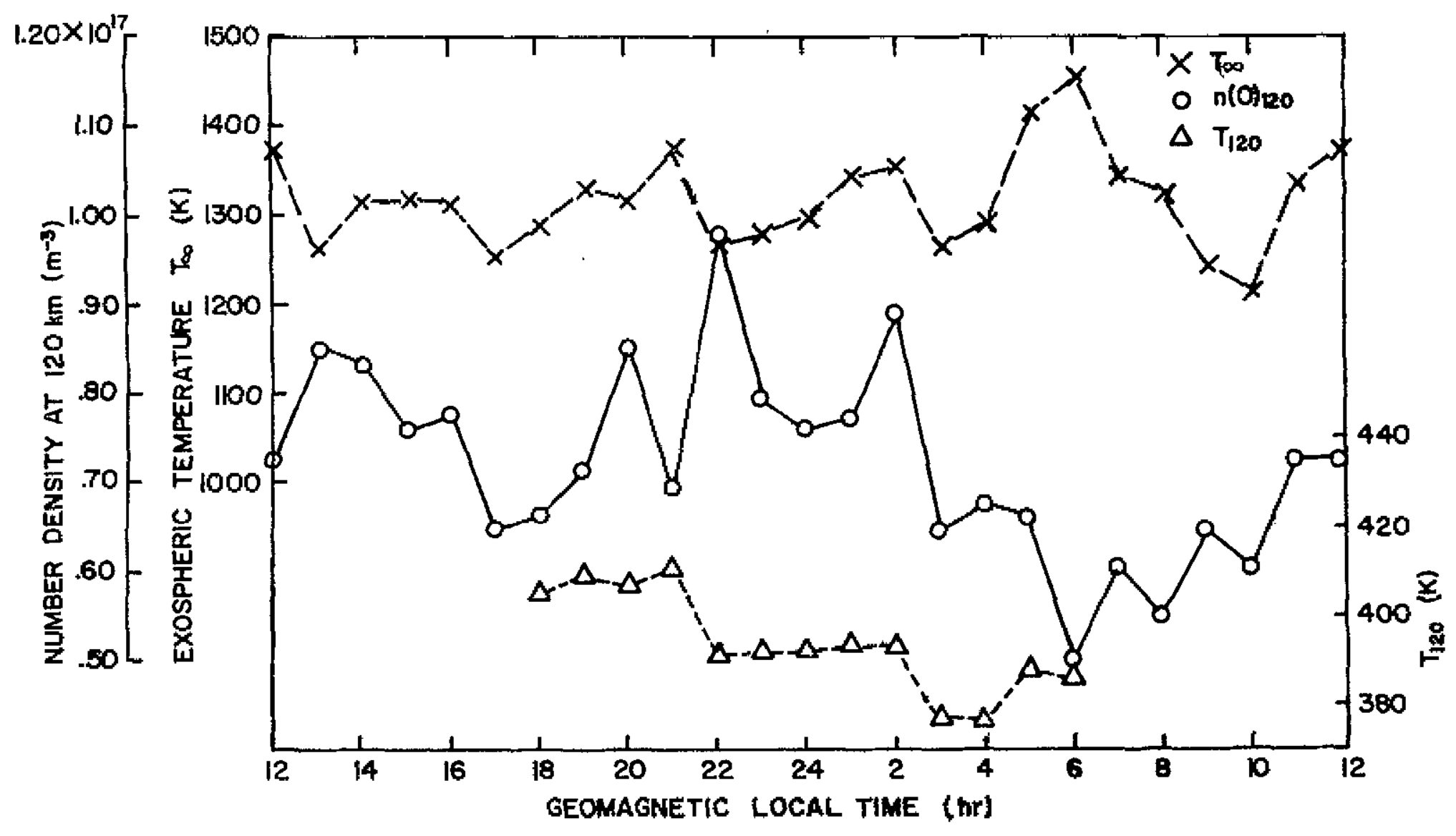

Fignure 6c Varlation with local time of boundary parameters during spring find Kp $4.1-9.0$. Data is representative of $70^{\circ} \mathrm{N}$ and $70^{\circ} \mathrm{s}$ geomagnetic latitudes. 
restrict our analysis to data representative of only relatively quiet magnetic conditions $(\mathrm{Kp}<4.0)$, The results of these measurements, then, were also excluded.

Figures 7 and 8 show the height integrated energy and mass fluxes above $120 \mathrm{~km}$ as determined for each of the 23 high latitude rocket flights. As is expected, the flow patterns in both cases are similar, while slight differences in the relative lengths of the arrows between the figures are the result of weighting effects from the different height distributions of the parameters involved. Most of the flights observed here were in or near the statistically determined auroral belt (Heppner, 1972). Accordingly, many of the features seen in Figures 7 and 8 have been observed previously using results from a number of high latitude barium cloud releases (Meriwether et al., 1973) and simultaneous $630 \mathrm{~nm}$ airglow and incoherent scatter observations (Nagy et al., 1974). Figures 7 and 8 show;

(i) Large, southerly directed flows in the predawn sector..

(ii) Reversal of the zonal component near 2300 hours geomagnetic local time. A shift occurs here from a westward zonal component in the premidnight sector to a generally eastward drift in the morning sector.

(iii) An anomalous west to east drift for the flights in the prenoon sector, where the effects of the diurnal solar tide would be expected to have the greatest influence and so give rise to an east to west drift component away from the afternoon diurnal bulge. The three flights used to provide flux estimates in the prenoon sector have been 

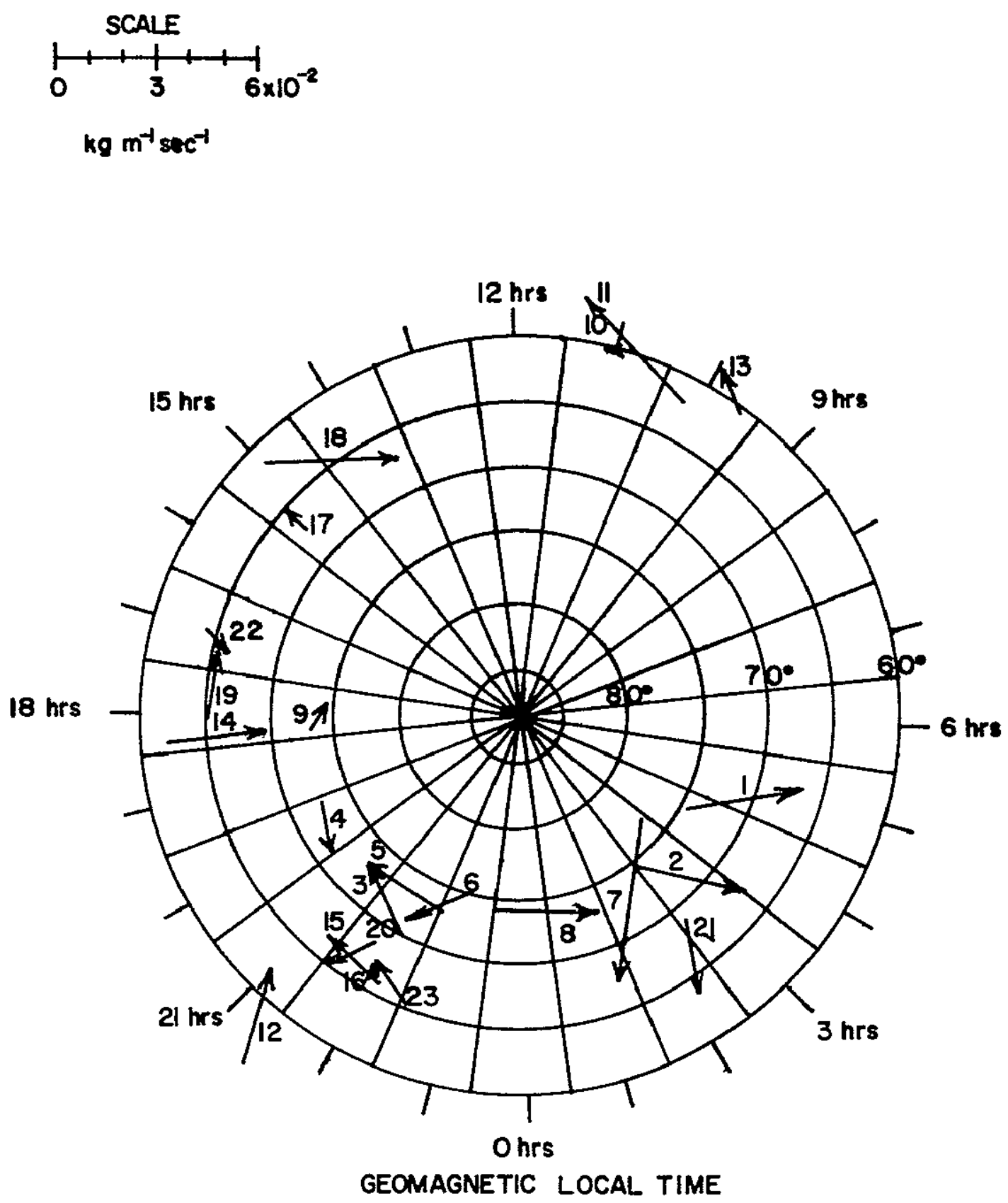

Figure 7 Total mass flow above $120 \mathrm{~km}$ derived from 23 high latitude vapor trail measurements. The center of each arrow corresponds to the location of each measurement. 

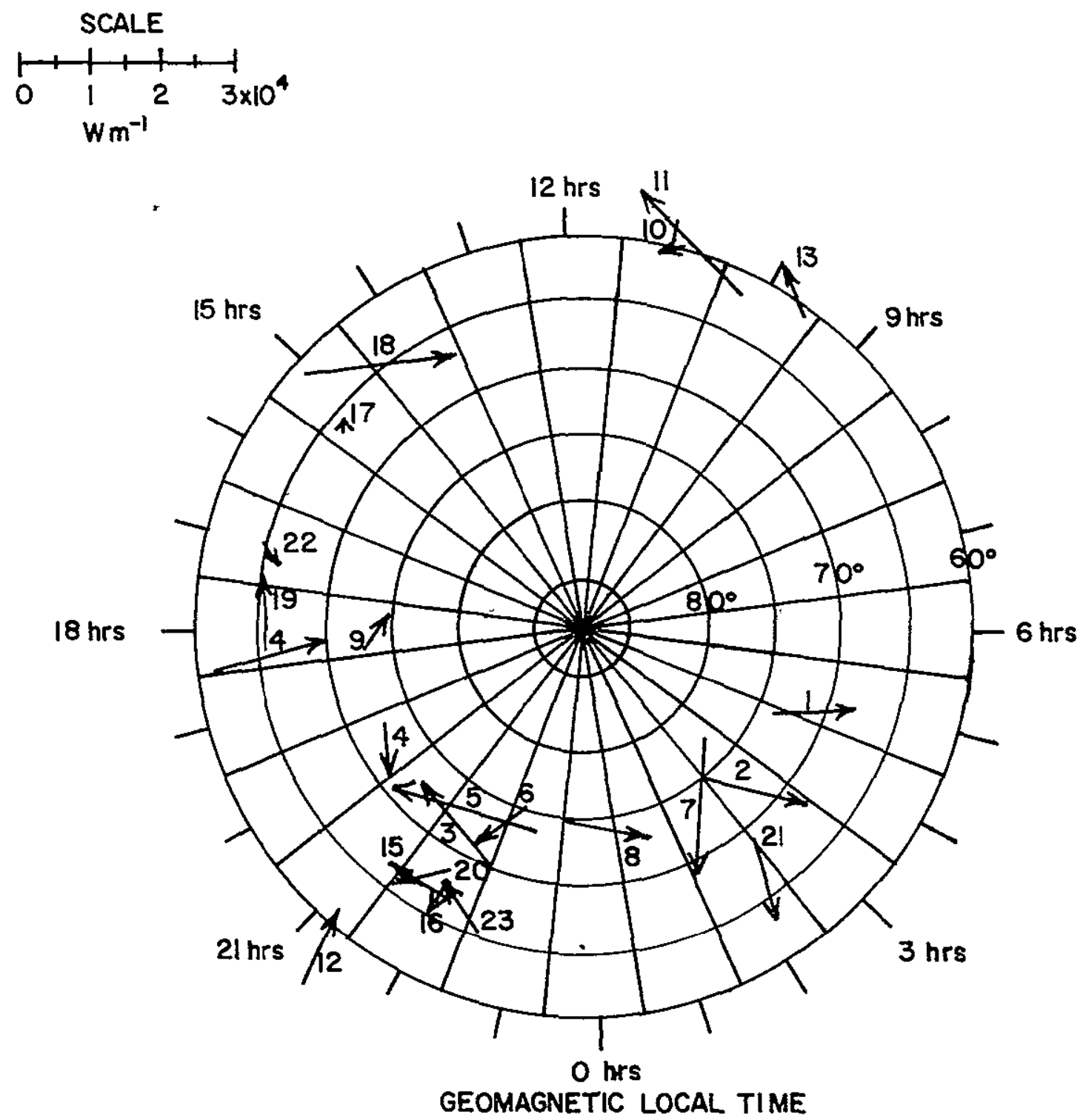

Figure 8 Energy flow above $120 \mathrm{~km}$ derived from $23 \mathrm{high}$ latitude vapor trail measurements. The center of each arrow corresponds to the location of each measurement. 
taken from Rees (1971), who has found a correspondence between the west to east neutral winds and south directed ground magnetic fields, which are present during each of the prenoon rocket flights employed here. No relationship of any kind has been found relating the ground magnetometer data and the north-south neutral wind, however, Thus, it has been assumed that the north components obtained here are representative of that geomagnetic latitude and local time.

A correlation has been found to exist between the local time dependence of the meridional components $\epsilon_{M}(\theta, t), \beta_{M}^{\prime}(\theta, t)$ and that of the $120 \mathrm{~km}$ atomic oxygen boundary densities, plotted on a logarithmic scale (Nisbet and Glenar, 1977). These relationships are shown graphically in Figures 9 and 10. Data for Kp 0.0-1.2 has been used here, although the same correlation exists for results from the other Kp ranges as well. Since data on the boundary densities are available over the entire 24 hours, this relationship allows one to estimate the meridional flows between 5.0 and 12.0 hours geomagnetic local time where there is a paucity of experimental wind results. Linear regression analyses between the densities and the fluxes were performed and the following relationships found.

$$
\begin{aligned}
& \epsilon_{M}^{\prime}(\vartheta, t)=1.638 \times 10^{5} \log _{10} \mathrm{n}(\mathrm{O})_{120}-2.806 \times 10^{6} \mathrm{~W} \mathrm{~m}^{-1} \\
& \beta_{M}^{\prime}(\theta, t)=0.3294 \log _{10} \mathrm{n}(O)_{120}-5.640 \mathrm{~kg} \mathrm{~m}^{-1} \mathrm{sec}^{-1}
\end{aligned}
$$




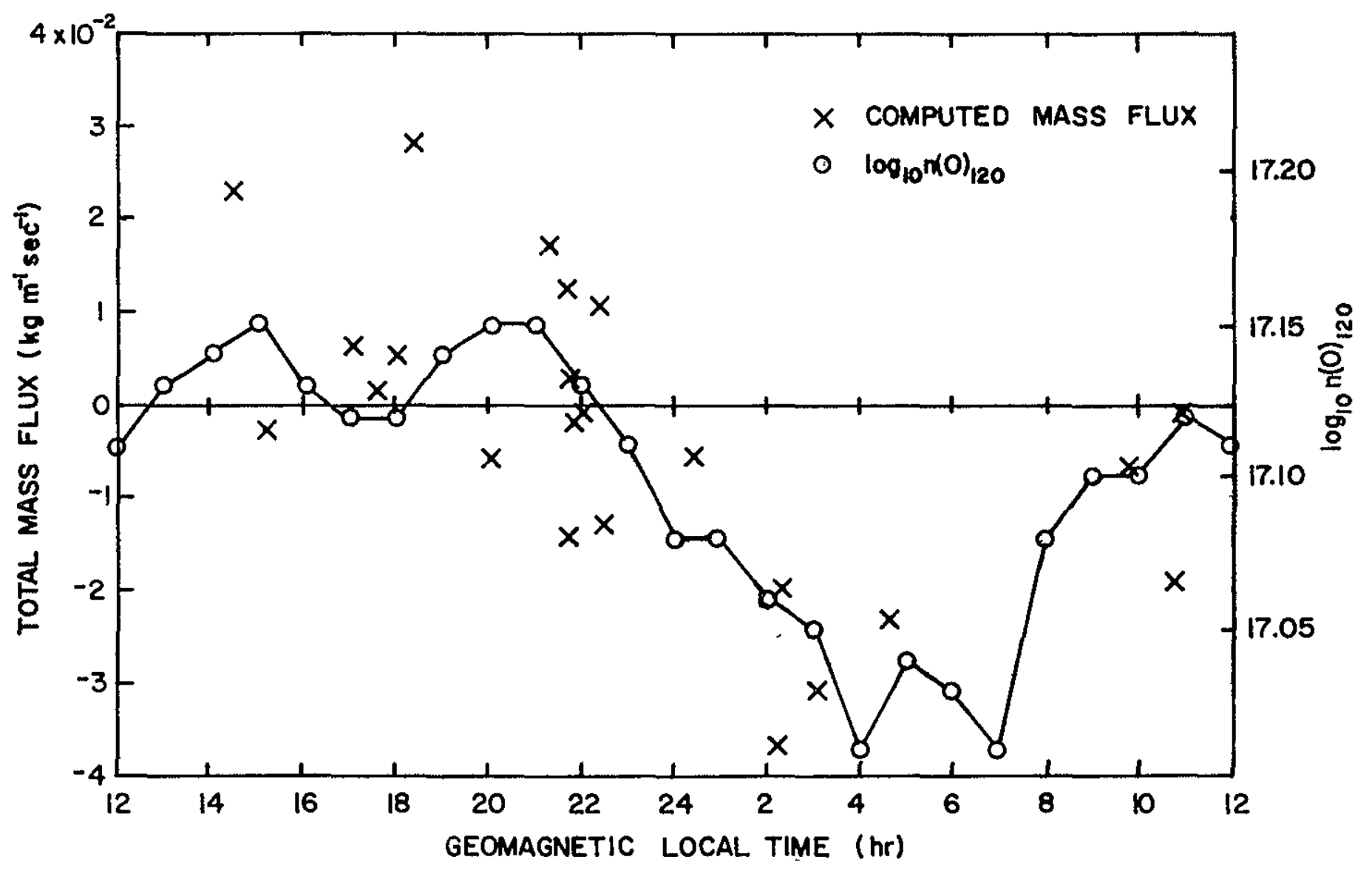

Figure 9 North components $\left(\beta_{M}(\theta, t)\right)$ of total mass flux at $70^{\circ} \mathrm{N}$ geomagnetic latitude $\left(\theta=20^{\circ}\right)$, height integrated above $120 \mathrm{~km}$. $\log _{10}$ values of the derived $120 \mathrm{~km}$ atomic oxygen density (Kp $0.0-1.2$ ) have been shown for comparative purposes. 


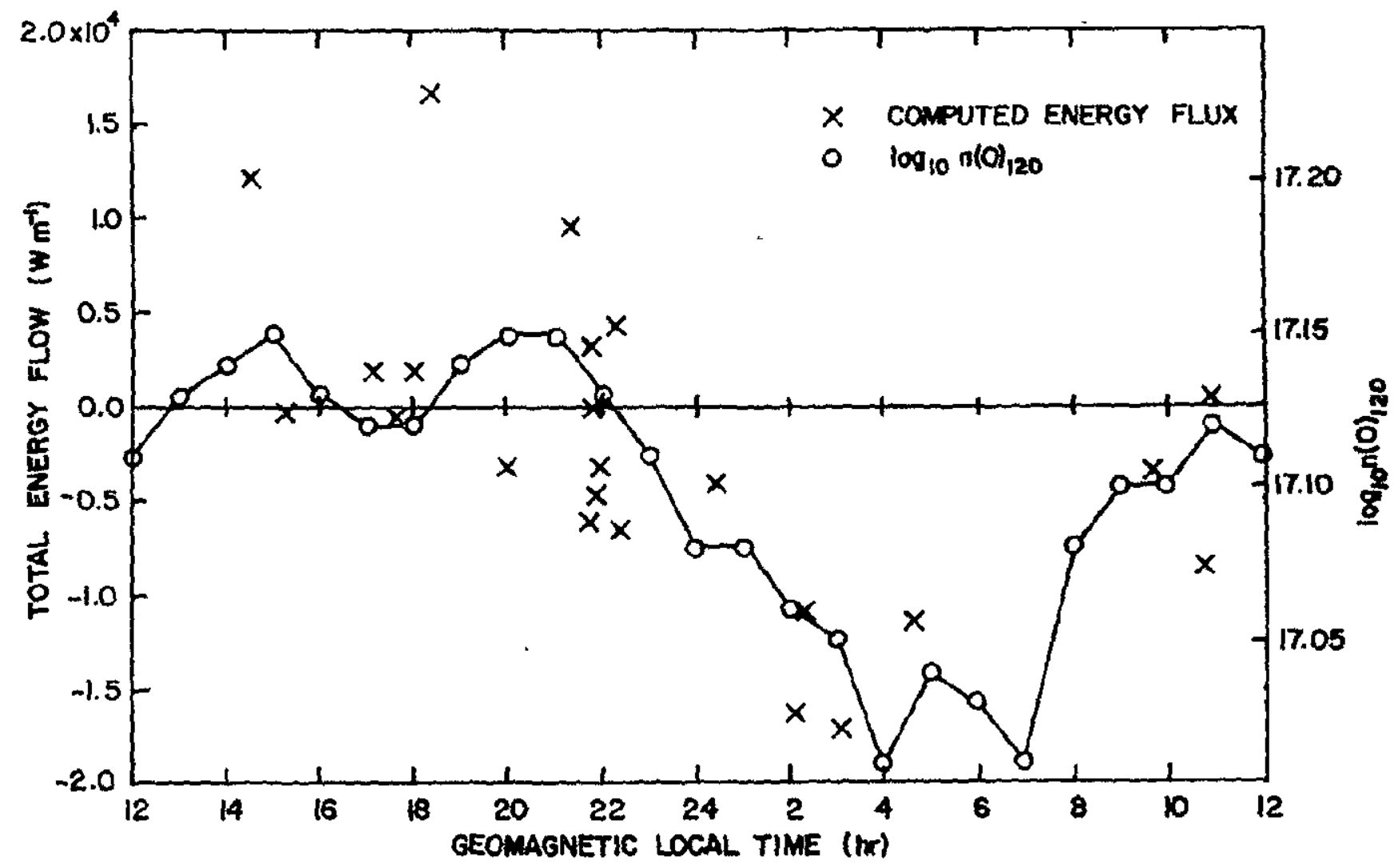

Figure 10 North components $(\varepsilon,(\theta, t))$ of total energy flux at $70^{\circ} \mathrm{N}$ geomagnetic latitude $\left(\theta=20^{\circ}\right)$, height integrated above $120 \mathrm{~km}$. $\log _{10}$ values of the derived $120 \mathrm{~km}$ atomic oxygen density ( $\mathrm{K}_{\mathrm{p}} 0.0-1.2$ ) have been shown for comparative purposes. 
The primes in equations (3.20) and (3.21) have been included to distinguish between the experimental values and the best fit values obtained from the regression analysis. Positive values of these quantities are those directed to the north in the northern hemisphere. Using these relations, equations (3.6) and (3.8) have been solved to obtain a value of approximately $2.3 \times 10^{10} \mathrm{~W}(23 \mathrm{GW})$ as the energy input from the north polar region into the system at $70^{\circ} \mathrm{N}$ geomagnetic latitude $\left(\theta=70^{\circ}\right)$. Since symmetry has been assumed between the high north latitude and the conjugate south polar regions, the estimate arrived at for the net energy input $Q_{P}$ to the nighttime system is, for $K p$ values from $0.2-4.0$,

$$
Q_{P}=4.6 \pm 2.3 \times 10^{10} \mathrm{~W}
$$




\section{ENERGY LOSS PROCESSES}

\subsection{Downward Conduction at the Lower Boundary}

The major heat loss from the night hemisphere is downward conduction due to the large vertical temperature gradient. The important parameters in establishing absolute magnitudes of the conduction loss are the temperature gradients, and to a lesser extent the absolute value of the temperature and the relative densities of the atomic and molecular major constituents which affect the conduction.

From equation (2.15), the downward conduction at the $120 \mathrm{~km}$ boundary is given by

$$
\mathrm{C}=\bar{\lambda} \frac{\partial \mathrm{T}}{\partial \mathrm{z}} \mathrm{J} \mathrm{m}^{-2} \mathrm{sec}^{-1}
$$

Here, $\partial T / \partial z$ is the vertical temperature gradient, and $\bar{\lambda}$ is the weighted mean thermal conductivity for the gas mixture. The values used for the thermal conductivity of $\mathrm{N}_{2}, \mathrm{O}_{2}$ and $\mathrm{O}$ are those given by Bauer (1972) and are expressed as follows

$$
\begin{aligned}
& \lambda\left(\mathrm{O}_{2}\right)=1.86 \times 10^{-4} \mathrm{~T}_{\mathrm{n}} .84 \\
& \lambda\left(\mathrm{N}_{2}\right)=2.72 \times 10^{-4} \mathrm{~T}_{\mathrm{n}} .80 \\
& \lambda(\mathrm{O})=6.71 \times 10^{-4} \mathrm{~T}_{\mathrm{n}} .71
\end{aligned}
$$

The mean thermal conductivity can then be expressed as 


$$
\bar{\lambda}=\frac{\lambda\left(\mathrm{N}_{2}\right)+\lambda\left(\mathrm{O}_{2}\right) \mathrm{n}\left(\mathrm{O}_{2}\right) / \mathrm{n}\left(\mathrm{N}_{2}\right)+\lambda(\mathrm{O}) \mathrm{n}(\mathrm{O}) / \mathrm{n}\left(\mathrm{N}_{2}\right)}{1+\mathrm{n}\left(\mathrm{O}_{2}\right) / \mathrm{n}\left(\mathrm{N}_{2}\right)+\mathrm{n}(\mathrm{O}) / \mathrm{n}\left(\mathrm{N}_{2}\right)}
$$

Using the 1972 Cospar International Reference Atmosphere (CIRA, 1972), representative density ratios at $120 \mathrm{~km}$ have been evaluated and used to compute the mean thermal conductivity. The result is

$$
\begin{aligned}
& \bar{\lambda}=1.8 \times 10^{-4} \mathrm{~T}_{\mathrm{n}} .80+1.72 \times 10^{-5} \mathrm{~T}_{\mathrm{n}} .84 \mathrm{H} . \\
& +1.64 \times 10^{-4} \mathrm{~T}_{\mathrm{n}}^{.71} \mathrm{~J} \mathrm{~m}^{-1} \mathrm{sec}^{-1} \dot{\mathrm{K}}^{-1}
\end{aligned}
$$

A number of difficulties are encountered in making experimental measurements of thermospheric temperatures at night. Probably the best estimates of temperature in the region above $120 \mathrm{~km}$ are obtained from incoherent scatter (Wand, 1974; Swartz and Nisbet, 1971). Unfortunately, electron densities at night in the region are so low that up until now only daytime measurements at these heights have been available. Individual rocket measurements of temperature in this region show a pronounced wave structure with considerable day to day variation with amplitudes of the order of $50 \mathrm{~K}$ and a phase variation with height. These factors combine to make individual in-situ measurements rather difficult to relate to average nighttime energy fluxes.

While the incoherent scatter data do not provide nighttime temperature gradients, it appears that the dominant tidal component is semidiurnal rather than diurnal (Salah and Wand, 1974) so that the uncertainty should not be large. In accord with the analysis by Fontanari (1973) of the temperature amplitudes and phase 
distributions and their associated errors (Section 3.1.4), the height and local time dependence of the temperature at St. Santin is given by

$$
\begin{gathered}
T(t, z)=T_{0}(z)+A(z) \cos (\pi / 12)\left(t-\phi_{d}(z)\right) \\
+B(z) \cos (\pi / 6)\left(t-\phi_{S}(z)\right)
\end{gathered}
$$

where $T_{0}(z)$ is the seasonal mean temperature

$A(z)$ is the amplitude of the diurnal component

$B(z)$ is the amplitude of the semidiurnal component

$\phi_{\mathrm{d}}(\mathrm{z})$ is the phase of the diurnal component in hours

$\phi_{S}(z)$ is the phase of the semidiurnal component in hours

The average value of the conduction over the night hemisphere at the latitude of St. Santin can then be obtained using equations (4.1), (4.6) and (4.7) and is given by

$$
\langle C\rangle=\frac{1}{24-\left(t_{s}-t_{r}\right)} \int_{t_{s}}^{t_{r}} \bar{\lambda} \partial T / \partial z d t
$$

where $t_{r}$ and $t_{s}$ are the times of local sunrise and sunset at St. Santin for the season under consideration

The conduction rate associated with the steady or diurnal average temperature gradient was calculated to be $5.2 \times 10^{-4} \mathrm{~J} \mathrm{~m}^{-2}$ isec $^{-1}$ for spring equinox, $4.1 \times 10^{-4} \mathrm{Jm}^{-2} \mathrm{sec}^{-1}$ for fall equinox and $4.8 \times 10^{-4} \mathrm{~J} \mathrm{~m}^{-2} \mathrm{sec}^{-1}$ for summer solstice. The corresponding 
ranges of solar $F_{10.7}$ flux were 123-232, $102-207$ and 109-239 $\mathrm{W} \mathrm{m} \mathrm{m}^{-2} \mathrm{~Hz}$ for spring equinox, fall equinox and summer solstice respectively. No analysis was performed for winter solstice, since the results of the measurements made were inconclusive. While there is considerable uncertainty associated with the diurnal component, the $120 \mathrm{~km}$ conduction averaged over the nighttime hours is found to be lower than the seasonal mean in each case with considerable variation in the amount of reduction. The values of average nighttime conduction were found to be $3.7 \pm 1.4 \times 10^{-4}$, $3.4 \pm 1.6 \times 10^{-4}$ and $4.7 \pm .7 \times 10^{-4} \mathrm{~J} \mathrm{~m}^{-2} \mathrm{sec}^{-1}$ for spring equinox, fall equinox and summer solstice respectively.

Similar analyses have been made at Millstone $\left(42.6^{\circ} \mathrm{N}\right)$ by Salah (1974) and at Millstone and St. Santin (44.6 ${ }^{\circ} \mathrm{N}$ ) by Salah and Wand (1974) for values of $F_{10.7}$ between 95 and $186 \times 10^{-22} \mathrm{~W} \mathrm{~m}^{-2} \mathrm{~Hz}^{-1}$. These studies provide estimates for the diurnal average conduction of 5.7 and $6.6 \times 10^{-4} \mathrm{~J} \mathrm{~m}^{-2} \mathrm{sec}^{-1}$ respectively.

Based on a statistical analysis of measured temperatures between the years 1966 and 1970, Rohrbaugh(1972) has analysed the local time variation of the $120 \mathrm{~km}$ conduction at Arecibo. The results are represented by the Fourier series

$$
\left(\frac{d T}{d z}\right)_{120}=\sum_{j=0}^{6}\left[A_{j} \cos \frac{2 \pi j}{24} t+B_{j} \sin \frac{2 \pi j}{24} t\right]
$$

where the sets of coefficients $A_{j}$ and $B_{j}$ have been determined by Rohrbaugh for equinox and winter and summer solstice conditions. When the steady state temperature given by the $A_{0}$ term is used to 
determine the thermal conductivity, the average nighttime conduction calculated using equation $(4.8)$ is found to be $2.8 \pm .8 \times 10^{-4}$ $\mathrm{J} \mathrm{m}^{-2} \mathrm{sec}^{-1}$ for spring and fall equinox, $2.3 \pm .5 \times 10^{-4} \mathrm{~J} \mathrm{~m}^{-2} \mathrm{sec}^{-1}$ for summer solstice and $2.2 \pm .9 \times 10^{-4} \mathrm{~J} \mathrm{~m}^{-2} \mathrm{sec}^{-1}$ for winter solstice, for values of $\mathrm{F}_{10.7}$ flux between 100 and $225 \times 10^{-22}$ $\mathrm{W} \mathrm{m} \mathrm{m}^{-2} \mathrm{~Hz}^{-1}$. The uncertainty in each of the above values has been deduced from statistical uncertainties as well as from the errors in the temperatures near $120 \mathrm{~km}$, as deduced from the Arecibo data. Figure 11 shows the results derived from both the St. Santin and the Arecibo data and indicates a marked difference in both the steady state conduction and the amount of variability between the two stations. For comparative purposes, individual values of conduction derived from isolated pitot tube measurements at Arecibo, Wallops Island and Ft. Churchill have been included. These data were obtained for values of $\mathrm{F}_{10.7}$ between 108 and 174 $\mathrm{W} \mathrm{m} \mathrm{m}^{-2} \mathrm{~Hz}^{-1}$. A discussion of the method of obtaining temperature gradients from pitot tube measurements has been given by Smith et al. (1967).

The variability of these individual measurements is assumed to be the effect of reversible heating from atmospheric gravity waves which exhibit a characteristic phase variation with height. Hines (1965) has shown that the amplitude of temperature fluctuations increases from roughly $10 \mathrm{~K}$ low in the E-region to as much as $30 \mathrm{~K}$ near $110 \mathrm{~km}$. In addition, from an analysis of $\mathrm{Na}$ cloud drifts, Kochanski (1964) has deduced vertical wavelengths of the order of $16 \mathrm{~km}$ near $120 \mathrm{~km}$, thought to result primarily from the effects of gravity waves. Assuming a temperature amplitude of 


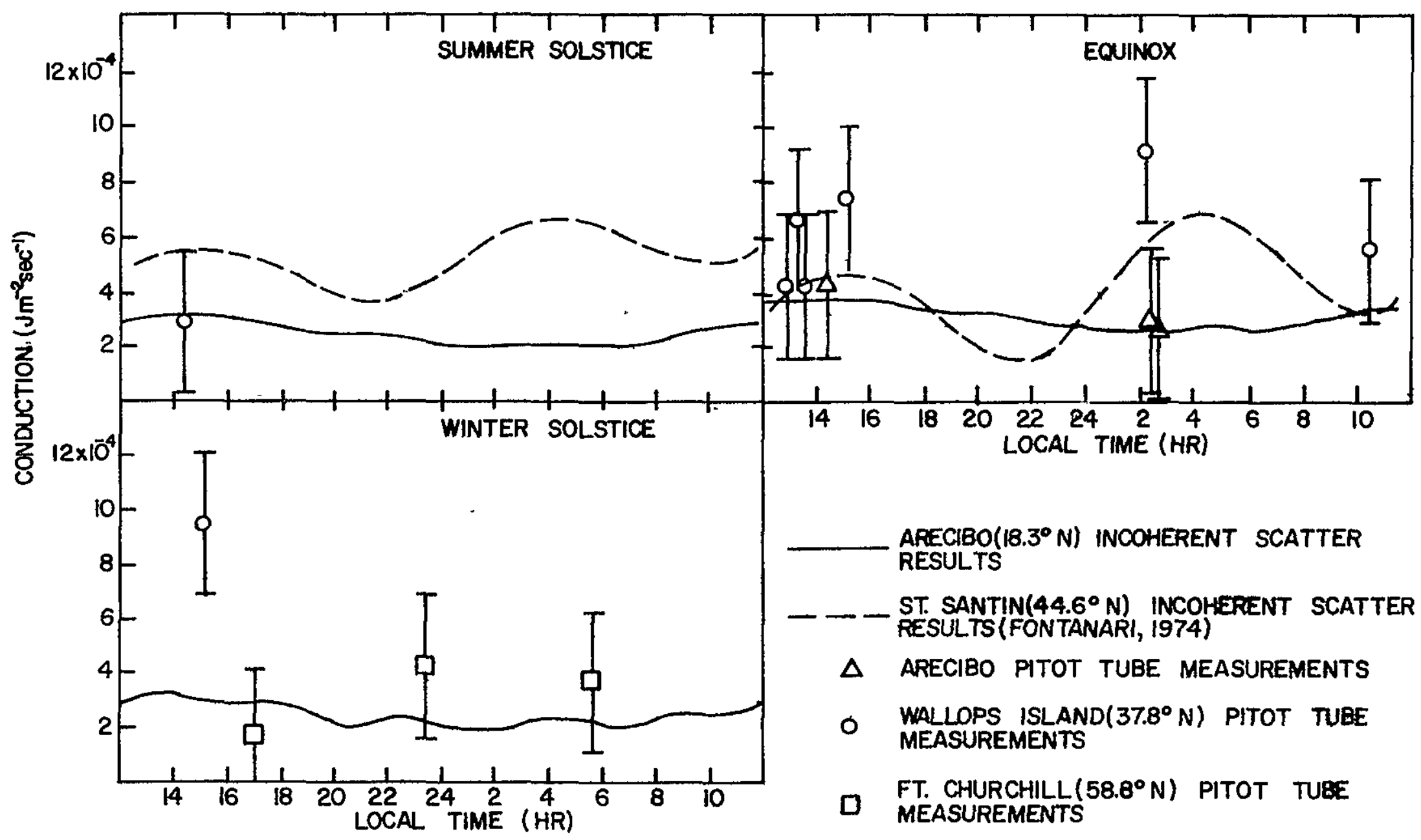

Figure 11 Diurnal varlation of downward heat conduction at $120 \mathrm{~km}$. 
$30 \mathrm{~K}$ and a representative vertical wavelength of $18 \mathrm{~km}$, a maximum departure from the steady state temperature gradient of about $10 \mathrm{~K} / \mathrm{km}$ is found to occur. At a $120 \mathrm{~km}$ temperature of $350 \mathrm{~K}$, this corresponds to deviations of the order of $3 \times 10^{-4} \mathrm{~J} \mathrm{~m}^{-2} \mathrm{sec}^{-1}$ from the steady state conduction at $120 \mathrm{~km}$. The size of this deviation is represented by the error bars in Figure 11.

If the latitudinal dependence of the nighttime conduction rate is adequately known, the total conduction over the $120 \mathrm{~km}$ boundary of the nighttime thermosphere for a given season is expressed as

$$
Q_{C}=1.85 \times 10^{11} \int_{-70^{\circ}}^{70^{\circ}}<C>L \cos \varphi d \varphi \quad W
$$

where $I$ is the length of night in hours

$\langle\mathrm{C}\rangle$ is the average nighttime conduction rate in $\mathrm{W} \mathrm{m}^{-2}$ $\varphi$ is the latitude in degrees

As in the treatment of the horizontal winds, the geometry at equinox allows the assumption of latitudinal symmetry in the conduction rate between the northern and southern hemispheres. Using the equinoctial conduction rates at the latitudes of Arecibo and St. Santin, four points are available which represent the variation of the conduction with latitude. This allows an approximate solution of equation (4.10) and yields a value of

$$
Q_{C}=8.6 \pm 2.7 \times 10^{10} \mathrm{~W} \text { equinox }
$$

for the total downward conduction at times ciose to equinox. 
For either summer or winter solstice conditions, the latitude dependence of the conduction is again obtained by using the rates appropriate for the latitudes of St. Santin and Arecibo in the northern hemisphere and applying these results to the conjugate hemisphere six months later.

Since it has not been found possible to estimate the winter solstice conduction rate at St. Santin, however, two cases have been studied. The first case assumes that the conduction rate is the same at winter solstice as it is at summer solstice. The second assumes that the rate oscillates around the equinox value with a 12 month period so that based on the results obtained, the winter solstice value lies below either of the equinox values. When this approach is taken, the following values for the total conduction result.

$$
\begin{aligned}
& Q_{C}=8.1 \pm 2.6 \times 10^{10} \mathrm{~W} \quad \text { solstice maximum } \\
& Q_{C}=6.6 \pm 2.1 \times 10^{10} \mathrm{~W} \quad \text { solstice minimum }
\end{aligned}
$$

\subsection{Infrared Radiative Losses}

\subsubsection{Emission at $63 \mu$ from Thermospheric Atomic Oxygen}

Kockarts and Peetermans (1970) have discussed the contribution to thermospheric cooling by infrared radiation from atomic oxygen in the height range between 50 and $250 \mathrm{~km}$. The ground state of atomic oxygen consists of three low lying levels ${ }^{3} P_{0},{ }^{3} P_{1}$ and ${ }^{3} \mathrm{P}_{2}$, and the kinetic energy of motion of the constituents is converted into infrared radiation by collisional excitation and subsequent spontaneous deexcitation to either the ${ }^{3} \mathrm{P}_{1}$ or the ${ }^{3} \mathrm{P}_{2}$ 
levels. As shown in Figure 12, the levels ${ }^{3} P_{0}$ and ${ }^{3} P_{1}$ lie .028 and $.020 \mathrm{eV}$ above the ground level ${ }^{3} \mathrm{P}_{2}$ and emit at $147 \mu$ and $63 \mu$ respectively. The transition probabilities $A_{i j}$ are simply the spontaneous transition rates per atom and are listed by Wiese et a1. (1966) as $A_{01}=1.70 \times 10^{-5} \mathrm{sec}^{-1}$ and $A_{12}=8.95 \times 10^{-5} \mathrm{sec}^{-1}$. The energy lost per unit volume from this mechanism may then be written

$$
\begin{aligned}
& L=I_{63 \mu}+L_{147 \mu} \\
& L=\epsilon_{1} A_{12} n_{1}(O)+\left(\epsilon_{0}-\epsilon_{1}\right) A_{01} n_{0}(O)
\end{aligned}
$$

where $\epsilon_{0}$ and $\epsilon_{1}$ are the energies of levels ${ }^{3} P_{0}$ and ${ }^{3} P_{1}$ with respect to ${ }^{3} \mathrm{P}_{2}$ (here, $\epsilon_{2}$ is taken to be zero).

$A_{12}$ and $A_{01}$ are the spontaneous emission coefficients from levels 1 to 2 and 0 to 1 respectively $n_{1}(O)$ and $n_{0}(O)$ are the populations of levels 1 and 0 respectively

In the region of interest here, the collision frequency between atomic oxygen and all constituents is assumed high enough to maintain a Boltzmann distribution, which relates the population of level $i$, i.e. $n_{i}(O)$, to the total number of atomic oxygen atoms. This relation is given by

$$
n_{i}(O)=n(O) \frac{g_{i} \exp \left(-\epsilon_{i} / k T\right)}{\sum_{j} g_{j} \exp \left(-\epsilon_{j} / k T\right)}
$$


OI

ENERGY

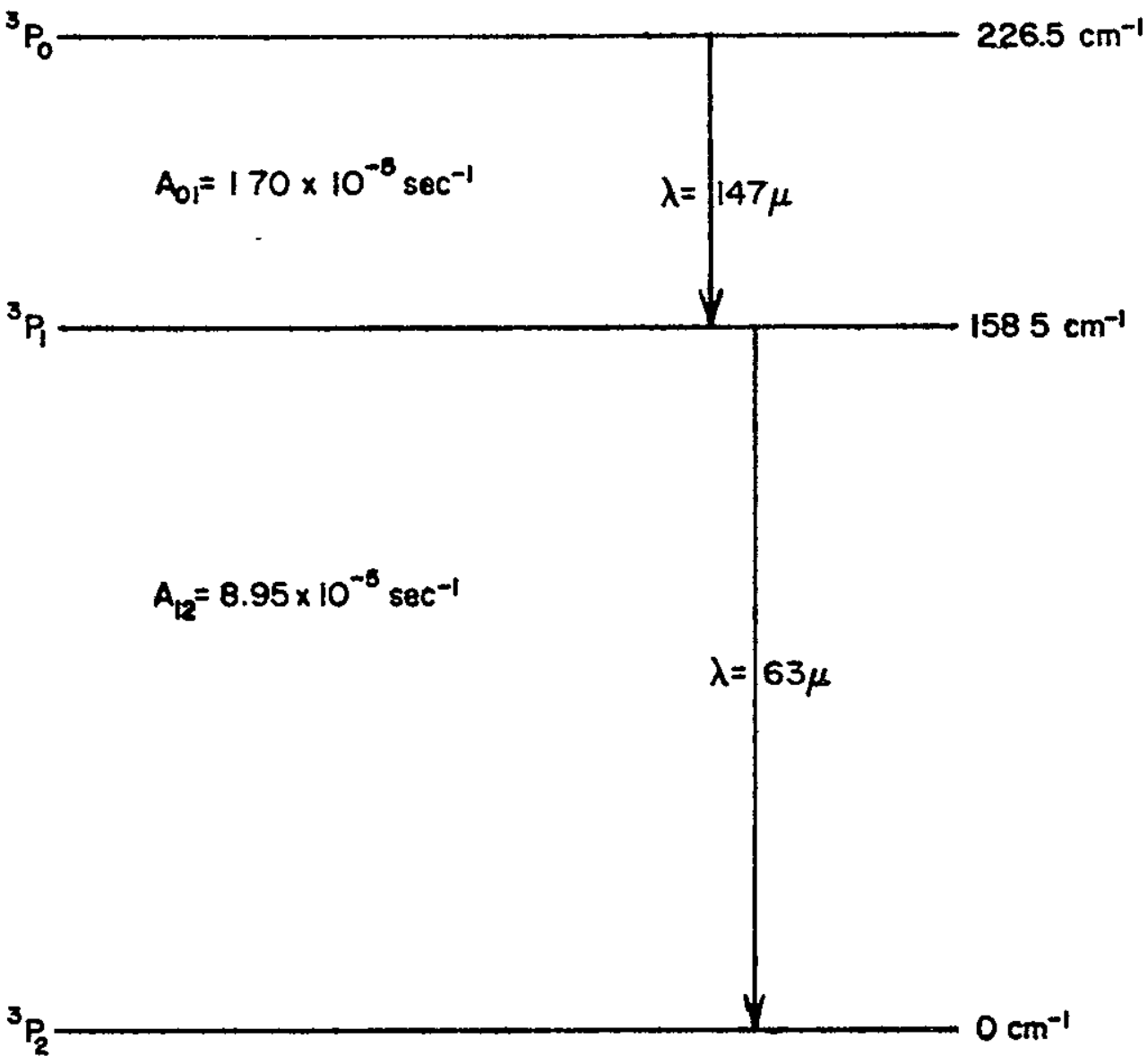

Figure 12 Atomic oxygen ground state transitions. (Reference: Kockarts and Peetermans, 1970) 
where $g_{i}$ and $g_{j}$ are the statistical weights of levels $i$ and $j$ respectively

$T$ is the temperature

$\mathrm{n}(\mathrm{O})$ is the total atomic oxygen density

At temperatures of the order of $500 \mathrm{~K}$, nearly all atoms are in one of the above three levels. Using values for the statistical weights of $g_{0}=1, g_{1}=3$ and $g_{2}=5$, the volume emissions $L_{63 \mu}$ and $L_{147 \mu}$ are found to be

$$
\begin{aligned}
& I_{63 \mu}=\frac{1.69 \times 10^{-25} \mathrm{n}(0) \exp (-228 / \mathrm{T})}{1+0.6 \exp (-228 / \mathrm{T})+0.2 \exp (-326 / \mathrm{T})} \mathrm{Wm}^{-3} \\
& I_{147 \mu}=\frac{4.59 \times 10^{-27} \mathrm{n}(\mathrm{O}) \exp (-326 / \mathrm{T})}{1+0.6 \exp (-228 / \mathrm{T})+0.2 \exp (-326 / \mathrm{T})} \mathrm{Wm}^{-3}
\end{aligned}
$$

where $n(O)$ is the number of oxygen atoms per $m^{-3}$.

Inspection of the above equations quickly shows that for the same values of $T$ and $n(O)$, the $147 \mu$ contribution to atomic oxygen emission is negligible. In consequence, only emission at $63 \mu$ will be considered.

The emission rate given by equation (4.14) applies only for an optically thin atmosphere, where the radiation travels unimpeded and ultimately leaves the atmosphere. In reality, some absorption of the radiation occurs in the reexcitation of atomic oxygen from the ${ }^{3} \mathrm{P}_{2}$ level and the rate of this process is directly proportional to the population of the ${ }^{3} \mathrm{P}_{2}$ level. As a result, the emission at a 
given height is reduced and the departure from optically thin emission increases as height decreases. Kockarts and Peetermans have obtained a reduction factor $\chi$ to be applied to equation (4.14) expressed as a fraction of the emission. Their results are shown in Figure 13 where curves corresponding to exospheric temperatures of $750 \mathrm{~K}$ and $2000 \mathrm{~K}$ have been included. The average of the two curves shown was chosen to represent a $1200 \mathrm{~K}$ exospheric temperature and used to compute the height profile of the emission. The resulting curve was fitted using the least squares technique and a good representation for $z \geqslant 120 \mathrm{~km}$ is given by

$$
1-x=\left(\frac{z-115}{107}\right)^{.343} \quad T_{\infty} \sim 1200 \mathrm{~K}
$$

where $z$ is the height in $\mathrm{km}$.

For the purpose of estimating radiative losses, a first order approximation to the atomic oxygen density distribution above 120 $\mathrm{km}$ is obtained assuming diffusive equilibrium. Using the temperature distribution given by equation (3.4), the height distribution of atomic oxygen ( $\mathrm{z}$ in $\mathrm{km}$ ) is thus given by

$$
n_{z}(O)=n_{120}(O) \frac{T_{120}}{T_{z}} \exp \left[-\frac{m_{O} g}{k T_{\infty}}\left(z-z_{o}+(1 / s) \ln \left(T_{z} / T_{120}\right)\right)\right]
$$

with $\mathrm{z}_{\mathrm{o}}=120 \mathrm{~km}$.

The emission $\left(\mathrm{q}_{63 \mu}\right)$ from a column of unit cross section and extending upward from $120 \mathrm{~km}$ can then be calculated using 
94

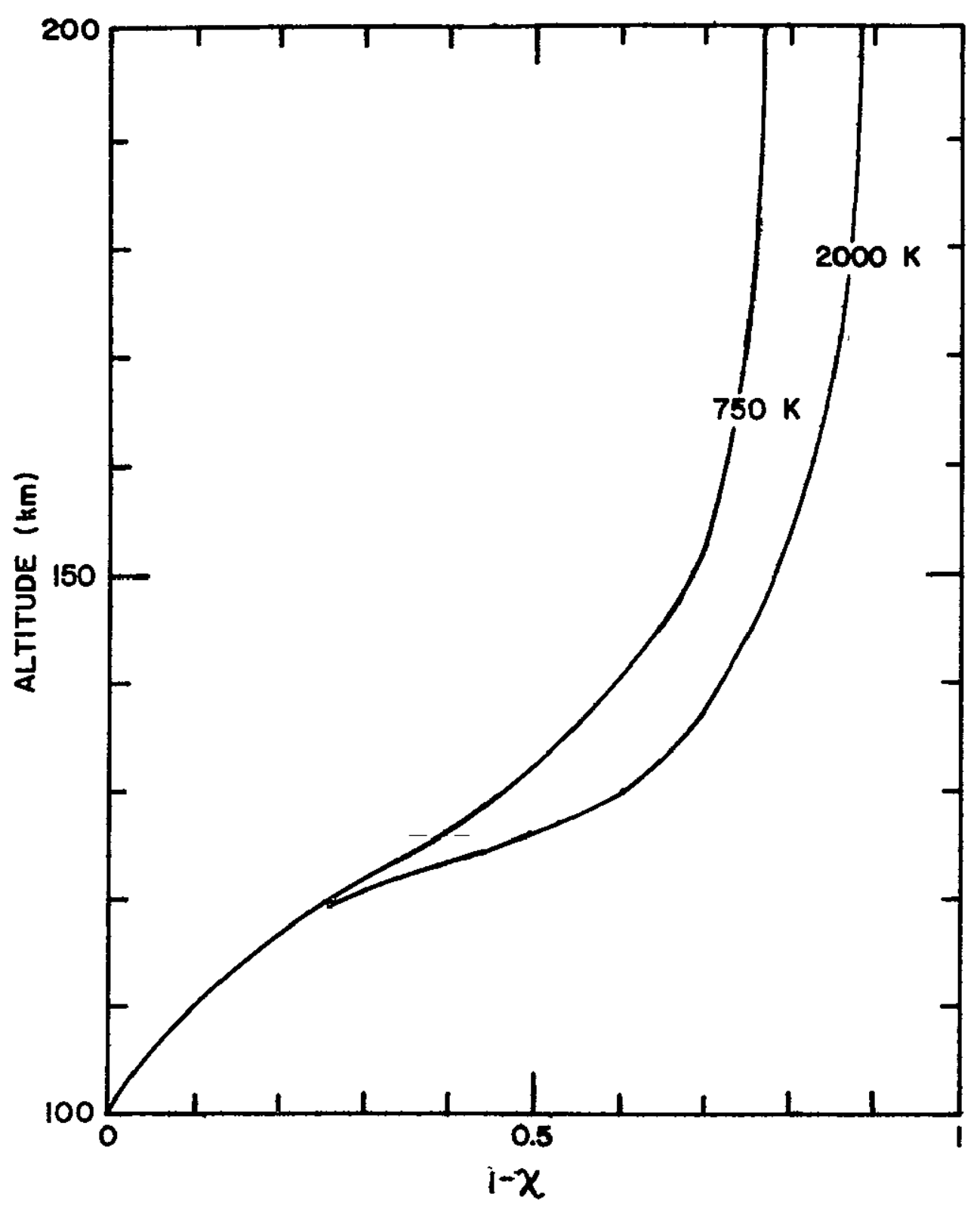

Figure 13 Reduction factor resulting from radiative transfer applied to $63 \mu$ emission. (Reference: Banks and Kockarts, 1973) 


$$
\mathrm{q}_{63 \mu}=\int_{120}^{\infty} I_{63 \mu}(1-x) d z \quad \mathrm{w} \mathrm{m}^{-2}
$$

where $L_{63 \mu}$ and $I-\chi$ are determined using equations (4.14) through (4.19) with appropriate boundary values.

Donahue et al. (1973) have determined the distribution of atomic oxygen as a function of altitude and latitude from OGO- 6 observations of the atomic oxygen ${ }^{1} \mathrm{~S}-{ }^{1} \mathrm{D}$ night airglow emission. They find that at $120 \mathrm{~km}$, a value for the satomic oxygen.density of $1.1 \times 10^{17} \mathrm{~m}^{-3}$ represents all but the most unusual conditions, while the observed values ranged from $0.41 \times 10^{17}$ to $1.35 \times 10^{17} \mathrm{~m}^{-3}$ (Donahue, 1976). It seemed appropriate, then, to assume that the $120 \mathrm{~km}$ atomic oxygen density lies usually between 0.9 and $1.2 \times 10^{17} \mathrm{~m}^{-3}$.

In order to establish a representative temperature profile, temperature parameters derived from the September 17, 1974 Arecibo incoherent scatter data (Table A.1) have been employed. This day represents low geomagnetic activity and the scatter results obtained on this date were among the best of the available measurements. The extremes of temperature listed in Table A.1 for this day should represent the maximum and minimum temperature over the entire 24 hours since the temperature oscillations at these heights are predominantly semidiurnal and since data was collected over a period of about 12 hours.

Using the above extremes in the density and temperatures, equation (4.20) has been evaluated and the $63 \mu$ loss rate per square 
meter was found to be

$$
q_{63 \mu}=0.86 \pm 0.13 \times 10^{-4} \mathrm{~W} \mathrm{~m}^{-2}
$$

4.2.2 Emission at $15 \mu$ from Thermospheric Carbon Dioxide An additional source of infrared radiative loss above $80 \mathrm{~km}$ arises from radiative deexcitations of the $v_{2}$ bending vibration band of $\mathrm{CO}_{2}$ at $15 \mu$. The basic considerations involved in calculating the radiative loss rate from this process are given by Houghton (1969). For total pressures significantly less than $10^{-6}$ atmospheres, collisional deexcitation of the excited states in the $v_{2}$ band becomes negligible compared to radiative deexcitation and in addition, the medium becomes optically thin for this transition. The radiative loss rate per unit volume over the entire $v_{2}$ band is then given by

$$
L_{15 \mu}=n\left(\mathrm{CO}_{2}\right) \frac{h v}{\tau_{c}} \frac{g_{2}}{g_{1}}\left[\exp \left(\frac{h v}{k T}\right)-1\right]^{-1}
$$

In equation (4.22) hv is the average transition energy over the $v_{2}$ band $\left(h \nu \sim 1.33 \times 10^{-13} \mathrm{erg}\right)$ while $g_{1}$ and $g_{2}$ are the statistical weights with values of 1 and 2 respectively. .The estimate obtained by Houghton for the vibrational relaxation time $\tau_{c}$ at $210 \mathrm{~K}$ is $6.0 \times 10^{-6} / \mathrm{p}$ sec where $\mathrm{p}$ is the total pressure in atmospheres. This value will be used in this analysis, although Houghton indicates that the value of $\tau_{c}$ decreases with increasing temperature. The term $\left(g_{2} / g_{1}\right)[\exp (\mathrm{h} v / \mathrm{kT})-1]^{-1}$ is the ratio of the probabilities of excitation from the ground state to deexcitation from an excited 
state when allowance is made for all excited states that comprise the $v_{2}$ band. Assuming a height independent volume mixing ratio for $\mathrm{CO}_{2}$ of $3.3 \times 10^{-4}$ (Houghton, 1969), equation (4.9) becomes

$$
\begin{aligned}
L_{15 \mu}= & 1.99 \times 10^{-46} \mathrm{~T}\left[\mathrm{n}\left(\mathrm{N}_{2}^{-}\right)+\mathrm{n}\left(\mathrm{O}_{2}\right)+\mathrm{n}(\mathrm{O})\right]^{2} \\
& {\left[\exp \left(\frac{964}{\mathrm{~T}}\right)-1\right]^{-1} \mathrm{~W} \mathrm{~m}^{-3} }
\end{aligned}
$$

The emission above $120 \mathrm{~km}$ from a column of unit area is then given by

$$
q_{15 \mu}=\int_{120}^{\infty} L_{15 \mu} d z \quad W m^{-2}
$$

Because of the quadratic dependence on the total density, rather large variations in the $15 \mu$ emission rate would normally be expected. Using the range of $120 \mathrm{~km} \mathrm{~N} \mathrm{~N}_{2}$ and $\mathrm{O}_{2}$ densities found in Table A,1 for September ,17, along with the previous boundary values, the $15 \mu$ emission has been found to be

$$
q_{15 \mu}=0.30 \pm 0.20 \times 10^{-4} \quad \mathrm{~W} \mathrm{~m}^{-2}
$$

\subsubsection{Total Radiative Loss}

From the preceeding sections, the sum of the $63 \mu$ and $15 \mu$ emissions above $120 \mathrm{~km}$ from a column of unit cross section is

$$
\mathrm{q}_{63 \mu}+\mathrm{q}_{15 \mu}=1.16 \pm 0.24 \times 10^{-4} \quad \mathrm{w} \mathrm{m} \mathrm{m}^{-2}
$$


where the error is determined by the bounds placed on the $120 \mathrm{~km}$ boundary values, as discussed previously. Over the entire nighttime thermosphere, the above value corresponds to a total loss rate $Q_{R}$ of

$$
Q_{R}=3.0 \pm 0.6 \times 10^{10} \mathrm{~W} \quad(4.27)
$$

for the contributions of $63 \mu$ and $15 \mu$ emission by thermospheric atomic oxygen and carbon dioxide to the energy balance. 


\section{CHAPTER V \\ RESULTS OF THE-ANALYSIS}

\subsection{Conclusions}

\subsubsection{Conduction and-Radiation Losses}

Two sources of data examined in establishing the lower boundary temperature gradients were incoherent scatter and rocket pitot tube measurements. From the St. Santin measurements, it was found that the mean nighttime conduction flux was $3.5 \times 10^{-4}$ $\mathrm{W} \mathrm{m} \mathrm{m}^{-2}$ at equinox and $4.7 \times 10^{-4} \mathrm{~W} \mathrm{~m}^{-2}$ at solstice for values of the $10.7 \mathrm{~cm}$ solar flux between 102 and $239 \times 10^{-22} \mathrm{~W} \mathrm{~m}^{-2} \mathrm{~Hz}^{-1}$. The values for Arecibo were measured at times when the $10.7 \mathrm{~cm}$ solar flux was between 100 and $225 \times 10^{-22} \mathrm{~W} \mathrm{~m}^{-2} \mathrm{~Hz}^{-1}$ and were found to be $2.8 \times 10^{-4} \mathrm{~W} \mathrm{~m}^{-2}$ at equinox and $2.3 \times 10^{-4} \mathrm{~W} \mathrm{~m}^{-2}$ at solstice.

In the case of the pitot tube measurements it was found difficult to make adequate estimates of the average temperature gradients because of the large wave components that are always present. The pitot tube estimates were found to lie between $3 \times 10^{-4}$ and $9 \times 10^{-4}-\mathrm{W} \mathrm{m}^{-2}$ at equinox and between $2 \times 10^{-4}$ and $10 \times 10^{-4}$ $\mathrm{W} \mathrm{m}^{-2}$ at solstice.

It appears that the incoherent scatter sounders provide the best data for measurements of the daytime temperatures and their gradients in the region near $120 \mathrm{~km}$. It is not possible at the present time, however, to measure nighttime temperatures in this region at mid latitudes using incoherent scatter. Using only daytime data to estimate the diurnal component of the temperature 
variation is not at all desirable. The small number of incoherent scatter stations also makes any assumed latitudinal variation conjectured. All that can be said for the pitot tube measurements is that they do not show any large diurnal component in either the temperatures or the gradients at $120 \mathrm{~km}$ and that the values are not inconsistent with the estimates based on incoherent scatter observations.

Based on the available data it was estimated that at equinox the downward energy conduction over the hemisphere was between $5.9 \times 10^{10}$ and $11.3 \times 10^{10} \mathrm{~W}$ at equinox and between $4.5 \times 10^{10}$ and $10.7 \times 10^{10} \mathrm{~W}$ at solstice. The radiation loss from the nighttime thermosphere from atomic oxygen and carbon dioxide was estimated to be between $2.4 \times 10^{10}$ and $3.6 \times 10^{10} \mathrm{~W}$.

\subsubsection{High Latitude Thermospheric Winds}

The contribution from the neutral winds blowing in the meridional direction was estimated using 23 high latitude rocket vapor trail measurements. These were made at different times, seasons and latitudes. Because of the complexity of the high latitude neutral wind system, a far larger data base would be desirable. Still, the general features of the wind pattern appear to be understood and the clear correlation with the OGO- 6 density data makes it appear that the results are of the right order of magnitude. Based on these wind velocities and high latitude density data it was estimated that this source provided between $2.3 \times 10^{10}$ and $6.9 \times 10^{10} \mathrm{~W}$ to the nighttime thermosphere. This includes the contribution from high latitude heating as well as that from the day to night flow across the pole. 


\subsubsection{Low Latitude Thermospheric Winds}

Because of the coordinate system chosen for this analysis it is convenient to consider two components separately, one due to the winds measured by an observer on the ground and the second due to the motion of the terminator with respect to that observer. For these components, quite different pieces of experimental data control the estimates of the energy. For the winds measured with respect to the observer fixed to the earth, the difference in the wind profiles at the morning and evening terminators is of prime importance. For the component due to the motion of the thermosphere across the terminator the velocity is known exactly and the dominant terms involve the difference in the densities and temperatures at the two terminators.

The winds relative to the ground were measured using data from 23 pairs of morning and evening rocket flights. Based on these measurements alone, the derived energy fluxes ranged from $0.24 \times 10^{4} \mathrm{~W} \mathrm{~m}^{-1}$ to $0.48 \times 10^{4} \mathrm{~W} \mathrm{~m}^{-1}$ of terminator length.

The preceding term has attracted most attention in estimates of energy transport from the day to the night hemisphere. The reason for this is that little direct data has been available regarding density and temperature variations in the region near $120 \mathrm{~km}$. As a result, CIRA 1965 and CIRA 19,72 use approximately constant densities, temperatures and temperature gradients at $120 \mathrm{~km}$. When changes are incorporated, they reflect primarily attempts to compensate for the shortcomings of diffusive equilibrium models in explaining the variations in density at satellite altitudes. Because of effects due to tidal components and wind induced diffusion, such 
models cannot be expected to provide good estimates of the relevant parameters in the $120 \mathrm{~km}$ region. It is thus not possible to use them in theoretical investigations of these effects.

In the present work it has been shown that the corotating winds, rather than the measured winds, are the dominant contributor in determining the energy gain or loss to the system from the winds, and that there is little density and temperature data on which to base good estimates of the energy exchange from this source. The semidiurnal tidal modes, although they can be well determined from incoherent scatter, do not affect the calculations in the first order and it is not possible to accurately resolve the diurnal amplitude from data obtained only during daylight hours. The estimates of the densities near the terminators were found to introduce large errors, and while the temperatures at the terminators rarely change by more than 15 or 20 percent of the average value, as observed in Tables A.1 and A.2, the densities quite commonly change by a factor of 2 or more. The conclusion to be drawn is that a knowledge of the boundary densities is of even greater importance than the temperatures in establishing the terminator energy and mass fluxes.

\subsection{Summary of Contributions to the Energy Input and Loss}

The estimates arrived at for the energy input and loss terms, as previously discussed, are listed in summary form in Table 5. From a comparison of the inputs and losses, there would appear to be a need, under both equinox and solstice conditions, for an additional energy source to satisfy the energy balance. The 
Table 5. Summary of Energy Inputs and Losses

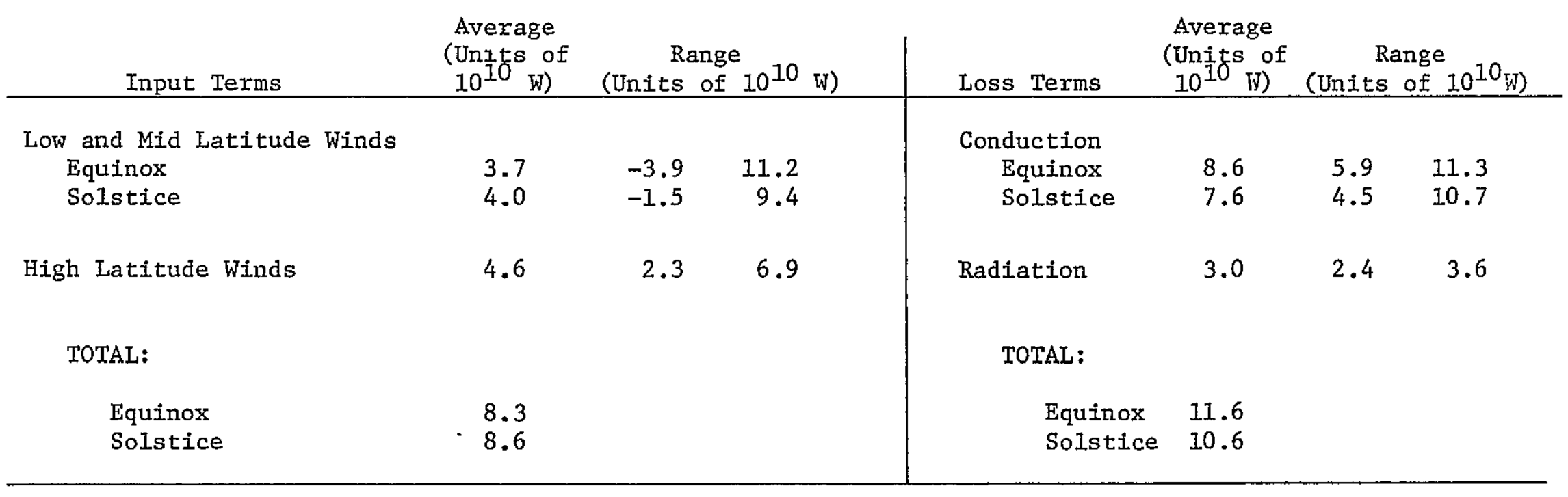


average deficit is $3.3 \times 10^{10} \mathrm{~W}\left(2.0 \times 10^{10} \mathrm{~W}\right)$ for equinox (solstice) with a possible range from a $16.5 \times 10^{10} \mathrm{~W}\left(13.5 \times 10^{10} \mathrm{~W}\right)$ deficit to a $7.8 \times 10^{10} \mathrm{~W}\left(9.4 \times 10^{10} \mathrm{~W}\right)$ excess.

It is interesting to compare these estimates of the energy deficit with terms that have not been included in the analysis. Ching and Chiu (1973) have modeled the volume Joule heating rate at local noon under spring equinox conditions and include the day to night heating ratio as well. If their rates are considered representative of the entire nighttime thermosphere, the total Joule heating is found to be $1.7 \times 10^{10} \mathrm{~W}$.

Using the results of satellite observations of neutral density perturbations, Klostermeyer (1973) has selected a dominant gravity wave mode and determined the energy dissipation by viscosity and ion-drag at thermospheric heights and for geographic latitudes near $50^{\circ} \mathrm{N}$. By height integrating the calculated heat input above $120 \mathrm{~km}$, a value of $1.7 \times 10^{-4} \mathrm{~W} \mathrm{~m}^{-2}$ is obtained. If this rate is applied over the entire nighttime thermosphere, the total heat dissipation from this gravity wave mode becomes $4.2 \times 10^{10} \mathrm{~W}$. These estimates of Joule and gravity wave heating constitute a sizable portion of the apparent discrepancy between the energy input and loss terms arrived at in this preliminary study. It is not proper to consider the above two sources as completely independent, however, since mechanisms have been proposed which couple Joule heating energy into that of gravity waves (Hines, 1965; Testud, 1970). Indeed, Chiu (1976) has discussed the problem of thermospheric response to auroral heating and points out the interdependence of 
auroral activity and the generation of an entire spectrum of wave perturbations, ranging from Rossby to acoustic-gravity modes.

An additional energy input to the nighttime thermosphere is thought to result from the influence of thermal tides, originating in the lower atmosphere. From an analysis of incoherent scatter measurements at Millstone Hill and St. Santin, Salah and Wand (1974) and Salah et al. (1975) have observed a predominantly semidiurnal temperature oscillation at heights near $120 \mathrm{~km}$, with a downward phase progression. This implies an upward flow of energy and the dissipation of this energy at higher altitudes. An earlier estimate of thermospheric heating from the semidiurnal-tide, performed by Lindzen and Blake (1970), led to a mean upward flux at $120 \mathrm{~km}$ between 3 and $4 \times 10^{-4} \mathrm{~W} \mathrm{~m}^{-2}$ from this source. This corresponds to a rate of 7.4 to $9.8 \times 10^{10} \mathrm{~W}$ for the total heating of the nighttime thermosphere from the semidiurnal tide.

The values for the energy deficit deduced from Table 5 are of the same order of magnitude as the above estimates and indicate. a need for an additional energy input to the low and mid latitude nighttime thermosphere.

\subsection{Recommendations for Further Experimental Work}

It is clear that further studies of this type will require an improved and expanded body of neutral density and temperature measurements at altitudes near $120 \mathrm{~km}$. Regarding the incoherent scatter technique, measurements made over a 24 hour period would be an enormous advantage even if a complete sequence cannot be obtained. A number of observations over several nights during times when the electron density is sufficiently large would be 
valuable in improving estimates of the odd harmonics in the density and temperature fluctuations. Secondly, since meaningful results can only be obtained on a statistical basis, a regular and systematic program of density and temperature measurements is required to ascertain seasonal variations and reduce the statistical uncertainties. A larger body of temperature measurements would also be useful in refining the conduction estimates.

Although the emphasis here has been placed on improved boundary values, there remains a need for additional morningevening rocket vapor trail measurements in the lower thermosphere. Additional twilight flights at a variety of latitudes and for different seasons would be of great help in revealing the nature of the wind system in the lower thermosphere and improving the overall heat balance.

Finally, a coherent series of high latitude rocket measurements, organized in terms of geomagnetic coordinates, would be invaluable in the study of the wind system at high geomagnetic latitudes. 


\section{REFERENCES}

Alcayde, D., P. Bauer, C. Jaeck, and J. L. Falin, Latitudinal diurnal variation of some atmospheric parameters determined by a simultaneous analysis of incoherent-scatter and satellite-drag data, J. Geophys. Res., 77, 2368, 1972.

Andreeva, L. A., M. L. Chanin, I. V. Elashova, L. A. Katasev, M. Maillard, G. F. Tulinov, and L. M. Uvarova, Measurements of wind, diffusion coefficients and temperatures from artificial luminous clouds on Heiss Island under quiet and disturbed geomagnetic situations, paper presented at the XVIII meeting of COSPAR, Varna, Bulgaria, May-June, 1975 .

Armstrong, J. C. and A. J. Zmuda, The atmospheric explorer magnetometer experiment, Radio Science, ㅇ, 401-405, 1973.

Banks, P. M. and G. Kockarts, Aeronomy Part B, Academic Press, New York, 1973.

Bates, D. R., Some problems concerning the terrestrial - .. atmosphere above about the $100 \mathrm{~km}$ level, Proc. Roy. Soc. London, $\mathrm{A(253)}, 451-462,1959$.

Bauer, S. J., Physics of Planetary Ionospheres, Springer-Verlag, New York-Heidelberg-Berlin, 1973.

Bedinger, J. F., Compendium of wind data from the vapor trail technique, GCA Technical Report No. 66-7-N, March, 1966.

Bedinger, J. F., GCA Technical Report No. 73-5-N, October, 1973.

Bedinger, J. F., TMA payload, field services and data reduction HAES No. 17, GCA Technical Report No. 75-2-A, February, 1975.

Blamont, J. E. and J. M. Luton, Geomagnetic effect on the neutral temperature of the $F$-region during the magnetic storm of September 1969, J. Geophys. Res., 77, 3534-3556, 1972 .

Blamont, J. E., J. M. Luton, and J. S. Nisbet, Global temperature distributions from OGO-6 6300 A airglow measurements, Radio Science, 9, 247-251, 1974. 
Brekke, A., J. R. Doupnik, and P. M. Banks, A preliminary study of the neutral wind in the auroral E-region, J. Geophys. Res., 78, 8235-8250, 1973 .

Butler, S. T. and K. A. Small, The excitation of atmospheric oscillations, Proc. Roy. Soc., 274, 91-121, 1963.

Cauffman, D. P. and D. A. Gurnell, Double - probe measurements of convection electric fields with the Injun- 5 satellite, J. Geophys. Res., 76, 6014, 1971.

Chandra, S., The diurnal heat budget of the thermosphere, Planet. Space Sci., 21, 593-604, 1973.

Chanin, M. L., M. Maillard, S. M. Poloskov, and G. F. Toulinov, New results on the thermospheric temperatuxe in the polar zone, Annls. Geophys., 28, 57, 1972.

Chapman, S. and R. S. Lindzen, Atmospheric Tides, D. Reidel Pub. Co., Dordrecht, Holland, 1970.

Ching, B. K. and Y. T. Chiu, Global distribution of thermospheric heat sources: EUV absorption and joule dissipation, Planet. Space Sci., -21, 1633, 1973.

Chiu, Y. T., Planetary scale wave response to auroral heating of the neutral atmosphere, J. Geophys. Res., 81, 1231, 1976.

Cole, K. D., Electrodynamic heating and movement of the thermosphere, Planet. Space Sci., 19, 59, 1971.

Detwiler, C. R., D. L. Garrett, J. D. Purcell, and R. Tousey, The intensity distribution in the ultraviolet solar spectrum, Annls. Geophys., 17, 263-272, 1961.

Donahue, T. M., B. Guenther, and R. J. Thomas, Distribution of atomic oxygen in the upper atmosphere deduced from OGO 6 airglow observations, J. Geophys. Res., 78, 6662 $6689,1973$.

Evans, J. V. and J. Holt, Observations of F-region vertical velocities at Millstone Hill, determination of altitude distribution of $\mathrm{H}^{+}$, Radio Science, $6,855-862,1971$.

Evans, J. V., J. E. Salah and R. H. Wand, Studies of the upper atmosphere and ionosphere at Millstone Hill, April 1974 March 1976, Progress report submitted to the National Science Foundation by Lincoln Laboratory, 1976. 
Fedder, J. A. and P. M. Banks, Convection electric fields and polar thermospheric winds, J. Geophys. Res., 77, 2328 2340,1972 .

Fontanari, J., Analyse de la température neutre observée par diffusion incohérente dans la basse thermosphère, Ph. $D_{\text {co. }}$ thesis, Université Paul Sabatier, Toulouse, France, 1973.

Fontanari, J. and D. Alcayde, Observation of neutral temperature tidal-type oscillations in the Fl-region, Radio Science, $\underline{9}$, $275-280,1974$.

Francis, S. H., Acoustic-gravity modes and large-scale traveling - ionospheric disturbances of a realistic dissipative atmosphere, J. Geophys. Res., 78, 2278, 1973a.

Francis, S. H., Lower atmospheric gravity modes and their relation to medium scale traveling ionospheric disturbances, J. Geophys. Res., $\underline{78}, 8289,1973 \mathrm{~b}$.

Friedman, J. P., Propagation of internal gravity waves in a thermally stratified atmosphere, J. Geophys. Res., 71, 1033, 1966.

Georges, T. M., HF-Doppler studies of travelling ionospheric disturbances, J. Atmos. Terr. Phys., 30, 735, 1968.

Goldberg, L., R. W. Noyes, W. H. Parkinson, E. M. Reeves, and G. L. Withbroe, Science, 162, 95, 1968.

Haerendel, G., Paper presented at International Symposium on Solar Terrestrial Physics, Leningrad, U.S.S.R, 1970.

Hedin, A. E., H. G. Mayr, C. A. Reber, N. W. Spencer, and G. R. Carignan, Emperical model of global thermospheric temperature and composition based on data from the OGO-6 quadrupole mass spectrometer, J. Geophys. Res., 79, $215-225,1974$.

Hedin, A. E., J. E. Salah $\mu$ J. V. Evans, C. A. Reber, G. P. Newton, N. W. Spencer, D. C. Kayser, D. Alcaydé, P. Bauer, L. Cogger, and J. P. McClure, A global thermospheric model based on mass spectrometer and incoherent scatter data, $1, \mathrm{~N}_{2}$ density and temperature, J. Geophys. Res., 82, 2148, 1977. 
Heppner, J. P., J. D. Stolarik, and E. M. Westcott, Electric field measurements and the identification of currents causing magnetic disturbances in the polar cap, J. Geophys. Res., 76, $6028,1971$.

Heppner, J. P., Electric field variations during substorms: OGO-6 measurements, Planet. Space Sci., 20, 1475, 1972.

Hines, C. O., Interval atmospheric gravity waves at ionospheric heights, Can. Jour. of Phys., 38, 1441-1481, 1960.

Hines, C. O., Dynamical heating of the upper atmosphere, J.Geophys. Res., 70, 177-183, 1965.

Hinteregger, H. E. and L. A. Hall, Solar XUV radiation and neutral particle distribution in July, 1963, thermosphere, Space Research V, North-Holland Pub. Co., Amsterdam, 1175, 1965.

Hinteregger, H. E., The extreme ultraciolet solar spectrum and its variation during a solar cycle, Annls. Geophys., 26, $547,1970$.

Houghton, J. T., Absorption and emission by carbon dioxide in the mesosphere, Quart. J. R. Met. Soc., 95, 1-21, 1969.

Huffman, R. E., Absorption cross sections of atmospheric gases for use in aeronomy, Can. J. Chem., 47, 1823-1834, 1969.

Jacchia, L. G., Influence of solar activity on the earth's upper atmosphere, Planet. Space Sci., 12, 355, 1964.

Jacchia, I. G., Static diffusion models of the atmosphere with emperical temperature profiles, Smithsonian Contr. Astrophys., $8,215,1965$.

Jacchia, L. G., Revised static models of the thermosphere and exosphere with emperical temperature profiles, Obs. Spec. Rep. 332, Smithson. Astrophys. Obs., Cambridge, Mass., 1971.

Justus, C. G. and H. D. Edwards, Tables of observed winds in the 70 to $170 \mathrm{~km}$ region of the upper atmosphere, Georgia Tech Projects: A-434, A-626, A-652, A-722, B-204, B-205, July 1965. 
Kent, G. S., Measurement of ionospheric movements, Rev. Geophys. and Space Phys., 8, 229, 1970.

Klostermeyer, J., Thermospheric heating by atmospheric gravity waves, J. Atmos. Terr. Phys., 35, 2267-2274, 1973.

Kochanski, A., Atmospheric motions from sodium cloud drifts, * J. Geophys. Res., 69, 3651-3662, 1964.

Kockarts, G. and W. Peetermans, Atomic oxygen infrared emission in the earth's upper atmosphere, Planet. Space Sci., $18,271,-1970$.

Kockarts, G., Neutral atmosphere modeling, in Atmospheres of Earth and the Planets, B. M. McCormac, Ed., D. Reidel Pub. Co., Boston, 1975.

Kockarts, G., Private communication, 1976.

Kohl, H., Winds and electric fields in the upper atmosphere, in Atmospheres of Earth and the Planets, B. M. McCormac, Ed., D. Reidel Pub. Co., Boston, 1975.

Lindzen, R. S. and D. Blake, Mean heating of the thermosphere by tides, J. Geophys, Res., 75, 6868, 1970.

Lindzen, R. S. and S. Hong, Effects of mean winds and horizontal temperature gradients on solar and lunar semidiurnal tides in the atmosphere, J.. Atmos. Sci., 31, 1421-1446, 1974.

Lloyd, K. H., C. H. Low, B. J. McAvaney, D. Rees, and R. G. Roper, Thermospheric observations combining chemical seeding and ground based techniques - I. Winds, turbulence and the parameters of the neutral atmosphere, Planet. Space Sci., 20, 761, 1972.

Maeda, H., Neutral winds and ion drifts in the polar ionosphere caused by convection electric fields - 1, J. Atmos. Terr. Phys., 38, 197-205, 1976.

Manring, E., J. Bedinger, H. Knaflich, and D. Layzer, An experimentally determined model for the periodic character of winds from 85 to $135 \mathrm{~km}$, NASA Contractor Report CR-36, 1964.

Meriwether, J. W., J. P. Heppner, J. D. Stolarik, and E. M. Wescott, Neutral winds above $200 \mathrm{~km}$ at high latitudes, J. Geophys. Res., 78, 6643-6661, 1973 . 
Montgomery, J. B., III, G. G. Justus and H. D. Edwards, Winds observed from November 1965 through December 1967 in the 70 to $230 \mathrm{~km}$ region of the upper atmosphere, AFCRL Report No. 68-0503, September, 1968.

Mozer, F. S., Power spectre of the magnetospheric electric field,

- J. Geophys. Res., 76, 3651, 1971.

Nagy, A. F., R. J. Acerone, P. B. Hays, D. D. McWatters, and J. W. Meriwether, Simultaneous measurement of ion and neutral motions by radar and optical techniques, Radio Science, 9, 315-321, 1974.

Newton, G. P., D. T. Pelz, and H. Volland, Direct in-situ measurements of wave propagation in the neutral thermosphere, J. Geophys. Res., 74, 183-195, 1969.

Nielsen, H., Private communication, 1976.

Nisbet, J. S. and D. A. Glenar, Thermospheric meridional winds and atomic oxygen depletion at high latitudes, accepted for publication in Journal of Geophysical Research, 1977.

Nisbet, J. S., B. J. Wydra, C. A. Reber, and J. M. Iuton, Global exospheric temperatures and densities under active solar conditions, Planet. Space Sci. , 25, 59-69, 1977.

Parkinson, W. H. and E. M. Reeves, Measurements in the solar spectrum between 1400 and $1875 \mathrm{~A}$ with a rocket-borne spectrometer, Solar Physics, 10, 342-347, 1969.

Poloskov, S. M., G. F. Toulinov, J. E. Blamont, M. L. Chanin, and M. Maillard, Mesure de la temperature de la haute atmosphere dans la region polaire, Annls. Geophys., 25, 444, 1969.

Prasad, S. S. and D. R. Furman, Is there a real need for doubling the solar EUV fluxes?, J. Geophys. Res., 79, 2463-2468, 1974.

Rees, D., Upper atmosphere neutral temperature profiles in the auroral zone, Planet. Space Sci., 19, 233, 1971.

Rees, D., Ionospheric winds in the auroral zone, J. Brit. Interplanet. Soc., 24, 233, 1971. 
Rees, D., R. G. Roper, K. H. Lloyd, and C. H. Low, Determination of the structure of the atmosphere between 90 and $250 \mathrm{~km}$ by means of contaminant releases at Woomera, May 1968, Philosophical Transactions of the Royal Society of London, A. Mathematical and Physical Sciences, 271, 631, 1972.

Richmond, A. D., Tidal winds at ionospheric heights, Radio Science, $\underline{6}, 175-189,1971$.

Rishbeth, H., Thermospheric winds and the $F$ region: A review, J. Atmos. Terr. Phys., 34, 1-47, 1972.

Roble, R. G. and R. E. Dickinson, Is there enough solar extreme ultraviolet radiation to maintain the global mean thermospheric temperature?, J. Geophys. Res., 78, 249-257, 1973.

Rohrbaugh, J. L., Neutral atmospheric models compatible with satellite orbital decay and incoherent scatter measurements, The Pennsylvania State University, Ionospheric Research Scientific Report No. 402, 1972.

Roper, R. G. and H. D. Edwards, Winds observed from May 1971 through October 1972 in the 77 to $194 \mathrm{~km}$ altitude region, AFCRI Report No.TR-74-0537, October, 1974.

Rosenberg, N. W. and H. D. Edwards, Observation of ionospheric wind patterns through the night, J. Geophys. Res., 69, $2819,1964$.

Salah, J. E., A study of the mid-latitude thermosphere by incoherent scatter radar, $\mathrm{Ph}$. D. thesis, Mass. Inst. of Technol., Cambridge, 1972.

Salah, J. E. and J. V. Evans, Measurements of thermospheric temperatures by incoherent scatter radar, Space Research XIII, Akademie-Verlag, Berlin, 1973

Salah, J. E., Daily Oscillations of the mid-latitude thermosphere studied by incoherent scatter at Millstone Fill, J. Atmos. Terr. Phys., 36, 1891, 1974.

Salah, J. E. and R. H. Wand, Tides in the temperature of the lower thermosphere at mid-latitudes, J. Geophys. Res., 79, 4295-4304, 1974.

Salah, J. E., R. H. Wand, and J. V. Evans, Tidal effects in the E-region from incoherent scatter radar observations, Radio Science, 10, 347, 1975 
Schoen, R. L., Laboratory measurements of photoionization, photoexcitation, and photo-detachment, Can. J. Chem., 47, $1879-1899,1969$.

Scialom, G., Neutral composition in the lower thermosphere, Radio Science, 9, 253-261, 1974.

Smith, W. S., J. S. Theon, P. C. Swartz, L. B. Katchen, and J. J. Horvath, Temperature, pressure, density, and wind measurements in the upper stratosphere and mesosphere, 1965, NASA Technical Report, NASA'TR R-263, 1967.

Smith, W. S., J. S. Theon, P. C. Swartz, J. F. Casey, and J. J. Horvath, Temperature, pressure, density, and wind measurements in the stratosphere and mesosphere, 1967, NASA Technical Report, NASA TR R-316, 1969.

Stair, A. T. and J. C. Ulwick, Altitude profiles of infrared radiance of $\mathrm{O}_{3}(9.6 \mu \mathrm{m})$ and $\mathrm{CO}_{2}(15 \mu \mathrm{m})$, Geophysical Research Letters, $1,117,1974$.

Stubbe, P., The thermosphere and the F-region - A reconciliation of theory with observations, The Pennsylvania State University, Ionospheric Research Scientific Report No. 418, 1973.

Swartz, W. E. and J. S. Nisbet, Diurnal variation of the neutral temperature profile at Arecibo from incoherent scatter measurements and its relevance to the 1400-hour density maximum, J. Geophys. Res., 76, 185-196, 1971.

Swartz, W. E., Electron production, recombination and heating in the F-region of the ionosphere, The Pennsylvania State University, Ionospheric Research Scientific Report No. 381, 1972.

Swartz, W. E., J. L. Rohrbaugh and J. S. Nisbet, The global energy budget of the thermosphere, Space Research XII, North-Holland Pub. Co., Amsterdam, 993-999, 1972.

Swartz, W. E. and J. S. Nisbet, Incompatibility of solar EUV fluxes and incoherent scatter measurements at Arecibo, J. Geophys. Res., 78, 5640-5657, 1973.

Testud, J. and G. Vasseur, Ondes de gravité dans la thermosphère, Annls. Géophys., 25, 525-546, 1969.

Testud, J., Gravity waves generated during magnetic substorms, J. Atmos. Terr. Phys., 32, 1793-1805, 1970. 
Thome, G. D., Incoherent scatter observations of traveling ionospheric disturbances, J. Geophys. Res., 69, 4047, 1964.

Thuillier, G., J. L. Falin, and C. Wachtel, XIX Meeting of COSPAR, Philadelphia, Pa., Paper IV. A. 3.8, June, 1976.

U. S. Standard Atmosphere Supplements, Environmental Science Services Administration, NASA, USAF, 1966.

Volland, H., A theory of thermospheric dynamics-I, Planet. Space Sci., 17, 1581, 1969.

Whiting, K. G. and E. M. Purcell, Personal communication with the author, 1969.

Whiting, K. G., J. D. Purcell, and G. D. Sandlin, The UV continuum 1450-2100 A and the problem of the solar temperature minimum, Solar Physics, 12, 52-62, 1970.

Wiese, W. L., M. W. Smith, and B. M. Glennon, Atomic transition probabilities, Hydrogen through neon, 1, 153, National Standard Reference Data System, Washington.

Zimmerman, S. P., Small-scale wind structure above $100 \mathrm{~km}$, J. Geophys. Res., 69, 784, 1964. 


\section{APPENDIX A: BOUNDARY CONDITIONS FROM ARECIBO AND ST. SANTIN}

Tables A.1 and A.2 list the temperature parameters and 120 $\mathrm{km}$ densities used in this study. The results in Table A.1 were derived from 18 days of observations at Arecibo between August, 1974 and November, 1976. The data in Table A.2 were obtained from the St. Santin facility between August, 1969 and June, 1970. 
Table A.1. Arecibo Boundary Conditions

\begin{tabular}{|c|c|c|c|c|c|c|c|c|c|c|}
\hline \multirow[b]{2}{*}{ Date } & \multirow[b]{2}{*}{ Season } & \multirow[b]{2}{*}{ L.S.T. } & \multirow[b]{2}{*}{$\mathrm{Kp}^{+}$} & \multirow[b]{2}{*}{$F_{10.7}$} & \multicolumn{3}{|c|}{ Temperature Parameters } & \multicolumn{3}{|c|}{$120 \mathrm{~km}$ Densities $\left(\mathrm{M}^{-3}\right)$} \\
\hline & & & & & $\mathrm{T}_{120}$ & $\mathrm{~T}_{\infty}$ & $\mathrm{S}$ & $\mathrm{n}\left(\mathrm{O}_{2}\right)$ & $\mathrm{n}\left(\mathrm{N}_{2}\right)$ & $\mathrm{n}(0)$ \\
\hline Aug. 12,1974 & Summer & $\begin{array}{r}6.40 \\
6.77 \\
7.14 \\
7.57 \\
17.09 \\
17.46 \\
17.83 \\
18.26\end{array}$ & 1.0 & 97 & $\begin{array}{l}264 \\
266 \\
300 \\
315 \\
304 \\
307 \\
310 \\
284\end{array}$ & $\begin{array}{l}779 \\
772 \\
781 \\
785 \\
922 \\
967 \\
986 \\
920\end{array}$ & $\begin{array}{l}.02188 \\
.04685 \\
.04424 \\
.06208 \\
.02338 \\
.02950 \\
.01774 \\
.02678\end{array}$ & $\begin{array}{l}5.51 \times 10^{16} \\
4.80 \\
4.68 \\
3.56 \\
4.37 \\
6.68 \\
3.12 \\
1.26 \times 10^{17}\end{array}$ & $\begin{array}{l}3.86 \times 10^{17} \\
3.36 \\
3.27 \\
2.49 \\
3.06 \\
4.67 \\
2.19 \\
8.81\end{array}$ & $\begin{array}{l}1.72 \times 10^{17} \\
9.92 \times 10^{16} \\
8.49 \\
7.06 \\
1.17 \times 10_{16}^{17} \\
7.99 \times 10_{17}^{17} \\
1.12 \times 10^{17} \\
1.04\end{array}$ \\
\hline Aug. 14, 1974 & Summer & $\begin{array}{r}5.85 \\
6.28 \\
6.65 \\
7.02 \\
17.11 \\
17.48 \\
17.85\end{array}$ & 0.7 & 91 & $\begin{array}{l}357 \\
334 \\
335 \\
319 \\
367 \\
366 \\
354\end{array}$ & $\begin{array}{l}795 \\
758 \\
850 \\
809 \\
875 \\
909 \\
972\end{array}$ & $\begin{array}{l}.01789 \\
.02550 \\
.01234 \\
.02497 \\
.03753 \\
.02803 \\
.01412\end{array}$ & $\begin{array}{l}1.17 \times 10^{16} \\
2.65 \\
2.11 \\
4.08 \\
2.54 \\
5.83 \\
5.85\end{array}$ & $\begin{array}{l}8.21 \\
1.86 \\
1.47 \\
2.85 \\
1.78 \\
4.08 \\
4.09\end{array}$ & $\begin{array}{l}9.15 \times 10^{16} \\
9.62 \\
1.35 \times 10^{17} \\
9.15 \times 10^{16} \\
6.79 \\
6.89 \\
1.03 \times 10^{17}\end{array}$ \\
\hline Sept. 17,1974 & Summer & $\begin{array}{r}6.29 \\
6.65 \\
7.09 \\
7.46 \\
7.83 \\
15.75 \\
16.12 \\
16.55 \\
16.92 \\
17.29 \\
17.72\end{array}$ & 0.7 & 99 & $\begin{array}{l}364 \\
387 \\
359 \\
337 \\
339 \\
347 \\
330 \\
309 \\
277 \\
291 \\
297\end{array}$ & $\begin{array}{r}706 \\
723 \\
728 \\
727 \\
760 \\
964 \\
996 \\
1004 \\
998 \\
979 \\
1012\end{array}$ & $\begin{array}{l}.04931 \\
.02182 \\
.04618 \\
.04892 \\
.03832 \\
.03563 \\
.02502 \\
.02114 \\
.02326 \\
.02593 \\
.01578\end{array}$ & $\begin{array}{l}8.02 \\
6.82 \\
7.00 \\
7.37 \\
6.30 \\
5.38 \\
5.30 \\
7.13 \\
8.53 \\
5.89 \\
8.52\end{array}$ & $\begin{array}{l}5.62 \\
4.78 \\
4.90 \\
5.16 \\
4.41 \\
3.76 \\
3.71 \\
4.99 \\
5.97 \\
4.12 \\
5.97\end{array}$ & $\begin{array}{l}1.00 \times 10^{17} \\
1.26 \\
9.97 \times 10^{16} \\
1.12 \times 10^{17} \\
1.09 \\
7.53 \times 10^{16} \\
9.17 \\
1.13 \times 10^{17} \\
1.25 \\
1.06 \\
1.46\end{array}$ \\
\hline
\end{tabular}

+ Average of three values preceding measurement. 
Table A.1. (Continued)

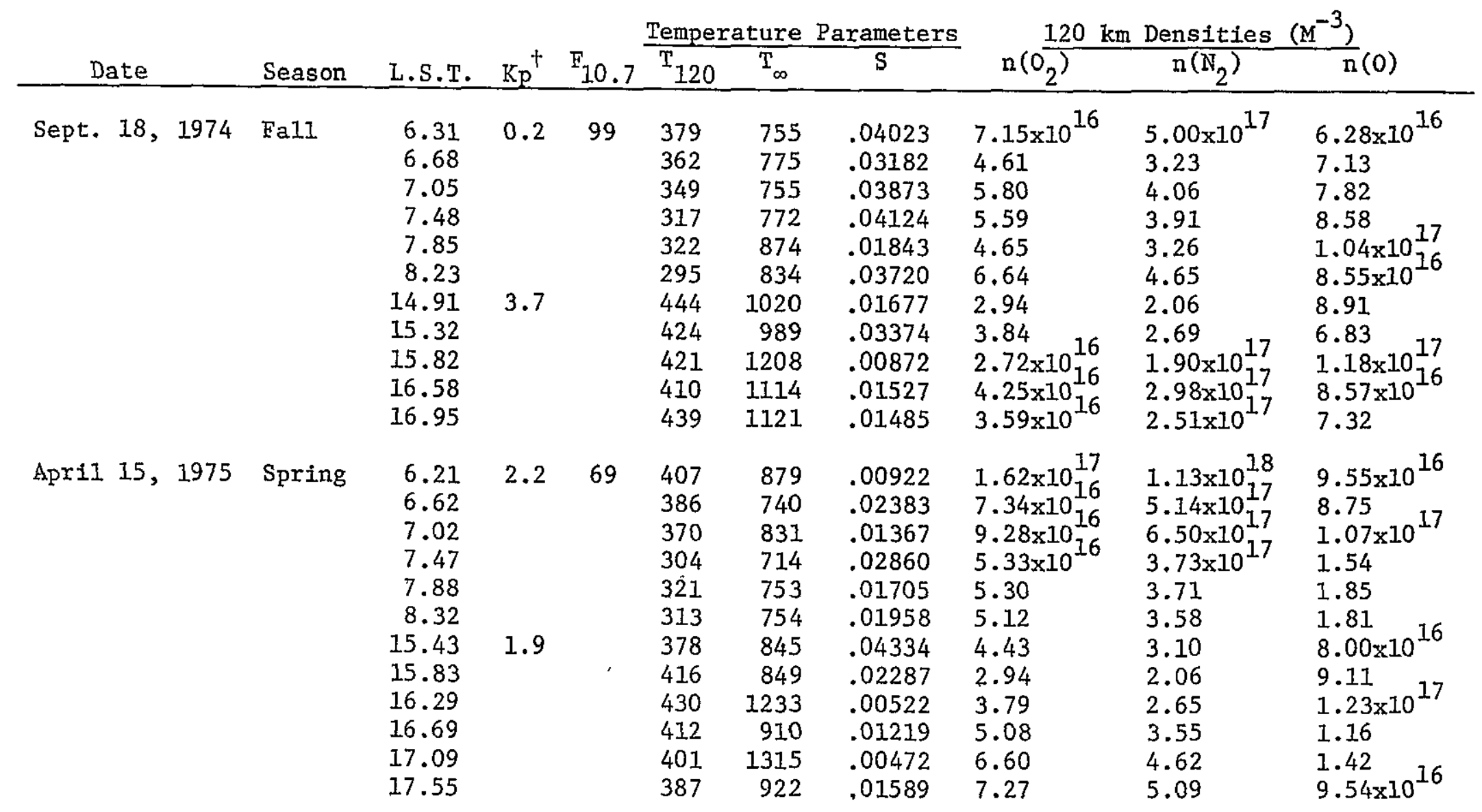

+ Average of three values preceding measurement. 
Table A.1. (Continued)

\begin{tabular}{|c|c|c|c|c|c|c|c|c|c|c|}
\hline \multirow[b]{2}{*}{ Date } & \multirow[b]{2}{*}{ Season } & \multirow[b]{2}{*}{ L.S.T. } & \multirow[b]{2}{*}{$\mathrm{K}_{\mathrm{p}}^{\dagger}$} & \multicolumn{4}{|c|}{ Temperature Parameters } & \multicolumn{3}{|c|}{$120 \mathrm{~km}$ Densities $\left(\mathrm{M}^{-3}\right)$} \\
\hline & & & & $\mathrm{F}_{10.7}$ & $\mathrm{~T}_{120}$ & $\mathrm{~T}_{\infty}$ & $\mathrm{S}$ & $\mathrm{n}\left(\mathrm{O}_{2}\right)$ & $\mathrm{n}\left(\mathrm{N}_{2}\right)$ & $\bar{n}(0)$ \\
\hline Apri1 16, 1975 & Spring & $\begin{array}{r}6.15 \\
6.56 \\
6.96 \\
7.41 \\
7.82 \\
8.22 \\
15.45 \\
15.85 \\
16.31 \\
16.72 \\
17.11\end{array}$ & 1.0 & 69 & $\begin{array}{l}432 \\
396 \\
389 \\
406 \\
397 \\
366 \\
347 \\
353 \\
368 \\
359 \\
370\end{array}$ & $\begin{array}{l}769 \\
685 \\
902 \\
863 \\
778 \\
755 \\
932 \\
891 \\
961 \\
882 \\
969\end{array}$ & $\begin{array}{l}.00819 \\
.02089 \\
.00826 \\
.00797 \\
.01846 \\
.03768 \\
.01457 \\
.02396 \\
.01244 \\
.01882 \\
.01165\end{array}$ & $\begin{array}{l}1.18 \times 10^{17} \\
3.02 \times 10^{16} \\
5.78 \\
3.89 \\
5.35 \\
6.65 \\
4.97 \\
5.07 \\
4.59 \\
5.23 \\
3.77\end{array}$ & $\begin{array}{l}8.23 \times 10^{17} \\
2.11 \\
4.05 \\
2.73 \\
3.75 \\
4.66 \\
3.48 \\
3.55 \\
3.21 \\
3.66 \\
2.64\end{array}$ & $\begin{array}{l}1.25 \times 10^{17} \\
1.18 \\
1.21 \\
1.29 \\
9.32 \times 10^{16} \\
8.30 \\
1.37 \times 10^{17} \\
9.45 \times 10^{16} \\
1.22 \times 10^{17} \\
1.08 \\
1.18\end{array}$ \\
\hline May 22,1975 & Summer & $\begin{array}{r}6.21 \\
6.61 \\
7.01 \\
7.60 \\
8.00 \\
8.40 \\
15.30 \\
15.70 \\
16.56 \\
16.96 \\
17.42\end{array}$ & 2.2 & 69 & $\begin{array}{l}385 \\
393 \\
369 \\
363 \\
360 \\
352 \\
347 \\
350 \\
408 \\
409 \\
402\end{array}$ & $\begin{array}{l}739 \\
914 \\
787 \\
788 \\
794 \\
810 \\
910 \\
880 \\
869 \\
956 \\
953\end{array}$ & $\begin{array}{l}.02725 \\
.00792 \\
.02852 \\
.01902 \\
.03745 \\
.02025 \\
.03297 \\
.03107 \\
.02728 \\
.01192 \\
.01273\end{array}$ & $\begin{array}{l}4.32 \\
4.25 \\
5.52 \\
3.78 \\
3.70 \\
3.76 \\
3.93 \\
3.16 \\
4.92 \\
3.59 \\
4.03\end{array}$ & $\begin{array}{l}3.02 \\
2.98 \\
3.86 \\
2.64 \\
2.59 \\
2.63 \\
2.75 \\
2.21 \\
3.45 \\
2.51 \\
2.82\end{array}$ & $\begin{array}{l}7.05 \times 10_{17}^{16} \\
1.04 \times 10_{16}^{17} \\
6.42 \times 10^{16} \\
9.33 \\
6.28 \\
9.61 \\
8.38 \\
9.31 \\
7.65 \\
1.05 \times 10^{17} \\
1.00\end{array}$ \\
\hline
\end{tabular}

† Average of three values preceding measurement. 
Table A.1. (Continued)

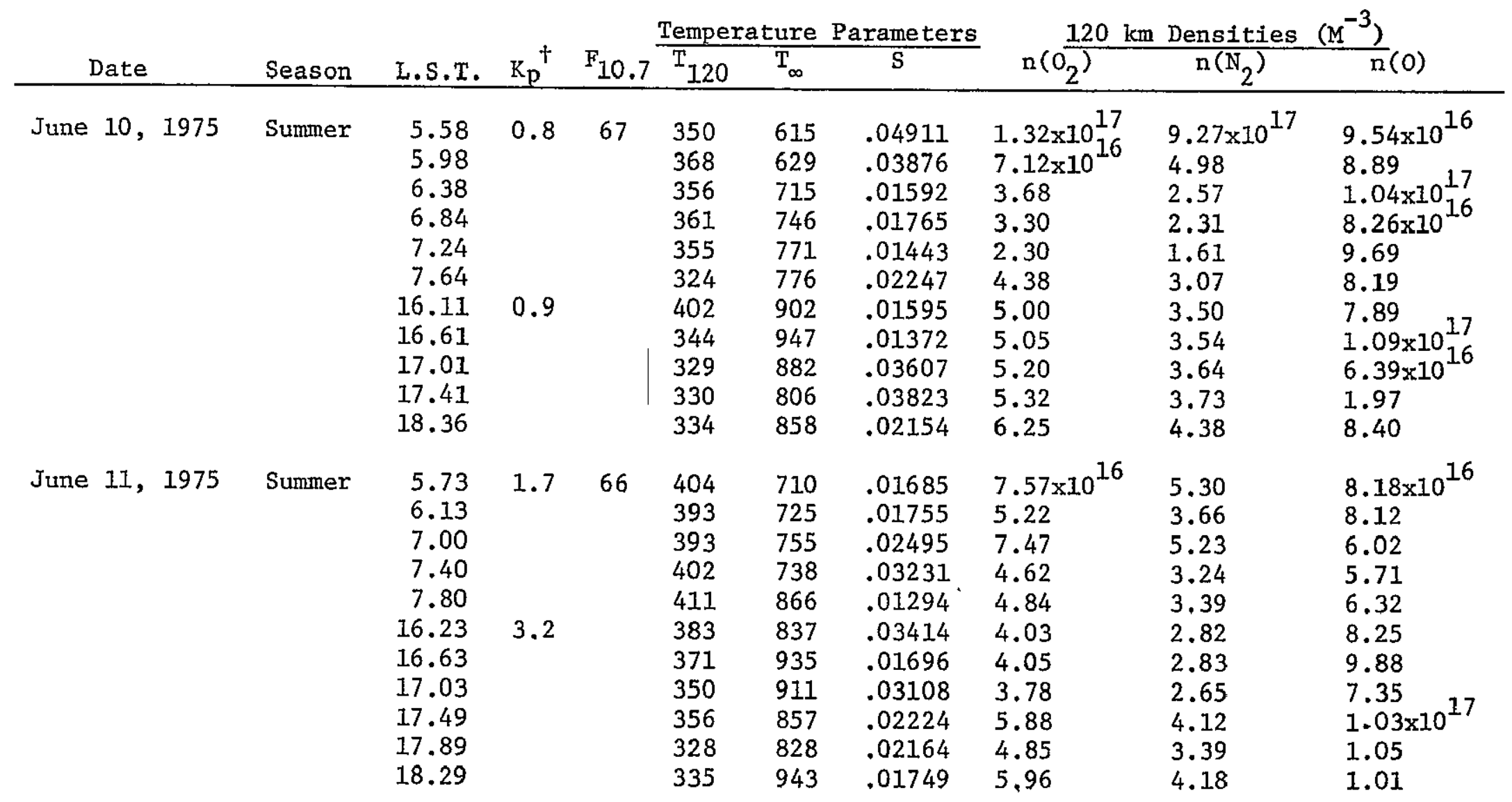

t Average of three values preceding measurement. 
Table A.1. (Continued)

\begin{tabular}{|c|c|c|c|c|c|c|c|c|c|c|}
\hline \multirow[b]{2}{*}{ Date } & \multirow[b]{2}{*}{ Season } & \multirow[b]{2}{*}{ L.S.T. } & \multirow[b]{2}{*}{$\mathrm{Kp}^{\dagger}$} & \multicolumn{3}{|c|}{ Temperature } & Parameters & \multicolumn{3}{|c|}{$120 \mathrm{~km}$ Densities $\left(\mathrm{M}^{-3}\right)$} \\
\hline & & & & $F_{10.7}$ & 120 & $I_{\infty}$ & & $\mathrm{n}\left(\mathrm{O}_{2}\right)$ & $\pi\left(N_{2}\right)$ & \\
\hline Oct. 14,1975 & Fal1 & $\begin{array}{r}7.07 \\
7.48 \\
7.89 \\
8.39 \\
9.04 \\
9.45 \\
15.04 \\
15.73 \\
16.13 \\
16.54 \\
17.04\end{array}$ & 2.7 & 80 & $\begin{array}{l}414 \\
405 \\
390 \\
383 \\
379 \\
360 \\
348 \\
349 \\
317 \\
318 \\
303\end{array}$ & $\begin{array}{l}695 \\
703 \\
719 \\
749 \\
778 \\
799 \\
911 \\
887 \\
927 \\
865 \\
943\end{array}$ & $\begin{array}{l}.04568 \\
.04098 \\
.04373 \\
.03292 \\
.02637 \\
.03189 \\
.02989 \\
.02651 \\
.02262 \\
.02837 \\
.01648\end{array}$ & $\begin{array}{l}4.65 \times 10^{16} \\
6.24 \\
9.25 \\
6.11 \\
3.81 \\
7.75 \\
1.01 \times 10^{17} \\
7.97 \times 10^{16} \\
4.87 \\
9.19 \\
7.08\end{array}$ & $\begin{array}{l}3.26 \times 10^{17} \\
4.37 \\
6.48 \\
4.28 \\
2.67 \\
5.42 \\
7.05 \\
5.58 \\
3.41 \\
6.43 \\
4.96\end{array}$ & $\begin{array}{l}8.06 \times 10^{16} \\
8.61 \\
8.59 \\
9.18 \\
1.00 \times 10^{17} \\
9.49 \times 10 \\
1.08 \times 10^{17} \\
1.23 \\
1.42 \\
1.43 \\
1.91\end{array}$ \\
\hline Jan. 20,1976 & Winter & $\begin{array}{r}6.64 \\
7.90 \\
8.30 \\
15.11 \\
15.51 \\
15.91 \\
16.37 \\
16.77 \\
17.17\end{array}$ & 2.6 & 77 & $\begin{array}{l}399 \\
363 \\
352 \\
321 \\
342 \\
387 \\
384 \\
410 \\
441\end{array}$ & $\begin{array}{l}705 \\
698 \\
658 \\
846 \\
829 \\
813 \\
810 \\
837 \\
956\end{array}$ & $\begin{array}{l}.01591 \\
.01906 \\
.03828 \\
.03970 \\
.05690 \\
.04253 \\
.04884 \\
.02063 \\
.01021\end{array}$ & $\begin{array}{l}1.15 \times 10^{17} \\
4.10 \times 10^{16} \\
5.48 \\
3.53 \\
3.02 \\
3.34 \\
4.06 \\
5.44 \\
7.02\end{array}$ & $\begin{array}{l}8.04 \\
2.87 \\
3.83 \\
2.47 \\
2.11 \\
2.33 \\
2.84 \\
3.81 \\
4.91\end{array}$ & $\begin{array}{l}1.20 \times 10^{17} \\
1.55 \\
1.43 \\
9.63 \times 10^{16} \\
7.89 \\
7.69 \\
7.30 \\
8.74 \\
8.64\end{array}$ \\
\hline
\end{tabular}

+ Average of three values preceding measurement. 
Table A.1. (Continued)

\begin{tabular}{|c|c|c|c|c|c|c|c|c|c|c|}
\hline Date & Season & L.S.T. & $\mathrm{K}_{\mathrm{p}}^{+}$ & $F_{10.7}$ & $\begin{array}{r}\text { Tempe } \\
\mathrm{T}_{120} \\
\end{array}$ & $\frac{\text { ture }}{\mathrm{T}_{\infty}}$ & $\frac{\text { arameters }}{\mathrm{S}}$ & $\mathrm{n}\left(\mathrm{O}_{2}\right)$ & $\frac{\text { Densities }}{\mathrm{n}\left(\mathrm{N}_{2}\right)}$ & $\frac{\left.M^{-3}\right)}{n(0)}$ \\
\hline Jan. 21, 1976 & Winter & $\begin{array}{r}6.81 \\
8.08 \\
8.48 \\
14.57 \\
14.97 \\
15.43 \\
15.83 \\
16.23\end{array}$ & $\begin{array}{l}3.5 \\
3.7\end{array}$ & 75 & $\begin{array}{l}451 \\
397 \\
381 \\
332 \\
416 \\
413 \\
411 \\
399\end{array}$ & $\begin{array}{l}765 \\
718 \\
725 \\
839 \\
876 \\
875 \\
999 \\
902\end{array}$ & $\begin{array}{l}.00964 \\
.02208 \\
.02844 \\
.06093 \\
.02910 \\
.02446 \\
.01138 \\
.01957\end{array}$ & $\begin{array}{l}5.42 \times 10^{16} \\
3.93 \\
5.34 \\
4.72 \\
3.14 \\
3.46 \\
3.50 \\
3.35\end{array}$ & $\begin{array}{l}3.79 \times 10^{17} \\
2.75 \\
3.73 \\
3.31 \\
2.20 \\
2.42 \\
2.45 \\
2.34\end{array}$ & $\begin{array}{l}1.07 \times 10^{17} \\
1.17 \\
1.10 \\
9.21 \times 10^{16} \\
7.83 \\
8.65 \\
1.09 \times 10^{17} \\
9.42 \times 10^{16}\end{array}$ \\
\hline Mar. 17, 1976 & Spring & $\begin{array}{r}6.32 \\
6.72 \\
7.18 \\
7.58 \\
7.98 \\
14.84 \\
15.25 \\
15.65 \\
16.10 \\
16.51 \\
16.91\end{array}$ & 2.8 & 75 & $\begin{array}{l}432 \\
453 \\
431 \\
416 \\
385 \\
393 \\
392 \\
396 \\
356 \\
362 \\
339\end{array}$ & $\begin{array}{l}686 \\
711 \\
762 \\
790 \\
786 \\
930 \\
872 \\
934 \\
892 \\
901 \\
851\end{array}$ & $\begin{array}{l}.04829 \\
.02206 \\
.01438 \\
.01474 \\
.02764 \\
.01745 \\
.02752 \\
.02122 \\
.03208 \\
.02821 \\
.02866\end{array}$ & $\begin{array}{l}7.11 \\
8.62 \\
1.02 \times 10^{17} \\
7.24 \times 10^{16} \\
1.00 \times 10^{17} \\
5.00 \times 10^{16} \\
4.62 \\
5.27 \\
6.43 \\
7.36 \\
5.41\end{array}$ & $\begin{array}{l}4.98 \\
6.04 \\
7.15 \\
5.07 \\
7.03 \\
3.50 \\
3.24 \\
3.69 \\
4.50 \\
5.15 \\
3.79\end{array}$ & $\begin{array}{l}8.00 \\
8.85 \\
1.06 \times 10^{17} \\
1.07 \\
8.70 \times 10^{16} \\
1.10 \times 10^{17} \\
9.62 \times 10^{16} \\
9.00 \\
9.28 \\
9.22 \\
1.18 \times 10^{17}\end{array}$ \\
\hline
\end{tabular}

+ Average of three values preceding measurement. 
Table A.1. (Continued)

\begin{tabular}{|c|c|c|c|c|c|c|c|c|c|c|}
\hline \multirow[b]{2}{*}{ Date } & \multirow[b]{2}{*}{ Season } & \multirow[b]{2}{*}{ L.S.T. } & \multirow[b]{2}{*}{$\mathrm{Kp}^{+}$} & \multicolumn{3}{|c|}{ Temperature } & Parameters & \multicolumn{3}{|c|}{$120 \mathrm{~km}$ Densities $\left(\mathrm{M}^{-3}\right)$} \\
\hline & & & & $\mathrm{F}_{10.7}$ & $\mathrm{~T}_{120}$ & $\mathrm{~T}_{\infty}$ & $\mathrm{S}$ & $\mathrm{n}\left(\mathrm{O}_{2}\right)$ & $\mathrm{n}\left(\overline{\mathrm{N}}_{2}\right)$ & $\bar{n}(0)$ \\
\hline May 13,1976 & Summer & $\begin{array}{r}5.80 \\
6.21 \\
6.61 \\
7.07 \\
7.47 \\
7.87 \\
15.15 \\
15.55 \\
16.41 \\
16.81 \\
17.27\end{array}$ & 1.9 & 72 & $\begin{array}{l}408 \\
365 \\
369 \\
353 \\
321 \\
295 \\
420 \\
395 \\
372 \\
352 \\
346\end{array}$ & $\begin{array}{l}773 \\
772 \\
823 \\
805 \\
758 \\
766 \\
904 \\
974 \\
909 \\
893 \\
876\end{array}$ & $\begin{array}{l}.01250 \\
.02893 \\
.01888 \\
.02810 \\
.03368 \\
.04037 \\
.01900 \\
.01436 \\
.01459 \\
.01928 \\
.01997\end{array}$ & $\begin{array}{l}7.92 \times 10^{16} \\
5.35 \\
7.03 \\
5.97 \\
8.26 \\
7.85 \\
5.00 \\
5.42 \\
5.37 \\
5.52 \\
6.57\end{array}$ & $\begin{array}{l}5.54 \times 10^{17} \\
3.75 \\
4.92 \\
4.18 \\
5.78 \\
5.50 \\
3.50 \\
3.80 \\
3.76 \\
3.86 \\
4.60\end{array}$ & $\begin{array}{l}8.99 \times 10^{16} \\
6.41 \\
7.07 \\
6.51 \\
8.88 \\
9.29 \\
8.43 \\
9.62 \\
1.26 \times 10^{17} \\
1.12 \\
1.15\end{array}$ \\
\hline Sept. 22, 1976 & Fal1 & $\begin{array}{r}6.63 \\
7.02 \\
7.49 \\
7.89 \\
8.28 \\
8.74 \\
15.26 \\
15.66 \\
16.05 \\
16.52 \\
16.92\end{array}$ & 3.2 & 70 & $\begin{array}{l}323 \\
341 \\
335 \\
320 \\
335 \\
326 \\
432 \\
441 \\
436 \\
428 \\
401\end{array}$ & $\begin{array}{l}816 \\
747 \\
717 \\
725 \\
746 \\
746 \\
780 \\
839 \\
858 \\
885 \\
897\end{array}$ & $\begin{array}{l}.01341 \\
.02066 \\
.02817 \\
.04823 \\
.04226 \\
.04444 \\
.04320 \\
.02716 \\
.02270 \\
.01892 \\
.02466\end{array}$ & $\begin{array}{l}5.78 \\
3.90 \\
4.06 \\
5.09 \\
3.93 \\
3.63 \\
2.62 \\
2.60 \\
3.60 \\
5.41 \\
4.94\end{array}$ & $\begin{array}{l}4.05 \\
2.73 \\
2.84 \\
3.57 \\
2.75 \\
2.54 \\
1.83 \\
1.82 \\
2.52 \\
2.79 \\
3.46\end{array}$ & $\begin{array}{l}1.80 \times 10^{17} \\
1.45 \\
1.46 \\
1.18 \\
1.09 \\
1.18 \\
9.47 \times 10^{16} \\
8.58 \\
8.84 \\
9.16 \\
8.13\end{array}$ \\
\hline
\end{tabular}

+ Average of three values preceding measurement. 
Table A.I. (Continued)

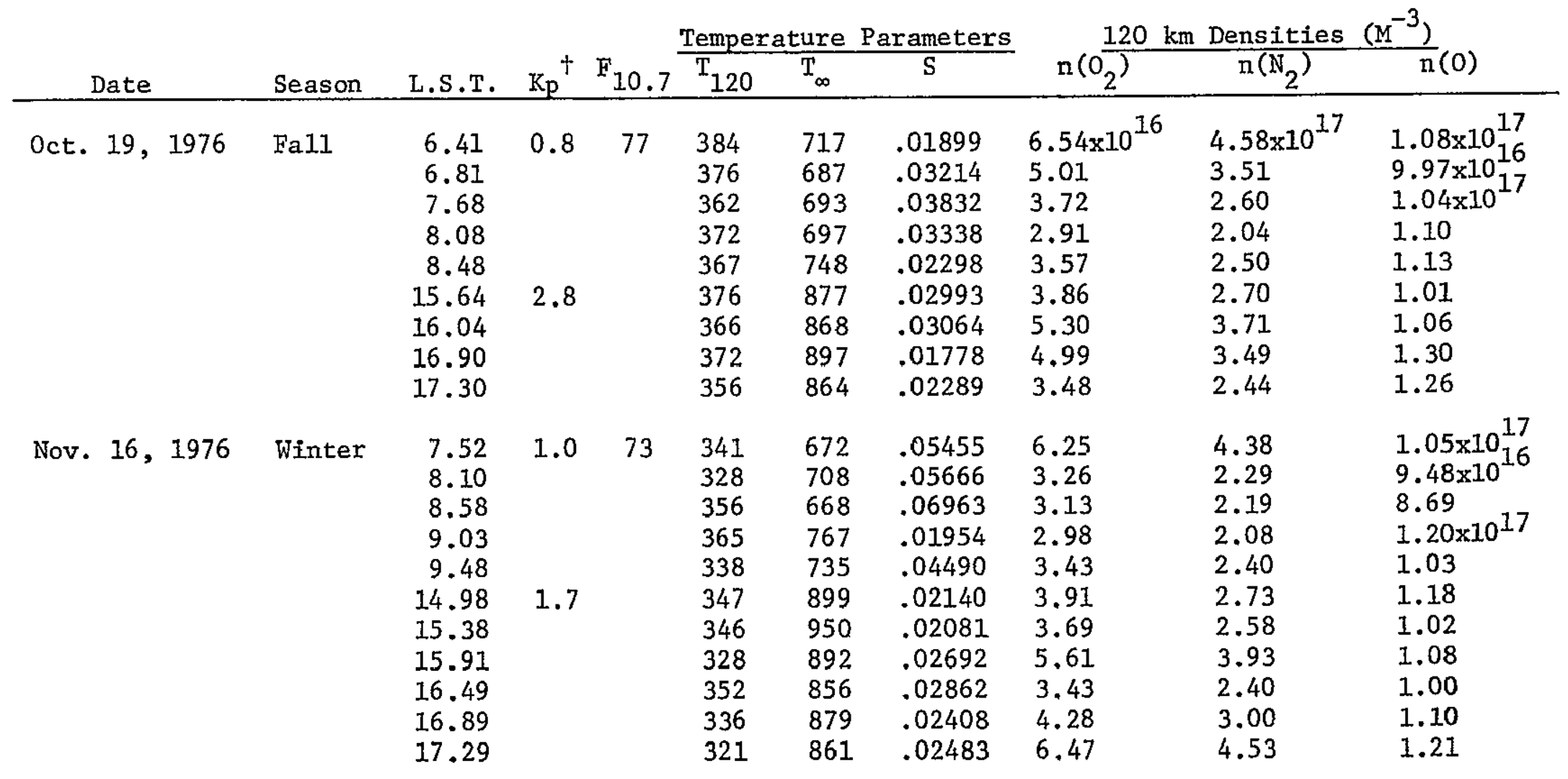

+ Average of three values preceding measurement. 
Table A.1. (Continued)

\begin{tabular}{|c|c|c|c|c|c|c|c|c|c|c|}
\hline \multirow[b]{2}{*}{ Date } & \multirow[b]{2}{*}{ Season } & \multirow[b]{2}{*}{ L.S.T. } & \multirow[b]{2}{*}{$\mathrm{Kp}^{\dagger}$} & \multicolumn{4}{|c|}{ Temperature Parameters } & \multicolumn{3}{|c|}{$120 \mathrm{~km}$ Densities $\left(\mathrm{M}^{-3}\right)$} \\
\hline & & & & $\mathrm{F}_{10.7}$ & $\mathrm{~T}_{120}$ & $T_{\infty}$ & $\mathrm{S}$ & $n\left(\overline{0_{2}}\right)$ & $\mathrm{n}\left(\mathrm{N}_{2}\right)$ & $\mathrm{n}(0)$ \\
\hline Nov. 17,1976 & Winter & $\begin{array}{r}6.90 \\
7.37 \\
7.77 \\
8.16 \\
9.01 \\
9.80 \\
14.96 \\
15.36 \\
15.83 \\
16.23 \\
16.62 \\
17.08\end{array}$ & 1.3 & 75 & $\begin{array}{l}392 \\
360 \\
370 \\
369 \\
396 \\
377 \\
336 \\
330 \\
314 \\
318 \\
364 \\
311\end{array}$ & $\begin{array}{r}753 \\
711 \\
736 \\
721 \\
771 \\
777 \\
866 \\
858 \\
844 \\
821 \\
1000 \\
929\end{array}$ & $\begin{array}{l}.01797 \\
.06276 \\
.05167 \\
.04695 \\
.02755 \\
.02312 \\
.02804 \\
.02640 \\
.03667 \\
.04185 \\
.00973 \\
.01808\end{array}$ & $\begin{array}{l}4.17 \times 10^{16} \\
3.18 \\
3.55 \\
3.90 \\
3.39 \\
4.35 \\
3.74 \\
4.65 \\
4.32 \\
5.05 \\
2.32 \\
3.27\end{array}$ & $\begin{array}{l}2.92 \times 10^{17} \\
2.23 \\
2.49 \\
2.73 \\
2.37 \\
3.05 \\
2.62 \\
3.26 \\
3.02 \\
3.54 \\
1.03 \\
2.29\end{array}$ & $\begin{array}{l}1.07 \times 10^{17} \\
8.08 \times 10^{16} \\
7.98 \\
9.37 \\
9.22 \\
1.21 \times 10^{17} \\
1.11 \\
1.21 \\
1.10 \\
1.07 \\
1.54 \\
1.33\end{array}$ \\
\hline
\end{tabular}

+ Average of three values preceding measurement, 
Table A.2. St. Santin Boundary Conditıons

\begin{tabular}{|c|c|c|c|c|c|c|c|c|c|}
\hline Date & Season & $\begin{array}{l}\text { L.S.T. } \\
\text { SR/SS }\end{array}$ & $\mathrm{K}_{\mathrm{p}}^{+}$ & $\mathrm{F}_{10.7}$ & \multicolumn{2}{|c|}{$\begin{array}{l}\text { Temperature } \\
\text { Parameters } \\
\end{array}$} & \multicolumn{3}{|c|}{$120 \mathrm{~km}$ Densities $\left(M^{-3}\right)$} \\
\hline Aug. 26, 1969 & $\begin{array}{l}\text { Fal1 \& } \\
\text { Summer }\end{array}$ & $\begin{array}{r}5.30 \\
18.70\end{array}$ & $\begin{array}{l}1.2 \\
2.4\end{array}$ & 153 & $\begin{array}{l}398 \\
428\end{array}$ & $\begin{array}{l}1025 \\
1170\end{array}$ & $\begin{array}{l}4.11 \times 10^{16} \\
7.34 \times 10^{16}\end{array}$ & $\begin{array}{l}2.88 \times 10^{17} \\
5.13 \times 10^{17}\end{array}$ & $\begin{array}{l}9.26 \times 10^{16} \\
8.42 \times 10^{16}\end{array}$ \\
\hline Oct. 7, 1969 & Fal1 & $\begin{array}{r}6.36 \\
17.64\end{array}$ & $\begin{array}{l}2.5 \\
0.6\end{array}$ & 145 & $\begin{array}{l}460 \\
485\end{array}$ & $\begin{array}{r}820 \\
1115\end{array}$ & $\begin{array}{l}4.86 \times 10^{16} \\
4.48 \times 10^{16}\end{array}$ & $\begin{array}{l}3.40 \times 10^{17} \\
3.14 \times 10^{17}\end{array}$ & $\begin{array}{l}1.41 \times 10^{17} \\
7.76 \times 10^{16}\end{array}$ \\
\hline Nov. 25,1969 & Winter & $\begin{array}{r}7.46 \\
16.54\end{array}$ & $\begin{array}{l}1.1 \\
1.8\end{array}$ & 191 & $\begin{array}{l}455 \\
357\end{array}$ & $\begin{array}{r}895 \\
1125\end{array}$ & $\begin{array}{l}4.23 \times 10^{16} \\
7.65 \times 10^{16}\end{array}$ & $\begin{array}{l}2.96 \times 10^{17} \\
5.35 \times 10^{17}\end{array}$ & $\begin{array}{l}1.08 \times 10^{17} \\
1.57 \times 10^{17}\end{array}$ \\
\hline Dec. 23, 1969 & Winter & $\begin{array}{r}7.69 \\
16.31\end{array}$ & $\begin{array}{l}2.0 \\
2.9\end{array}$ & 162 & $\begin{array}{l}422 \\
380\end{array}$ & $\begin{array}{r}860 \\
1100\end{array}$ & $\begin{array}{l}4.91 \times 10^{16} \\
9.87 \times 10^{16}\end{array}$ & $\begin{array}{l}3.44 \times 10^{17} \\
6.91 \times 10^{17}\end{array}$ & $\begin{array}{l}1.59 \times 10^{17} \\
1.24 \times 10^{17}\end{array}$ \\
\hline Feb. 5, 1970 & Winter & $\begin{array}{r}7.09 \\
16.91\end{array}$ & $\begin{array}{l}2.4 \\
2.1\end{array}$ & 125 & $\begin{array}{l}300 \\
420\end{array}$ & $\begin{array}{r}850 \\
1050\end{array}$ & $\begin{array}{l}2.95 \times 10^{16} \\
4.19 \times 10^{16}\end{array}$ & $\begin{array}{l}2.07 \times 10^{17} \\
2.93 \times 10^{17}\end{array}$ & $\begin{array}{l}2.87 \times 10^{17} \\
1.17 \times 10^{17}\end{array}$ \\
\hline Mar. 17, 1970 & Spring & $\begin{array}{r}6.09 \\
17.91\end{array}$ & $\begin{array}{l}0.6 \\
2.1\end{array}$ & 135 & $\begin{array}{l}398 \\
490\end{array}$ & $\begin{array}{r}960 \\
1150\end{array}$ & $\begin{array}{l}6.87 \times 10^{16} \\
9.71 \times 10^{16}\end{array}$ & $\begin{array}{l}4.81 \times 10^{17} \\
6.80 \times 10^{17}\end{array}$ & $\begin{array}{l}1.14 \times 10^{17} \\
7.52 \times 10^{16}\end{array}$ \\
\hline Apr. 28,1970 & Summer & $\begin{array}{r}5.04 \\
18.96\end{array}$ & $\begin{array}{l}2.1 \\
1.0\end{array}$ & 147 & $\begin{array}{l}408 \\
475\end{array}$ & $\begin{array}{r}970 \\
1105\end{array}$ & $\begin{array}{l}6.21 \times 10^{16} \\
4.75 \times 10^{16}\end{array}$ & $\begin{array}{l}4.35 \times 10^{17} \\
3.33 \times 10^{17}\end{array}$ & $\begin{array}{l}1.26 \times 10^{17} \\
9.27 \times 10^{16}\end{array}$ \\
\hline June 9,1970 & Summer & $\begin{array}{r}4.36 \\
19.64\end{array}$ & $\begin{array}{l}1.2 \\
1.6\end{array}$ & 134 & $\begin{array}{l}443 \\
457\end{array}$ & $\begin{array}{l}1060 \\
1170\end{array}$ & $\begin{array}{l}6.95 \times 10^{16} \\
6.78 \times 10^{16}\end{array}$ & $\begin{array}{l}4.87 \times 10^{17} \\
4.74 \times 10^{17}\end{array}$ & $\begin{array}{l}8.35 \times 10^{16} \\
7.20 \times 10^{16}\end{array}$ \\
\hline Sept. 1, 1970 & Fal1 & $\begin{array}{r}5.45 \\
18.55\end{array}$ & $\begin{array}{l}1.9 \\
4.0\end{array}$ & 151 & $\begin{array}{l}425 \\
408\end{array}$ & $\begin{array}{l}1160 \\
1185\end{array}$ & $\begin{array}{l}6.05 \times 10^{16} \\
7.02 \times 10^{16}\end{array}$ & $\begin{array}{l}4.23 \times 10^{17} \\
4.92 \times 10^{17}\end{array}$ & $\begin{array}{l}7.86 \times 10^{16} \\
8.86 \times 10^{16}\end{array}$ \\
\hline
\end{tabular}

+ Average of three values preceding measurement. 


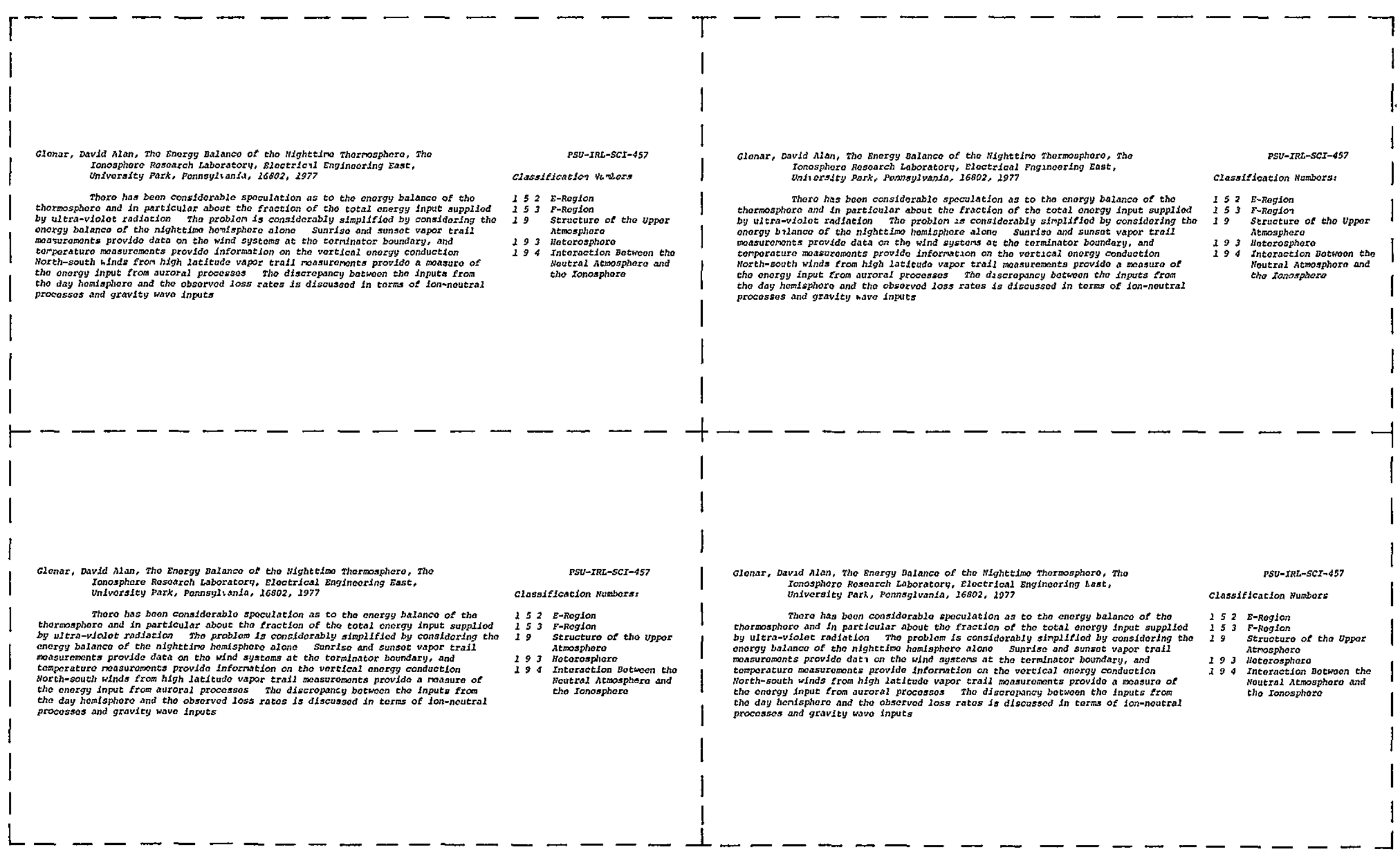




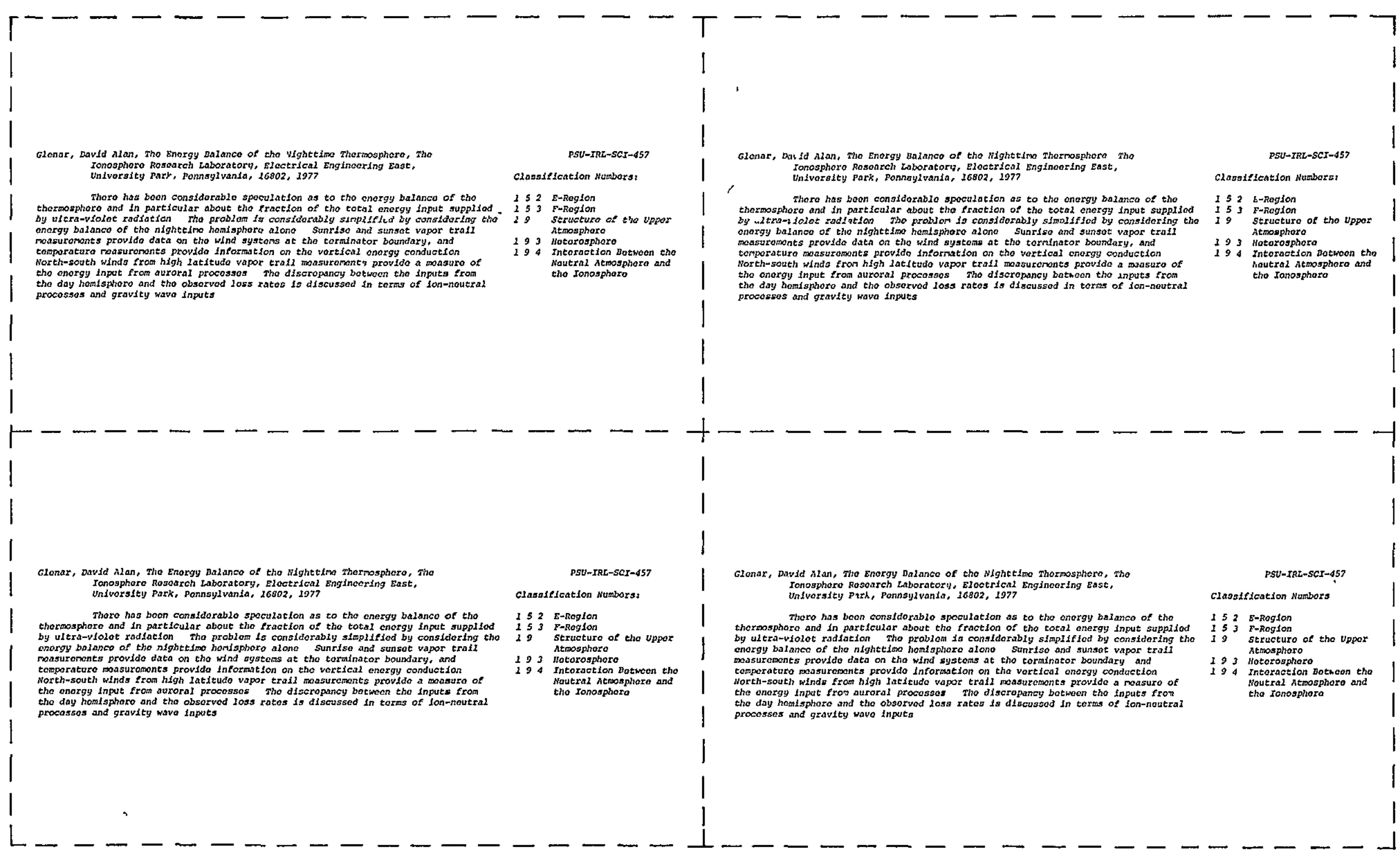

